\title{
Mixing Cell Model: A One- Dimensional Numerical Model for Assessment of Water Flow and Contaminant Transport in the Unsaturated Zone
}

Arthur S. Rood

October 2010 


\title{
Mixing Cell Model: A One-Dimensional Numerical Model for Assessment of Water Flow and Contaminant Transport in the Unsaturated Zone
}

\author{
Arthur S. Rood
}

October 2010

Idaho Cleanup Project

Idaho Falls, Idaho 83415

Prepared for the

U.S. Department of Energy

Assistant Secretary for Environmental Management

Under DOE-NE Idaho Operations Office

Contract DE-AC07-05ID14516 


\section{DISCLAIMER}

This information was prepared as an account of work sponsored by an agency of the U.S. Government. Neither the U.S. Government nor any agency thereof, nor any of their employees, makes any warranty, express or implied, or assumes any legal liability or responsibility for the accuracy, completeness, or usefulness of any information, apparatus, product, or process disclosed, or represents that its use would not infringe privately owned rights. References herein to any specific commercial product, process, or service by trade name, trademark, manufacturer, or otherwise, does not necessarily constitute or imply its endorsement, recommendation, or favoring by the U.S. Government or any agency thereof. The views and opinions of authors expressed herein do not necessarily state or reflect those of the U.S. Government or any agency thereof. 


\section{ABSTRACT}

This report describes the Mixing Cell Model code, a one-dimensional model for water flow and solute transport in the unsaturated zone under steady-state or transient flow conditions. The model is based on the principles and assumptions underlying mixing cell model formulations. The unsaturated zone is discretized into a series of independent mixing cells. Each cell may have unique hydrologic, lithologic, and sorptive properties. Ordinary differential equations describe the material (water and solute) balance within each cell. Water flow equations are derived from the continuity equation assuming that unit-gradient conditions exist at all times in each cell. Pressure gradients are considered implicitly through model discretization. Unsaturated hydraulic conductivity and moisture contents are determined by the material-specific moisture characteristic curves. Solute transport processes include explicit treatment of advective processes, first-order chain decay, and linear sorption reactions. Dispersion is addressed through implicit and explicit dispersion. Implicit dispersion is an inherent feature of all mixing cell models and originates from the formulation of the problem in terms of mass balance around fully mixed volume elements. Expressions are provided that relate implicit dispersion to the physical dispersion of the system.

Two FORTRAN codes were developed to solve the water flow and solute transport equations: (1) the Mixing-Cell Model for Flow (MCMF) solves transient water flow problems and (2) the Mixing Cell Model for Transport (MCMT) solves the solute transport problem. The transient water flow problem is typically solved first by estimating the water flux through each cell in the model domain as a function of time using the MCMF code. These data are stored in either ASCII or binary files that are later read by the solute transport code (MCMT). Code output includes solute pore water concentrations, water and solute inventories in each cell and at each specified output time, and water and solute fluxes through each cell and specified output time. Computer run times for coupled transient water flow and solute transport were typically several seconds on a $2 \mathrm{GHz}$ Intel Pentium IV desktop computer. The model was benchmarked against analytical solutions and finite-element approximations to the partial differential equations (PDE) describing unsaturated flow and transport. Differences between the maximum solute flux estimated by the mixing-cell model and the PDE models were typically less than two percent. 


\section{CONTENTS}

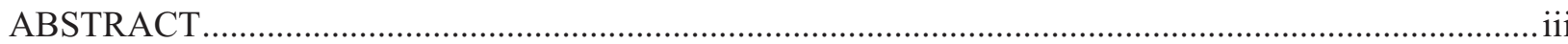

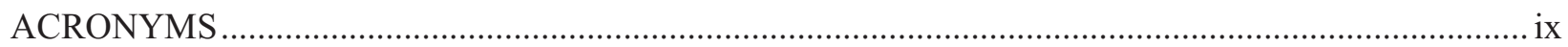

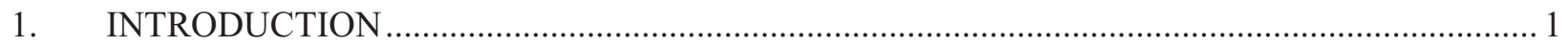

2. CONCEPTUAL AND MATHEMATICAL MODEL ................................................................. 2

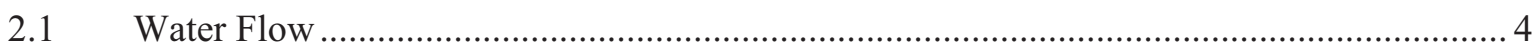

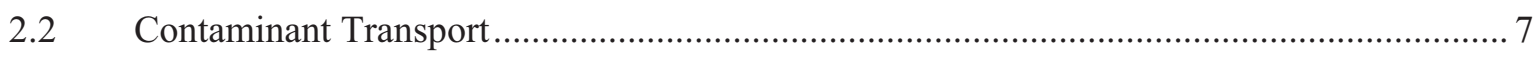

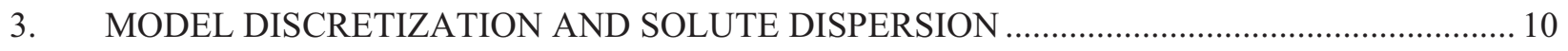

3.1 Comparison of Mixing Cell Model with an Analytical Solution for Solute Flux ............... 11

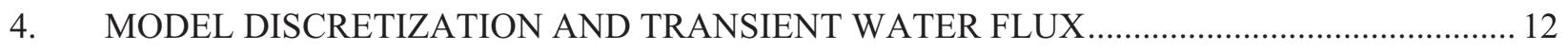

4.1 Coupling Water Flow and Solute Transport............................................................ 18

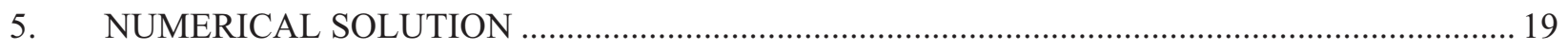

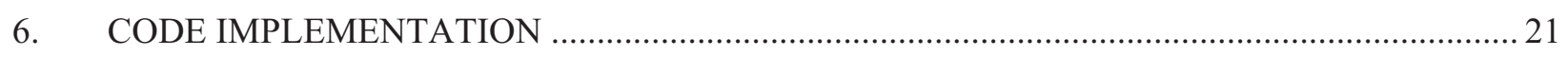

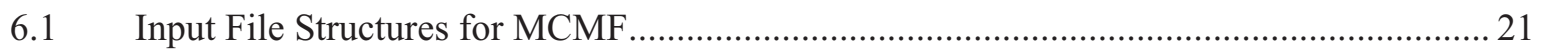

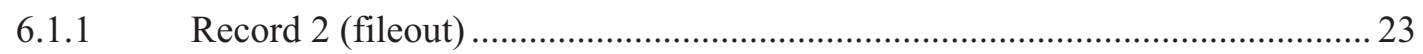

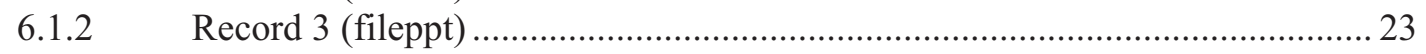

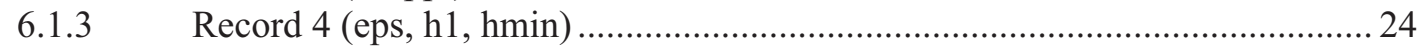

6.1.4 Record 5 (mlayer, nmat, nkt, qmax, qmin, iflag, and abin)............................ 24

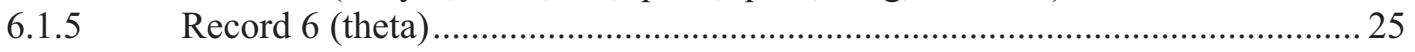

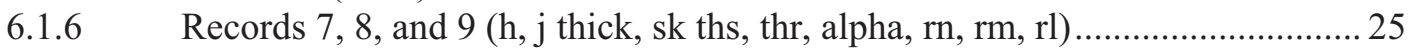

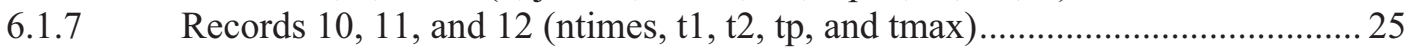

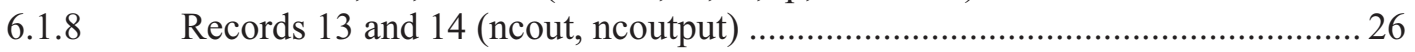

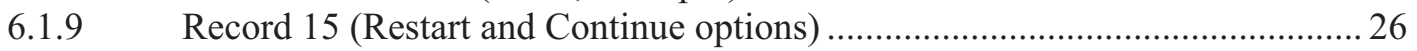

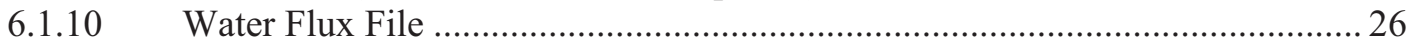

6.2 Code Execution and MCMF Output Files and Utilities .............................................. 27

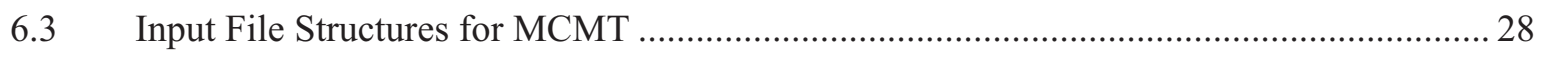

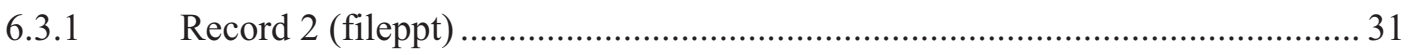

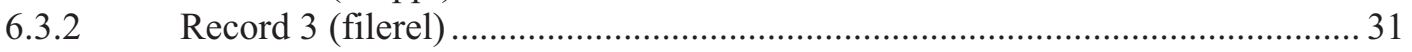

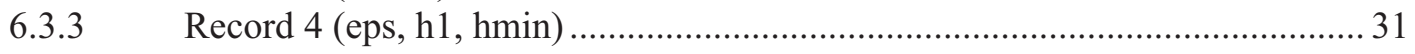

6.3.4 Record 5 (mlayer, nprog, nmat, iunits, and abin) ........................................ 31

6.3.5 Record 6, 7, 8, 9, 10, and 11 (cname, mw, sol, thalf, bratio, dwater) ............... 32

6.3.6 Records 15, 16, and 17 (h, j thick, rho, sk ths, thr, alpha, rn, rl, rm)................. 32

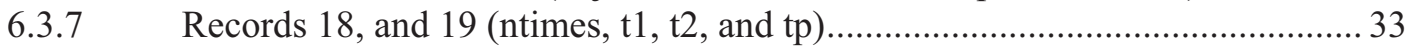

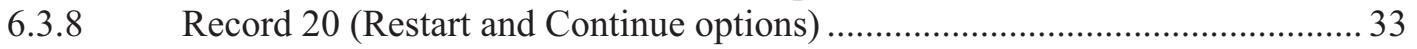

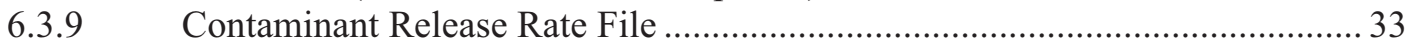




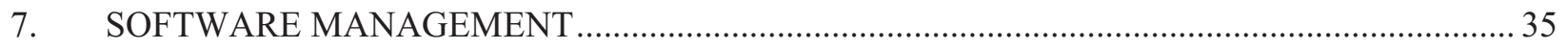

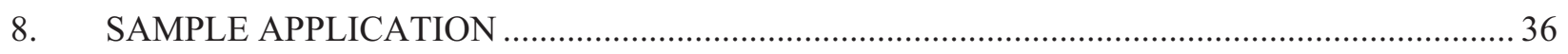

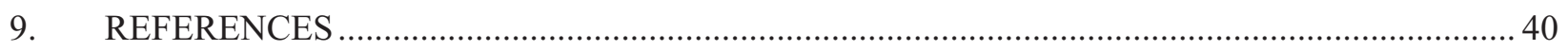

Appendix A Software Design Description and Configuration Management Plan................................... 1

Appendix B Code Verification and Benchmark Problems .................................................................. 1

\section{FIGURES}

Figure 1. The MCM conceptual model for water flow (left) and contaminant transport (right). The model domain is discretized into $n$ cells and extends to a depth of $z=Z$. Interchange between cells is indicated the variable $D_{i, j}$ where $i$ is the index of the donor cell and $j$ is the index of the receiving

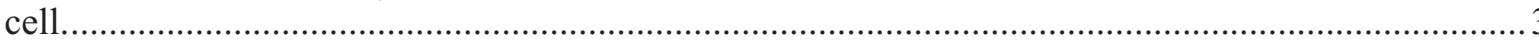

Figure 2. Normalized solute flux versus dimensionless time for various Peclet numbers for the mixing-cell model with interchange and an analytical solution to the advection-dispersion equation for flux. Solute fluxes are normalized to the peak advection dispersion equation flux for a $P e$ of 100 .

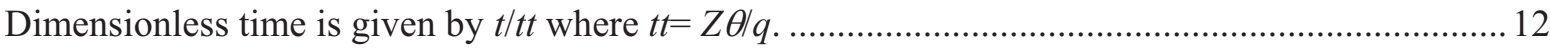

Figure 3. Conceptual model for examination of transient water flux. The mixing-cell model is composed of $n$ equal-dimension cells and initial moisture contents correspond to an initial infiltration rate of $q_{o}$. A new water flux $\left(q_{n}\right.$, where $\left.q_{n}>q_{o}\right)$ is applied to the top of the domain at $t>0$ for a time, $t p$. The downward advance of a wetting front created by the new water flux is shown at three times $\left(t_{1}, t_{2}, t_{3}\right)$.

Figure 4. Relative water flux at $\mathrm{z}=\mathrm{Z}$ as a function of dimensionless time for various numbers of mixing cells. In the left graph (A), tp $=\infty$ whereas in right graph (B), tp $=1.16$ twf. For comparison, the same conditions were simulated with HYDRUS. Time has been normalized to the wetting front arrival time. The variable $\mathrm{n}$ is the number of equal-dimension mixing cells in the simulation. The left graph (A) is for a heterogeneous (i.e., layered) unsaturated zone whereas the right graph (B) is for a homogeneous unsaturated zone.

Figure 5. Relative water flux versus time for HYDRUS and mixing-cell model simulations involving a 30-m clay unsaturated zone. These data were used to develop the regression given in Equation 35. 16

Figure 6. The number of mixing cells (n) versus the dimensionless variable $\varphi$ required to approximate the behavior of the water-flux profile at $\mathrm{z}=\mathrm{Z}$. The abscissa was plotted in log-scale so as to better visualize the points for $\varphi<100$.

Figure 7. Problem description, model domain, and input parameters for the sample application of the MCM models. Initial concentrations of each radionuclide after the end facility operations is illustrated on the left graph. The initial moisture content and moisture content profile in subsequent years for the no action alternative is shown in the graph on the right. 
Figure 8. MCMF (top) and MCMT (bottom) input files for the no action alternative of the sample application.

Figure 9. Radionuclide flux to the aquifer as a function of time for the three remediation options and the Steady-State case for the sample application of MCM.

\section{TABLES}

Table 1. Mean representative values of the saturated hydraulic conductivity $\left(K_{\text {sat }}\right)$, residual moisture content $\left(\theta_{r}\right)$, saturated moisture content $\left(\theta_{s}\right)$, and the van Genuchten fitting parameters $\alpha$ and $n$ for various soil types (from Carsel and Parrish 1988). Parameters $m$ and $l$ are the default values given in Eq 9.

Table 2. Model data used to develop regression between $n$ and $\varphi$. All mixing cells were of equal

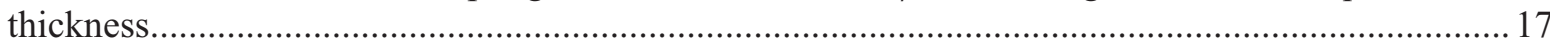

Table 3. Format for the MCMF parameter definition file.................................................................... 22

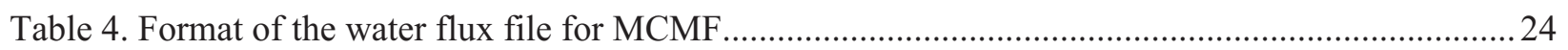

Table 5. Format for the MCMFPRT parameter definition file. ............................................................ 27

Table 6. Format for the MCMT parameter definition file. ......................................................................29

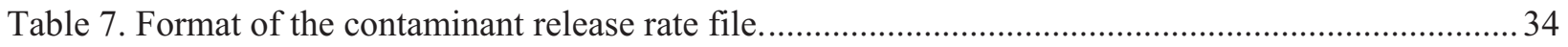

Table 8. Format for the MCMTPRT parameter definition file. ............................................................... 35

Table 9. MCP-550 software quality assurance requirements and where they are addressed in the MCM

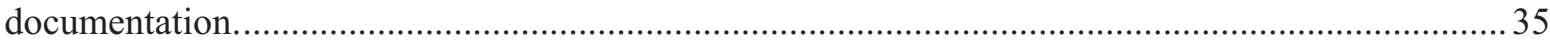




\section{ACRONYMS}

DUST Disposal Unit Source Term

MCM Mixing-Cell Model

MCMF Mixing-Cell Model for Flow

MCMT Mixing-Cell Model for Transport

ODE ordinary differential equation

PDE partial differential equation 


\section{Mixing Cell Model: A One-Dimensional Numerical Model for Assessment of Water Flow and Contaminant Transport in the Unsaturated Zone}

\section{INTRODUCTION}

Evaluation of contaminant transport in the unsaturated zone is both a complex and evolving science. Typically, one is presented with the problem of assessing the release and transport of contaminants to a potable aquifer from radionuclides and chemicals disposed in an engineered waste disposal facility or present in the form of residual contamination in surface soils. Many models ranging from the simple to complex have been developed to address this problem. Examples of relatively simple assessment models that include one-dimensional transport in the unsaturated zone are RESRAD (Yu et al. 2000), MEPAS (Whelan et al., 1996), SESOIL (Scott and Hetrick 1994), MMSOILS (EPA 1992), and GWSCREEN (Rood 1999). Other models, such as the Disposal Unit Source Term Model (DUST) (Sullivan 1996) include a more sophisticated treatment of source release mechanisms coupled with a one-dimensional finite-difference solution to the advection-dispersion equation for transport in the unsaturated zone. Models that numerically approximate the non-linear partial differential equations (PDE) governing fluid flow and solute transport in a variable saturated porous media are the most flexible in terms of conceptual model development, understanding the behavior of the system, and examination of transport process, but can be cumbersome to use in risk assessment. Several examples of such models include STOMP (PNNL 1996), HYDRUS (Simunek et al. 1999), and PORFLOW (ACRI 1996). Often times the subsurface environment is poorly characterized which limits the effectiveness of a complex model. Furthermore, many of assessments are prospective and entail model predictions out to tens of hundreds (and sometimes thousands) of years. The reliability of any model is limited under such conditions and by their very nature, such model predictions cannot be confirmed with field observations. The nature of the prospective analysis and the complexity of problem often times leads to simplifying but conservative assumptions about contaminant release and transport in the subsurface environment. The model described in this report is intended to provide an assessment tool (as opposed to a research tool) for evaluating one-dimensional contaminant transport in the unsaturated zone under steady-state and transient flow conditions.

Transient infiltration is defined here as a change in the net infiltration rate that affects the water and contaminant flux to the aquifer over the assessment time frame, typically tens of hundreds of years in arid climates that exist at the Idaho National Laboratory (INL). Net infiltration (sometimes referred to as drainage) is defined as the amount of water that drains from the near surface layers to underlying strata, typically below the root zone. Net infiltration is a function of precipitation, evapotranspiration, and runoff. Other models (UNSAT-H [Fayer 2000] and HELP [Schroeder et al. 1994]) explicitly address these processes and may be used to provide net infiltration rates to the model described here.

Transient infiltration as defined here can occur with the installation and subsequent failure of an infiltration-limiting cover over buried waste or contaminated soil, disturbance of the natural soil layer, discharge of liquid effluent to an infiltration basin, or long-term changes in natural precipitation. In situations such as these, water fluxes beneath the root zone are temporally and spatially variable over the assessment period. The aforementioned simple assessment models lack the capability to address spatially and temporally variable water fluxes in the unsaturated zone in a quantitative manner, and therefore, one is left with using the relatively complex fluid-flow and transport models to estimate the effects of transient infiltration on contaminant transport. The Mixing-Cell Model (MCM) offers a relatively simple assessment approach that includes transient infiltration. 
Ordinary differential equations describe the water and contaminant mass balance in a series of "mixing cells" into which the model domain is discretized. Other authors refer to this type of model as a compartment model (Whicker and Shultz 1982), box model, and tanks-in-series model (Shanahan and Harleman 1984; Rao and Hathaway 1989). Mixing-cell models have been used extensively for lake water quality modeling, contaminant transfer in biota, and chemical engineering applications. The primary output from MCM is contaminant flux at the unsaturated-saturated interface, but output also includes pore water concentrations, moisture profiles, water fluxes, and contaminant inventories in mixing cells as a function of time. While MCM is designed primarily for unsaturated transport, it is also amenable to one-dimensional saturated flow as well. The model was designed to incorporate readily available data and the dominant processes that tend to impact the results of such assessments. Such processes include time-variable net water infiltration rates, subsurface heterogeneity, and differential transport of contaminant degradation products formed during transport. MCM output is compared and contrasted against other models employing solutions to the partial differential equations describing unsaturated water flow and solute transport.

\section{CONCEPTUAL AND MATHEMATICAL MODEL}

The basis for the MCM is described in Rood (2004). The conceptual model envisions the unsaturated subsurface environment to be composed of a series of individual mixing cells (Figure 1). Within each mixing cell, the moisture content (fraction of the mixing cell volume composed of water) and contaminant concentration are uniform and assumed to equilibrate instantaneously in response to a change in the amount of water or contaminant entering the cell. Each mixing cell may have its own unique properties that include vertical dimensions, bulk density, hydraulic characteristics (e.g., porosity, residual moisture content, and hydraulic conductivity), and sorptive properties. Water balance within each cell is maintained by the difference between inflow and outflow. The water flux or specific discharge entering the uppermost mixing cell $(q)$ is assumed to be the net infiltration rate past the root zone. The net infiltration rate may change with time and, in turn, affect the specific discharge through all remaining cells below it. Water movement is assumed to be downward and under unit gradient conditions within a mixing cell. Specific discharge is assumed to be less than the saturated hydraulic conductivity of any of the materials comprising the unsaturated zone.

The conceptual model for contaminant transport considers two processes: advection and dispersion. Advective processes ( $F$ in Figure 1) move the contaminant downward while dispersive processes ( $D$ in Figure 1) can move the contaminant upward or downward depending on the concentration gradient between two adjacent cells. Dispersion results in greater spreading of the contaminant among the mixing cells. As shown later, dispersion effects can be simulated through the implicit dispersion inherent in a mixing-cell model, or may be simulated by including interchange between adjacent mixing cells.

Contaminant degradation is assumed to be a first-order process described by a half-life. The contaminant may degrade into one or more degradation products, each formed from the preceding product and thereby forming a chain of degradation products. A radionuclide decay chain is perhaps the best example of this process. However, the framework can also be adapted to chemical constituents that degrade in a similar manner.

Contaminants entering a cell mix, sorb, decay, and are eventually removed by the downward movement of water. Contaminants sorb on to the solid matrix as described by the equilibrium partitioning coefficient or $K d$. Sorption retards the overall downward movement of contaminants. The rate of transport of the degradation products that form during vertical transport are governed by the sorptive properties of the degradation product, and not those of the originating contaminant. 

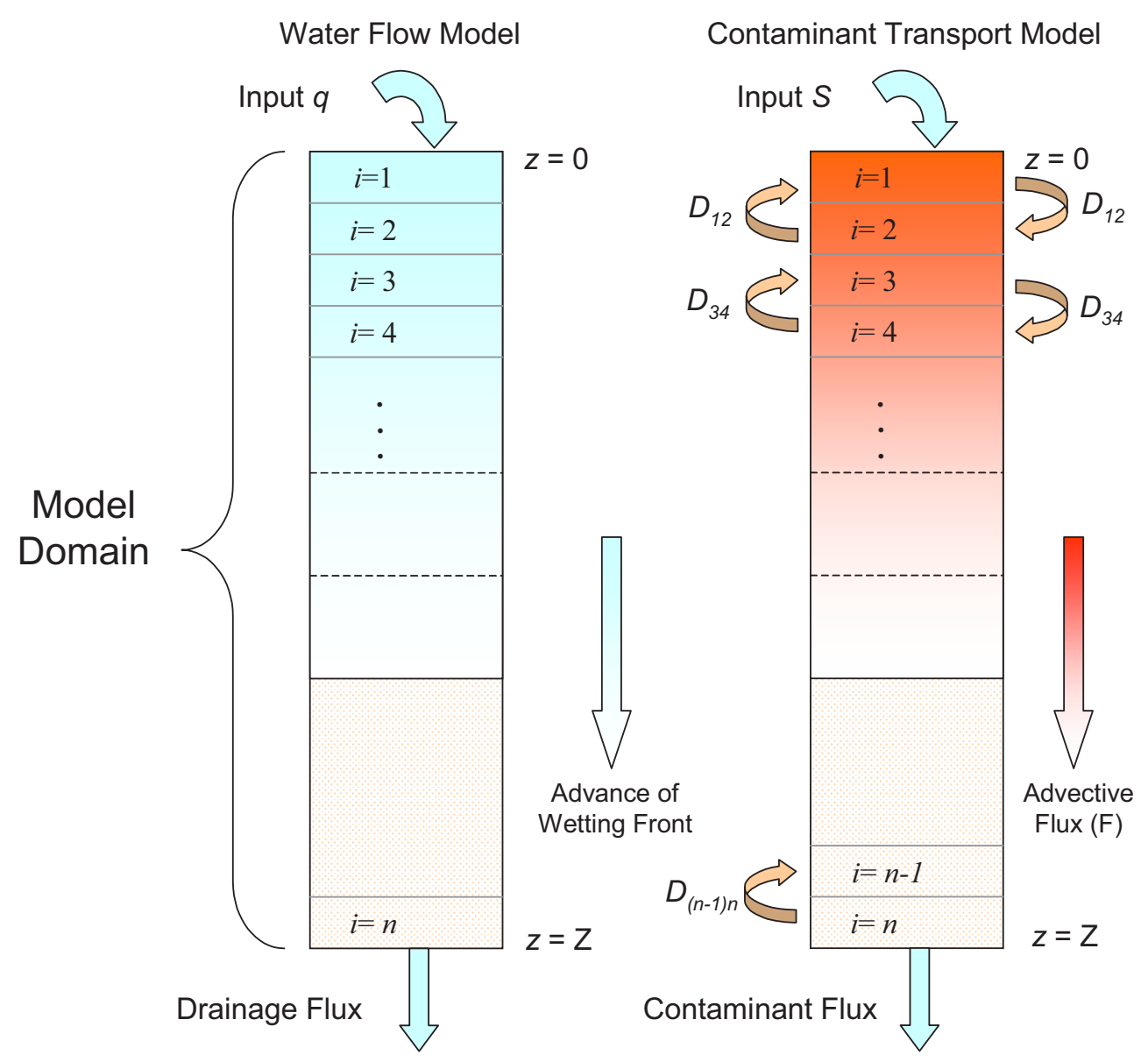

Figure 1. The MCM conceptual model for water flow (left) and contaminant transport (right). The model domain is discretized into $n$ cells and extends to a depth of $z=Z$. Interchange between cells is indicated the variable $D_{i, j}$ where $i$ is the index of the donor cell and $j$ is the index of the receiving cell.

As formulated, contaminants may be present in each of the mixing cells at the start of the simulation, or alternatively, the contaminant may be placed over time through an external source ( $S$ in Figure 1). Concentrations of contaminants in pore water are not allowed to exceed their element or compound-specific solubility limit.

Conceptually, the model is very similar to the SESOIL model. However, significant differences exist, namely in the manner in which water flow in the unsaturated zone is treated, the selection of the number of mixing cells, and transport of degradation products. The SESOIL model calculates a net infiltration rate using precipitation records and site-specific evapotranspiration data. The MCM model assumes this value is known or estimated external to the model. More importantly, SESOIL assumes the unsaturated zone is a single homogenous cell whereas MCM allows for multiple cells and can represent a heterogeneous unsaturated zone with spatially and temporally variable water flux. In terms of solute transport, SESOIL computes concentrations and fluxes for a single contaminant with first-order decay whereas the MCM model has been written in terms of a contaminant with multiple degradation products. 


\subsection{Water Flow}

A simple one-dimensional water-balance model coupled with material-specific moisture characteristic curves are used to calculate the net water flux through each mixing cell assuming unit gradient conditions exist throughout each cell. Additionally, water is assumed to be incompressible, its density remain constant, vapor-phase flow is inconsequential, and hydrostatic conditions are assumed to never exist (i.e., a net water flux of zero). The unit gradient model assumes water infiltration in the soil column is downward and driven by gravitational forces only. The specific discharge (sometimes referred to as the Darcy velocity or Darcy flux) in a one dimensional, vertically aligned, unsaturated soil column may be described by:

$q=-K\left(\frac{\partial H}{\partial z}+\frac{\partial \psi}{\partial z}\right)$

where

$$
\begin{aligned}
& q \quad=\text { specific discharge }\left(\mathrm{L} \mathrm{T}^{-1}\right) \\
& \theta \quad=\text { volumetric moisture content }\left(\mathrm{L}^{3} \mathrm{~L}^{-3}\right) \\
& H \quad=\text { elevation head }(\mathrm{L}) \\
& \psi \quad=\text { suction or pressure head from capillary forces }(\mathrm{L}) \\
& K \quad=\text { unsaturated hydraulic conductivity of the column }\left(\mathrm{L} \mathrm{T}^{-1}\right) \\
& z \quad=\text { distance positive downward from the top of the column }(\mathrm{L}) .
\end{aligned}
$$

Under unit gradient conditions, $\partial \psi / \partial z=0$, and $\partial H / \partial z=1$. Therefore, $q=K$, provided $q$ is less than the saturated hydraulic conductivity. That is, the amount of water discharged from a mixing cell is equal to the unsaturated hydraulic conductivity at a given volumetric moisture content. The volumetric moisture content is the fraction of the bulk media that is filled with water. When a porous media is saturated (i.e., all the pore spaces are filled with water), the volumetric moisture content is equal to the effective porosity of the media. In this model, we have assumed the effective porosity is equal to the total porosity. Unit gradient conditions are assumed to exist at all times within a mixing cell. That is, once water enters the mixing cell, it is instantaneously and uniformly distributed within the mixing cell. Capillary forces are explicitly excluded from the model by assuming unit gradient conditions exist at all times. However, as shown later, these forces are implicitly accounted for through discretization of the domain into a series of mixing cells. Each cell is treated as an independent unit that may receive water from a cell above it and discharge water to the cell beneath it.

The continuity equation for a constant water density states that the change in the water stored in a unit volume of soil must equal the difference between the flux into and out of the unit volume and is given by:

$$
\frac{\partial \theta}{\partial t}=-\frac{\partial q}{\partial z}
$$

Combining Equations 1 and 2 with $\partial H / \partial z=1$ gives the traditional formulation for one-dimensional unsaturated flow in a porous medium known as Richard's equation: 
$\frac{\partial \theta}{\partial t}=\frac{\partial}{\partial z}\left(K \frac{\partial \psi}{\partial z}-K\right)$

The unsaturated hydraulic conductivity is a function of the moisture content and described by the moisture characteristic curve. Combining Equations 1 and 2, with the assumption of unit gradient conditions (i.e., $\partial \psi / \partial z=0$ ) gives:

$\frac{\partial \theta}{\partial t}=-\frac{\partial K(\theta)}{\partial z}$

The term, $\partial K(\theta) / \partial z$ is approximated for the mixing cell model by:

$\frac{\partial \theta_{i}}{\partial t}=\frac{K_{i-1}\left(\theta_{i-1}\right)-K_{i}\left(\theta_{i}\right)}{z_{i}-z_{i-1}}$

where $i$ is the cell index number and zi is the depth of cell $i$ below a datum at index $i=0, z=0$. The water storage in the $i^{\text {th }}$ mixing cell $\left(\phi_{i}\right)$ is given by:

$\phi_{i}=\theta_{i} T_{i}$

where $T_{i}$ is the thickness of the $i^{\text {th }}$ mixing cell which is equivalent to $z_{i}-z_{i-1}$. Equation 5 is now rewritten in terms of the change in water storage with respect to time and given by:

$$
\begin{aligned}
& \frac{\mathrm{d} \phi_{\mathrm{i}}}{\mathrm{dt}} \frac{1}{\mathrm{~T}_{\mathrm{i}}}=\frac{\mathrm{K}_{\mathrm{i}-1}\left(\theta_{\mathrm{i}-1}\right)-\mathrm{K}_{\mathrm{i}}\left(\theta_{\mathrm{i}}\right)}{\mathrm{T}_{\mathrm{i}}} \\
& \frac{\mathrm{d} \phi_{\mathrm{i}}}{\mathrm{dt}}=\mathrm{K}_{\mathrm{i}-1}\left(\theta_{\mathrm{i}-1}\right)-\mathrm{K}_{\mathrm{i}}\left(\theta_{\mathrm{i}}\right) .
\end{aligned}
$$

For the uppermost mixing cell $(i=1), K_{i-1}\left(\theta_{i-1}\right)=K_{0}\left(\theta_{0}\right)=q(t)$ where $q(t)$ is the net infiltration rate as a function of time into the uppermost mixing cell. Note that volumetric flow rates are achieved by multiplying Equation 7 by the horizontal surface area of the cells.

The functional relationship between the unsaturated hydraulic conductivity and moisture content is made using established empirical relationships that relate suction head to volumetric moisture content and unsaturated hydraulic conductivity. The relationship between these three parameters is referred to hereafter as the moisture characteristic curve. For this model, the unsaturated hydraulic conductivity as a function of moisture content as described by van Genuchten (1980) was used and is given by:

$$
K(\theta)=K_{\text {sat }}\left(\frac{\theta-\theta_{r}}{\theta_{s}-\theta_{r}}\right)^{l}\left\{1-\left[1-\left(\frac{\theta-\theta_{r}}{\theta_{s}-\theta_{r}}\right)^{\frac{1}{m}}\right]^{m}\right\}^{2}
$$

and 
$\left(\frac{\theta-\theta_{r}}{\theta_{s}-\theta_{r}}\right)=\left(\frac{1}{1+(\alpha \psi)^{n g}}\right)^{m} \quad\left(\theta_{r} \leq \theta \leq \theta_{s}\right)$

where

$$
\begin{aligned}
& \theta \quad=\text { volumetric moisture content }\left(\mathrm{L}^{3} \mathrm{~L}^{-3}\right) \\
& \theta_{r}=\text { residual moisture content }\left(\mathrm{L}^{3} \mathrm{~L}^{-3}\right) \\
& \theta_{S}=\text { saturated moisture content }\left(\mathrm{L}^{3} \mathrm{~L}^{-3}\right) \\
& K_{\text {sat }}=\text { saturated hydraulic conductivity }\left(\mathrm{L} \mathrm{T}^{-1}\right) \\
& \psi \quad=\text { soil water matric suction pressure }(\mathrm{L}) \\
& \alpha \quad=\text { empirical fitting parameter }\left(\mathrm{L}^{-1}\right) \\
& n g \quad=\text { empirical fitting parameter } \\
& m \quad=\text { emperical fitting parameter }(\text { default value of } 1-1 / n g) \\
& l \quad=\text { emperical fitting parameter (default value of } 0.5)
\end{aligned}
$$

Equations 8 and 9 are valid when $q<K_{\text {sat }}$. Hydraulic properties that consider hysteresis were not included in this formulation. Other functional relationships of unsaturated soil hydraulics were derived by Brooks and Corey (1964), Gardener (1960), and Campbell (1974). Ideally, site-specific parameter values of the moisture characteristic curve would be available. However, more often than not, generic values are used in the early stages of an assessment when field data are lacking. Some representative van Genuchten fitting parameter values for various lithologies are given in Table 1.

Table 1. Mean representative values of the saturated hydraulic conductivity $\left(K_{\text {sat }}\right)$, residual moisture content $\left(\theta_{r}\right)$, saturated moisture content $\left(\theta_{s}\right)$, and the van Genuchten fitting parameters $\alpha$ and $n$ for various soil types (from Carsel and Parrish 1988). Parameters $m$ and $l$ are the default values given in Eq 9.

\begin{tabular}{lccccccr}
\multicolumn{1}{c}{ Soil Type } & $\begin{array}{c}\text { Percent } \\
\text { sand }\end{array}$ & $\begin{array}{c}\text { Percent } \\
\text { clay }\end{array}$ & $n$ & $\begin{array}{c}\alpha \\
\left(\mathrm{cm}^{-1}\right)\end{array}$ & $\theta_{r}$ & $\theta_{s}$ & $\begin{array}{r}K_{\text {sat }} \\
\left(\mathrm{cm} \mathrm{yr}^{-1}\right)\end{array}$ \\
\hline Clay & 14.9 & 55.2 & 1.09 & 0.008 & 0.068 & 0.38 & 1,752 \\
Clay loam & 29.8 & 32.6 & 1.31 & 0.019 & 0.095 & 0.41 & 2,278 \\
Loam & \multicolumn{1}{c}{ (4) } & 19.7 & 1.56 & 0.036 & 0.078 & 0.43 & 9,110 \\
Loamy sand & 80.9 & 6.4 & 2.28 & 0.124 & 0.057 & 0.41 & 127,808 \\
Silt & 5.8 & 9.5 & 1.37 & 0.016 & 0.034 & 0.46 & 2,190 \\
Silt loam & 16.6 & 18.5 & 1.41 & 0.020 & 0.067 & 0.45 & 3,942 \\
Silty clay & 6.1 & 46.3 & 1.09 & 0.005 & 0.070 & 0.36 & 175 \\
Silty clay loam & 7.6 & 33.2 & 1.23 & 0.010 & 0.089 & 0.43 & 613 \\
Sand & 92.7 & 2.9 & 2.68 & 0.145 & 0.045 & 0.43 & 260,172 \\
Sandy clay & 47.5 & 41.0 & 1.23 & 0.027 & 0.100 & 0.38 & 1,051 \\
Sandy clay loam & 54.3 & 27.4 & 1.48 & 0.059 & 0.100 & 0.39 & 11,476 \\
Sandy loam & 63.4 & 11.1 & 1.89 & 0.075 & 0.065 & 0.41 & 38,719 \\
\hline
\end{tabular}


The moisture content in the $i^{\text {th }}$ mixing cell is used in combination with the moisture characteristic curve to determine $K_{i}\left(\theta_{i}\right)$, the specific discharge through the $i^{\text {th }}$ mixing cell. The value of $K_{i}\left(\theta_{i}\right)$ as a function of time is then passed to the transport model.

\subsection{Contaminant Transport}

The model for solute transport explicitly treats advective processes and implicitly or explicitly treats dispersive processes. The model is based on the one-dimensional PDE for mass transport in a variably saturated porous medium. The general transport equation for a single contaminant with first-order decay is given by (Codell et al. 1983):

$R d A \theta \frac{\partial C}{\partial t}=A \frac{\partial}{\partial z}\left(\theta D \frac{\partial C}{\partial z}\right)-A \frac{\partial q C}{\partial z}-\left(R d \theta \lambda+R d \frac{\partial \theta}{\partial t}\right) A C$

where

$$
\begin{aligned}
& C=\text { solute concentration }\left(\mathrm{M} \mathrm{L}^{-3}\right) \\
& D \quad=\text { dispersion and diffusion coefficient }\left(\mathrm{L}^{2} \mathrm{~T}^{-1}\right) \\
& A \quad=\text { cross sectional area perpendicular to flow }\left(\mathrm{L}^{2}\right) \\
& R d \quad=\text { retardation coefficient (unitless) } \\
& q \quad=\text { specific discharge or Darcy velocity }\left(\mathrm{L} \mathrm{T}^{-1}\right) \\
& \lambda \quad=\text { first-order decay constant }\left(\mathrm{T}^{-1}\right) .
\end{aligned}
$$

The mixing cell approximation is written in terms of the mass balance around fully mixed volume elements. Assuming unidirectional flow in the positive $z$ direction, the mixing-cell model formulation for interior cells (i.e., $i \neq 1$ and $i \neq n$ where $n$ is the number of cells) of equal thickness, $T$ is given by:

$$
T_{i} R d_{i} A \theta_{i} \frac{d C_{i}}{d t}=A \sum_{k} \frac{D_{i k}}{T_{i k}}\left(\theta_{k} C_{k}-\theta_{i} C_{i}\right)+A\left(q_{i-1} C_{i-1}\right)-A\left(q_{i} C_{i}\right)-T_{i} A R d_{i} \theta_{i} \lambda C_{i}+S_{i}
$$

where $i$ is the cell index, $k$ is the index for cells adjacent cell $i$ (i.e., $i-1$ and $i+1$ ), $D_{i k}$ is the dispersion coefficient between cell $i$ and $k\left(\mathrm{~L}^{2} \mathrm{~T}^{-1}\right) T_{i k}$ is the distance separating the center of cell $i$ and $k(\mathrm{~L})$, and $S_{i}$ is an external source to cell $i\left(\mathrm{M} \mathrm{T}^{-1}\right)$. The first term in Equation 9 represents dispersion, the second and third terms represent advection, and the last term represents decay. The variables, $\theta$ and $q$, can be time-variable or constant depending on whether transient infiltration or steady-state flow is considered.

The term, $R d \partial \theta / \partial t$ in Equation 8, enforces continuity between the moisture content and solute concentration. This term is zero under steady-state flow conditions. Continuity between the two quantities ( $\theta$ and $C$ ) under transient flow conditions is achieved by determining the time-dependent moisture content at each time step. Moisture content as a function of time is calculated in the water flow portion of the code. The concentration in each cell at a given time-step is adjusted for the moisture content by: 


$$
C_{i}^{m}=\frac{Q_{i}^{m}}{\theta_{i}^{m} A T\left(1+\frac{K d_{i} \rho_{i}}{\theta_{i}^{m}}\right)}
$$

where

$$
\begin{aligned}
& C_{i}^{m}=\text { contaminant pore water concentration in cell } i \text { at time-step } m\left(\mathrm{M} \mathrm{L}^{-3}\right) \\
& Q_{i}^{m}=\text { mass of contaminant in cell } i \text { at time step } m(\mathrm{M}) \\
& K d_{i}=\text { equilibrium partition coefficient for mixing cell } i\left(\mathrm{~L}^{3} \mathrm{M}^{-1}\right) \\
& \rho_{i} \quad=\text { bulk density of mixing cell } i\left(\mathrm{M} \mathrm{L}^{-3}\right) \\
& \theta_{i}^{m} \quad=\text { the moisture content in mixing cell } i \text { at time step } m\left(\mathrm{M} \mathrm{L}^{-3}\right) .
\end{aligned}
$$

The term, $1+K d_{i} \rho_{i} / \theta_{i}$ is the retardation coefficient $(R d)$ and is unity for a $K d$ of zero. Darcy fluxes in each cell and at each time-step are calculated using the time-dependent value of $\theta$ and the material-specific moisture characteristic curve. If $C_{i}$ as given by Equation 10 exceeds the solubility limit, then $C_{i}=C_{S l}$ where $C_{S l}$ is the solubility limit of the contaminant. The solubility adjustment does not affect the total mass of contaminant in the cell. The left-hand side of Equation 9 and the decay terms can now be rewritten in terms of the state variable (contaminant mass) by substituting the right hand side of Equation 10 for $C$.

$$
\frac{d Q_{i}}{d t}=A \sum_{k} \frac{D_{i k}}{T_{i k}}\left(\theta_{k} C_{k}-\theta_{i} C_{i}\right)+A\left(q_{i-1} C_{i-1}\right)-A\left(q_{i} C_{i}\right)-\lambda Q_{i}+S_{i}
$$

where $Q_{i}$ is the contaminant mass in the cell $i$. Equation 11 is valid for all non-boundary cells. Imposing the following boundary conditions

$$
D \frac{d C}{d z}=0 \quad \text { at } \quad z=0 \quad \text { and } \quad z=Z
$$

then gives the mass balance equations for the first $(i=1)$ and last $(i=\mathrm{n})$ cell in the system.

$$
\begin{array}{ll}
\frac{d Q_{1}}{d t}=A \frac{D_{12}}{T_{12}}\left(\theta_{2} C_{2}-\theta_{1} C_{1}\right)-A\left(q_{1} C_{1}\right)-\lambda Q_{1}+S_{1} & \text { for } i=1 \\
\frac{d Q_{n}}{d t}=A \frac{D_{n-1 n}}{T_{n-1 n}}\left(\theta_{n-1} C_{n-1}-\theta_{n} C_{n}\right)-A\left(q_{n} C_{n}\right)+A\left(q_{n-1} C_{n-1}\right)-\lambda Q_{n}+S_{n} \quad \text { for } i=n
\end{array}
$$

Implementation of Equation 11 in the MCM code is performed differently than what is presented in Rood (2004). A simple procedure is used where each cell is treated as an independent unit and advective and dispersive rate constants are defined. Sources are only considered for the first cell. The advective $(\kappa)$ and dispersion $(\delta)$ rate constants are defined as follows. 
$\kappa_{i}=\frac{q}{T_{i} \theta_{i} R d_{i}} \quad$ and $\quad \delta_{i}=\frac{D_{i}}{T_{i}^{2}}$

The advective rate constant is equivalent to the leach rate constant as described in Baes and Sharp (1983). An optional rate constant (designated $k x$ ) is also introduced into the governing equations that describes the transfer from cell $i$ to cell $i+1$. This rate constant is provided by the user and is calculated external to the code. Assigning rate constants to the advection, dispersive, and optional transfer processes, and expanding the summation term results in the following equation for interior cells

$\frac{d Q_{i}}{d t}=A\left[\delta_{i-1} C_{i-1} \theta_{i-1} T_{i-1}+\delta_{i+1} C_{i+1} \theta_{i+1} T_{i+1}-2 \delta_{i} C_{i} \theta_{i} T_{i}\right]+\left(k x_{i-1}+\kappa_{i-1}\right) Q_{i-1}-\left(k x_{i}+\kappa_{i}\right) Q_{i}-\lambda Q_{i}$

and

$$
\begin{aligned}
& \frac{d Q_{1}}{d t}=A\left[\delta_{2} C_{2} \theta_{2} T_{2}-\delta_{1} C_{1} \theta_{1} T_{1}\right]-\left(k x_{1}+\kappa_{1}\right) Q_{1}-\lambda Q_{1}+S_{1} \quad \text { for } i=1 \\
& \frac{d Q_{n}}{d t}=A\left[\delta_{n-1} C_{n-1} \theta_{n-1} T_{n-1}-\delta_{n} C_{n} \theta_{n} T_{n}\right]+\left(k x_{n-1}+\kappa_{n-1}\right) Q_{n-1}-\left(k x_{n}+\kappa_{n}\right) Q_{n}-\lambda Q_{n} \quad \text { for } i=n
\end{aligned}
$$

for the boundary cells. Equation 15 can now be expanded to include the transport of multiple decay products.

$$
\begin{aligned}
& \frac{d Q_{i, j}}{d t}=A\left[\delta_{i-1, j} C_{i-1, j} \theta_{i-1} T_{i-1}+\delta_{i+1, j} C_{i+1, j} \theta_{i+1} T_{i+1}-2 \delta_{i, j} C_{i, j} \theta_{i} T_{i}\right] \\
& +\left(k x_{i-1, j}+\kappa_{i-1, j}\right) Q_{i-1, j}-\left(k x_{i, j}+\kappa_{i, j}\right) Q_{i, j}-\lambda_{j} Q_{i, j}+B R_{j} \lambda_{j-1} Q_{i, j-1}
\end{aligned}
$$

where, $j$ is the index for the decay chain member, $B R_{j}$ is the fraction of decay product $j-1$ that decays to product $j$, and $k x_{i, j}$ is the optional rate constant describing transfer from cell $i$ to cell $i+1$ for contaminant $j$. For the originating contaminant in a series of degradation products, the term, $B R_{j} \cdot \lambda_{j-1} Q_{i, j-1}$ is omitted from Equation 17. The decay rate constant is given by:

$$
\lambda_{j}=\frac{\ln (2)}{t h_{j}}
$$

where $t h_{j}$ is the half-life of contaminant $j$. Equation 17 describes the mixing-cell model with interchange. Equation 17 also gives the mixing-cell model without interchange except the dispersive terms are omitted (i.e., $\delta=0$ ). The mixing-cell model without interchange is useful because relatively simple analytical solutions exist for the equations describing the system. These solutions are useful for simple conceptual models and model verification exercises.

The overall objective of the model is to provide a solute flux to the aquifer. The solute flux to the aquifer for degradation product $j$ at $z=Z(i=n)$ for the stated boundary conditions is given by:

$$
F_{j}=A\left(q_{n} C_{n, j}\right)=\frac{q_{n} Q_{n, j}}{\theta_{n} T_{n} R d_{n, j}}
$$

where $F_{j}$ is the solute flux to the aquifer from cell $n$ for decay product $j$. 


\section{MODEL DISCRETIZATION AND SOLUTE DISPERSION}

The dispersive behavior of the mixing-cell model is similar to that of the advection dispersion equation and is related to the physical dispersion of the system (Zvirin and Shinnar 1976; Van Ommen 1985; Appelo and Willemsen 1987; Shanahan and Harleman 1984). Shanahan and Harleman (1984) use the term implicit dispersion to describe the dispersion that is inherent in the formulation of mass transport around fully mixed volume elements (cells) and described in terms of ordinary differential equations (ODEs). The dimensionless Peclet number characterizes dispersion and is given by:

$P e=\frac{Z}{D} \frac{q}{\theta}$

where $P e$ is the Peclet number, $Z$ is the length of the unsaturated zone $(\mathrm{L})$, and $D$ is the dispersion coefficient $\left(\mathrm{L}^{2} \mathrm{~T}^{-1}\right)$. The dispersion coefficient is given by:

$D=\alpha_{L} q / \theta+D_{m}$

where $D_{m}$ is the effective molecular diffusion coefficient in pore water $\left(\mathrm{L}^{2} \mathrm{~T}^{-1}\right)$, and $\alpha_{L}$ is the longitudinal dispersivity $(\mathrm{m})$. Molecular diffusion may be important for systems with extremely low specific discharge. Equation 20 is referred to here as the scale-length Peclet number because it is the ratio of advection to dispersion for the entire system. If molecular diffusion is neglected, Equation 20 reduces to $Z / \alpha_{L}$.

Levenspiel and Bischoff (1963) established a relationship between the number of equal-thickness mixing cells and the scale-length Peclet number for the mixing cell-model without interchange. They concluded that the number of mixing cells is approximately related to the Peclet number as given by:

$\frac{1}{n}=\frac{2}{P e^{2}}\left(P e-1+e^{-P e}\right)$

which can be approximated by (Shanahan and Harleman 1984)

$n=\frac{P e+1}{2}$

or as $n$ becomes large

$n \cong \frac{P e}{2}$.

Zvirin and Shinnar (1976) as reported in Shanahan and Harleman (1984) defined the relationship between an equivalent Peclet number $(\mathrm{Pe})$ and $n$ for the mixing-cell model with interchange as:

$P e=\frac{2 n}{1+2 \beta}$

where $\beta$ is the ratio of the exchange flow to through-flow and all cells are of equal size. The influence of cell interchange is to decrease the Peclet number (increase dispersion) by the factor $1+2 \beta$. Shanahan 
and Harleman (1984) define exchange flow as $D A / T$ and through-flow as $A q / \theta$, where $T$ is the distance separating adjacent mixing cells. If molecular diffusion is neglected, $\beta$ can be written in terms of the local dispersivity:

$\beta=\frac{D A}{A q / \theta T}=\frac{\alpha_{L^{*}} q \theta}{T q \theta}=\frac{\alpha_{L^{*}}}{T}$.

The term $\beta$ is essentially the inverse of the local (or grid) Peclet number. The term $\alpha_{L^{*}}$ represents the equivalent local dispersivity accounting for implicit dispersion. If the dispersivity of the overall system is $\alpha_{L}$, then the equivalent local dispersivity can be derived from Equations 20, 25, and 26:

$\alpha_{L^{*}}=\left[\frac{2 n \alpha_{L}}{Z}-1\right] \frac{T}{2}$.

It can be shown that as $n \rightarrow \infty, \alpha_{L^{*}} \rightarrow \alpha_{L}$. If $\alpha_{L^{*}}$ is negative, then implicit dispersion is greater than the dispersion defined by $\alpha_{L}$ and additional cells must be added. For the case where molecular diffusion is not negligible, an equivalent local dispersion coefficient $\left(D^{*}\right)$ is calculated for each cell and given by Equation 28:

$D^{*}=\left[\frac{2 D_{i}}{q_{i} / \theta_{i}}-1\right] \frac{T q_{i} / \theta_{i}}{2}$

\subsection{Comparison of Mixing Cell Model with an Analytical Solution for Solute Flux}

Assuming a unidirectional constant flow field in a homogeneous isotropic porous media, the flux from an instantaneous unit release at $z=0$ with the initial conditions $C=0$ at $t=0$ for all $z$, and boundary conditions $C=0$ at $z= \pm \infty$ is (Codell et al. 1983)

$$
F(z, t)=\frac{\left(z+\frac{q t}{\theta R d}\right)}{4 \sqrt{D \pi t^{3} / R d}} \exp \left(\frac{-\left(z-\frac{q t}{\theta R d}\right)^{2}}{4 D t / R d}-\lambda t\right)
$$

A comparison of the analytical flux to the flux estimated by the mixing-cell model with interchange is illustrated in Figure 2. The model was discretized into sixty equal-thickness cells of 1-meter thickness. Each cell was assigned a specific discharge of $0.05 \mathrm{~m} \mathrm{yr}^{-1}$ and moisture content of 0.3 . A unit mass was placed in cell ten. The percent difference between the maximum flux for the two models was $\sim 0.2 \%$ for $P e=100$. The percent difference increases with decreasing Pelect number to a maximum of $\sim 4 \%$ for a Pe of 10 . 


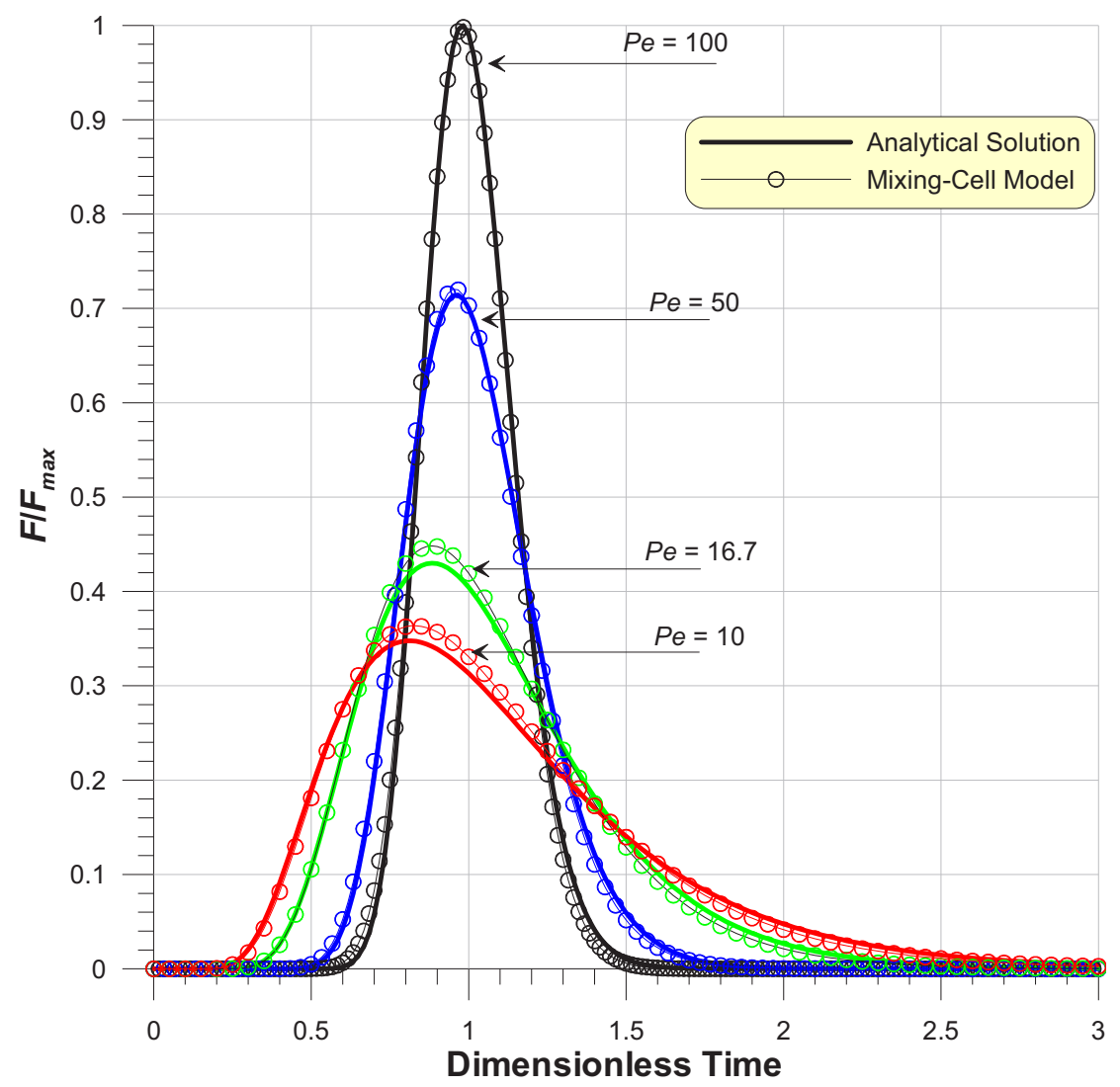

Figure 2. Normalized solute flux versus dimensionless time for various Peclet numbers for the mixing-cell model with interchange and an analytical solution to the advection-dispersion equation for flux. Solute fluxes are normalized to the peak advection dispersion equation flux for a $P e$ of 100 . Dimensionless time is given by $t / t t$ where $t t=Z \theta / q$.

\section{MODEL DISCRETIZATION AND TRANSIENT WATER FLUX}

Under steady-state infiltration conditions, Equation 7 is unnecessary, and solute transport calculations only require an infiltration rate and a corresponding moisture content, which may be obtained from an appropriate moisture characteristic curve. Under transient infiltration conditions, water flux is spatially and temporally variable, and Equation 7 must be solved for as a function of time for each mixing cell defining the unsaturated zone. Rood (2004) describes a method to estimate the number of mixing cells necessary to simulate a wetting front. His method is summarized in this section.

Figure 3 illustrates the conceptual model Rood (2004) used to examine transient water fluxes with the mixing-cell model. The model domain is discretized into $n$, equal-thickness mixing cells and initialized to a constant water flux, $q_{o}$. The water flux entering the top of the column is then increased to a new value, $q_{n}$, at the start of the simulation and continues for a time, $t_{p}$, after which, the water flux returns to its initial value, $q_{o}$. The water flux out the bottom of the domain (at $z=Z$ and $i=n$ in Figure 3 ) is the primary endpoint that was examined. 


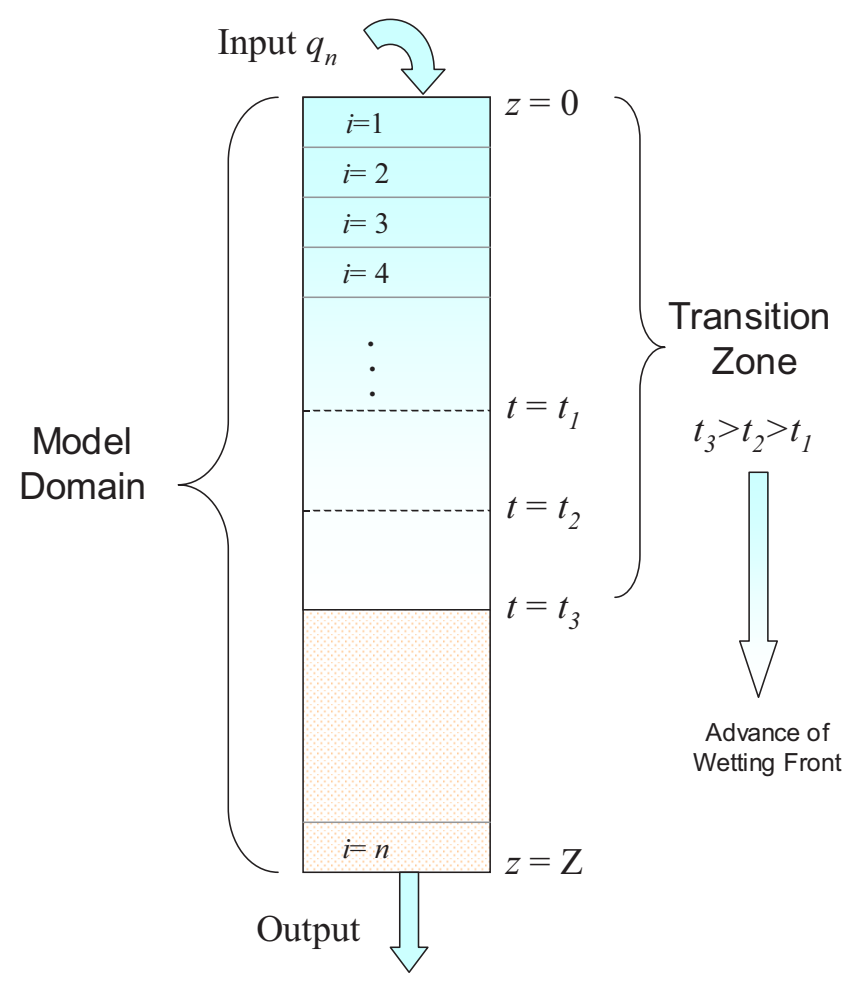

Figure 3. Conceptual model for examination of transient water flux. The mixing-cell model is composed of $n$ equal-dimension cells and initial moisture contents correspond to an initial infiltration rate of $q_{o}$. A new water flux $\left(q_{n}\right.$, where $\left.q_{n}>q_{o}\right)$ is applied to the top of the domain at $t>0$ for a time, $t p$. The downward advance of a wetting front created by the new water flux is shown at three times $\left(t_{1}, t_{2}, t_{3}\right)$.

Gravitationally-driven flow within a cell is the primary assumption underlying the mixing-cell water flow model, although capillary gradients are considered implicitly. A moisture profile is a function of both gravitationally-driven flow and capillary gradients. Capillary gradients tend to dampen the effects of pure gravitational flow (i.e., pure translation of the wetting front) and result in a more disperse wetting front.

Consider the conceptual model illustrated in Figure 3, where $q$ is described by a step-function, $q(0)=q_{o}, q(t>0)=q_{n}, q(\infty)=q_{n}$, and $q_{n}<K_{\text {sat }}$. The asymptotic water flux at any point in the model domain behind the wetting front (designated the transition zone in Figure 3 ) is $q_{n}$ which is equivalent to $K\left(\theta_{n}\right)$, where $\theta_{n}$ is the new moisture content corresponding to the new water flux, $q_{n}$. The asymptotic water flux at the wetting-front boundary is $K\left(\theta_{n}\right)-K\left(\theta_{o}\right)$ and the speed of the advancing wetting front is therefore (Philip 1957 as given in Smith et al., 2002; Hillel 1998):

$u_{w f}=\frac{K\left(\theta_{n}\right)-K\left(\theta_{o}\right)}{\theta_{n}-\theta_{o}}$

where $u_{w f}$ is the velocity of the wetting front $\left(\mathrm{L} \mathrm{T}^{-1}\right), \theta_{o}$ and $K\left(\theta_{o}\right)$ are the initial moisture content and hydraulic conductivity respectively of the soil column that corresponds to a water flux of $q_{o}$, and $\theta_{n}$ and $K\left(\theta_{n}\right)$ are the new moisture content and hydraulic conductivity respectively of the soil column that corresponds to the new water flux, $q_{n}$. The wetting front time-of-arrival at $z=Z$ is given by: 


$$
t_{w f}=\frac{Z}{u_{w f}}
$$

where $t_{w f}$ is the wetting-front arrival time (T). In a heterogeneous unsaturated zone composed of $m$ layers of different materials, the wetting-front travel time can be approximated as:

$$
t_{w f} \approx \sum_{k=1}^{m} \frac{Z_{k}}{u_{w f_{k}}}
$$

where $m$ is the number of different layers, $Z_{k}$ is the layer thickness (L), and $k$ is the index for the layer. Equation 31 and 32 provide the arrival time of a wetting front provided $t_{p}>t_{w f}$. Under these conditions $\left(t_{p}>t_{w f}\right)$, the water flux at $Z$ approaches an equilibrium value equivalent to $q_{n}$. When $t_{p}<t_{w f}$, the water flux at $Z$ is less than $q_{n}$ and the arrival time of the wetting front is less than $t_{w f}$ because the characteristic wave velocity overtakes the shock velocity of the wetting front (Smith et al., 2002).

Capillary forces may be characterized in terms of the hydraulic diffusivity, which is used to convert the two-variable (pressure and moisture) based Richard's equation into a single-variable (moisture) version. The hydraulic diffusivity is given by (Hillel 1998):

$$
D_{h}(\theta)=K(\theta) \frac{d \psi}{d \theta}
$$

where

$$
\begin{aligned}
& D_{h}(\theta)=\text { the hydraulic diffusivity of the medium for a given moisture content }\left(\mathrm{L}^{2} \mathrm{~T}^{-1}\right) \\
& K(\theta)=\text { the hydraulic conductivity of the medium at the moisture content, } \theta \text {. }
\end{aligned}
$$

The shape of an advancing wetting front is influenced by the initial hydraulic diffusivity (i.e., the hydraulic diffusivity at $q=q_{o}$ ) of the medium. Materials with relatively high $D_{h}$ values like clays will exhibit more diffuse wetting fronts while materials like sand, with relatively low $D_{h}$ values exhibit sharp wetting fronts. After passage of the wetting front, capillary forces are not as important because the capillary gradient $(\partial \psi / \partial z)$ relaxes and is zero under steady-state conditions. The effects of capillary forces on the shape of the water flux profile are implicitly accounted for in the mixing-cell model by discretization of the model domain. That is, the number of cells used in a mixing-cell model simulation affects the shape of the wetting front as it exits the model domain.

Figure 4 illustrates the sensitivity of the number of equal-thickness mixing cells on the shape of the wetting front at $z=Z$ for a homogeneous and heterogeneous unsaturated zone. In all cases, the maximum water flux achieved during the simulation was $q_{n}$. For comparison, the same conditions were simulated with the numerical flow and transport code, HYDRUS (Simunek et al., 1999). HYDRUS is a finite-element approximation to the nonlinear partial differential equation (Richard's equation) for unsaturated flow and coupled solute transport. The HYDRUS simulation shows a near step-function of water flux with respect to time as the advancing wetting-front exits the model domain at $z=Z$. The mixing-cell model produces a curve that approaches the step function with increasing number of cells. In general, discretization of the model domain into more cells results in a sharper wetting front. 

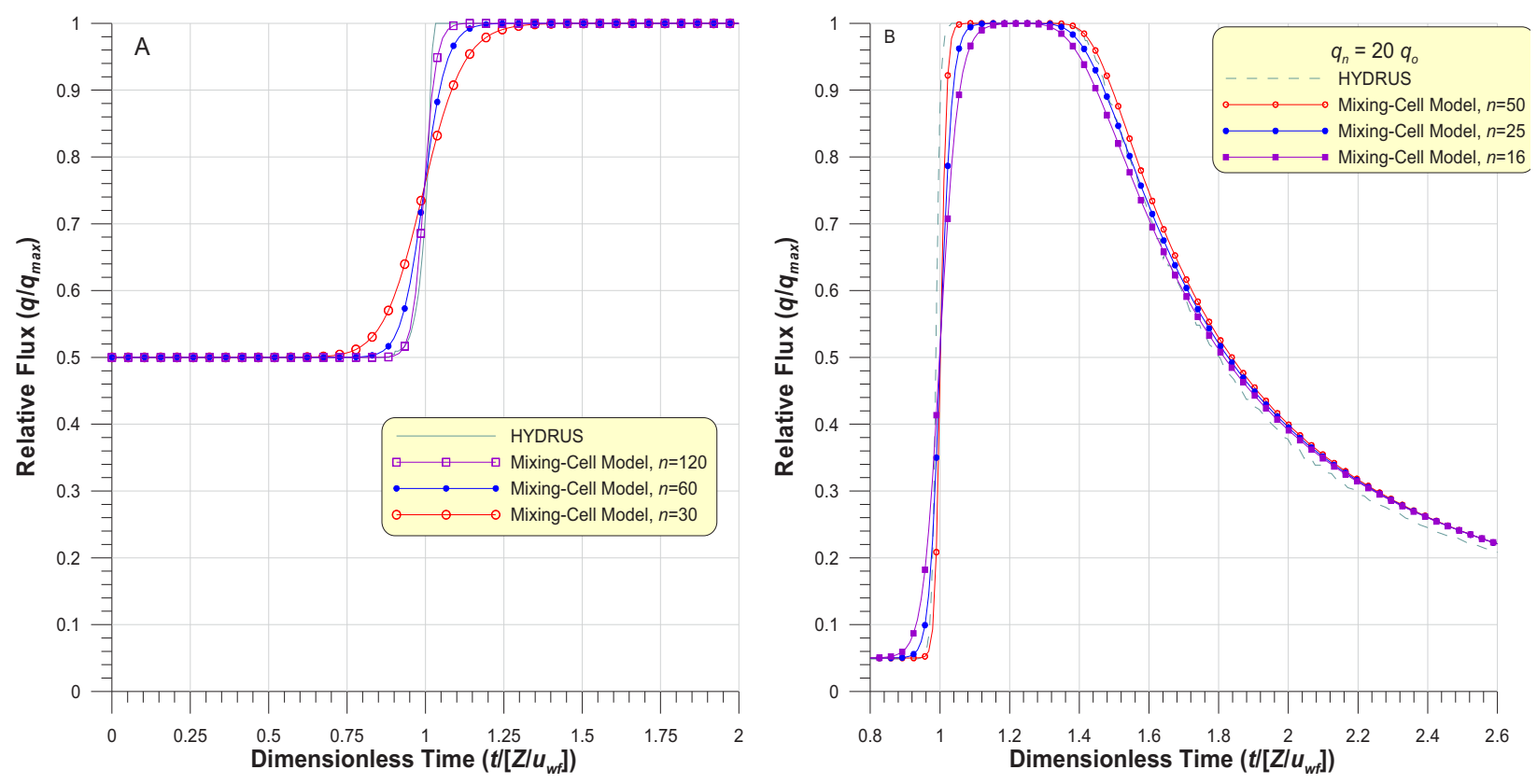

Figure 4. Relative water flux at $\mathrm{z}=\mathrm{Z}$ as a function of dimensionless time for various numbers of mixing cells. In the left graph (A), tp $=\infty$ whereas in right graph (B), tp $=1.16$ twf. For comparison, the same conditions were simulated with HYDRUS. Time has been normalized to the wetting front arrival time. The variable $\mathrm{n}$ is the number of equal-dimension mixing cells in the simulation. The left graph (A) is for a heterogeneous (i.e., layered) unsaturated zone whereas the right graph (B) is for a homogeneous unsaturated zone.

The relationship between the number of mixing cells and the water-flux versus time profile at $z=Z$ was established empirically by fitting the mixing-cell model temporal water-flux profile to same quantity determined by simulations with HYDRUS (Figure 5). An empirical relationship was established between a dimensionless variable, similar in form to the Peclet number, and the number of mixing cells required to adequately simulate the water-flux versus time profile generated by HYDRUS. The dimensionless variable (designated $\varphi$ ) relates the wetting-front velocity and distance traveled to the initial hydraulic diffusivity and is given by:

$\varphi=\frac{Z u_{w f}}{\left|D_{h o}\right|}$

where

$D_{h o}=$ the hydraulic diffusivity at the initial moisture content of the unsaturated zone $\left(\mathrm{L}^{2} \mathrm{~T}^{-1}\right)$. 


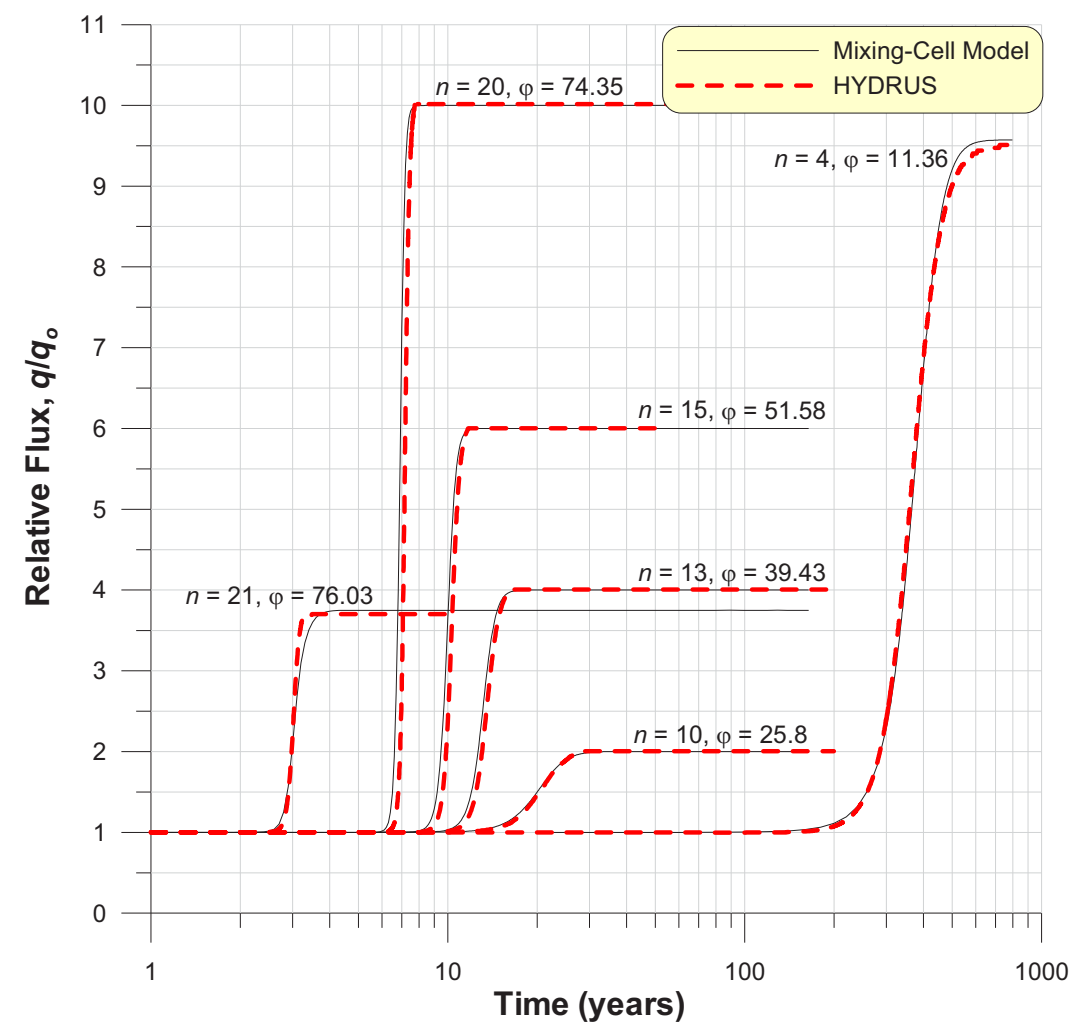

Figure 5. Relative water flux versus time for HYDRUS and mixing-cell model simulations involving a $30-\mathrm{m}$ clay unsaturated zone. These data were used to develop the regression given in Equation 35.

The relationship between $n$ and $\varphi$ is based on the assumptions described earlier in Figure 3 . The hydraulic diffusivity was calculated from the van Genuchten $\theta-\psi$ curves at the specified initial water flux $\left(q_{o}=K\left(\theta_{o}\right)\right)$. The number of mixing cells required to match the HYDRUS results were then fit to $\varphi$ for various lithologies, initial conditions, and water fluxes (Table 2 and Figure 6). An adequate match was achieved when the slope of the water flux versus time curve at $z=Z$ and $t \approx t_{w f}$ for the two models were visually matched. A linear and polynomial fit between $n$ and $\varphi$ yielded the following equations $\left(r^{2}=0.997\right)$ :

$$
\begin{array}{ll}
n=0.229 \varphi+3.6 & 30<\varphi<550 \\
n=1.89+0.1037 \varphi+0.00814 \varphi^{2} & 3<\varphi \leq 30
\end{array}
$$

where $n$ is the number of cells rounded to the nearest whole number. In general, $\varphi$ values greater than about 100 for a 30-m model domain resulted in a near square-wave shape of the water-flux profile as it passes the lower boundary of the model domain at $z=Z$. For a heterogeneous (layered) environment, the number of cells for each layer may be determined independently for each layer and used directly, or alternatively, summed and divided into the total unsaturated thickness to yield single mixing-cell thickness that can be applied to all layers. For $\varphi$ values greater than 550, Equation 35 may estimate an unreasonable number of cells for a model simulation, and the wetting front can be approximated with fewer cells. 
Table 2. Model data used to develop regression between $n$ and $\varphi$. All mixing cells were of equal thickness.

\begin{tabular}{|c|c|c|c|c|c|c|c|c|c|}
\hline Lithology & $\begin{array}{c}q_{o} \\
\left(\mathrm{~m} \mathrm{yr}^{-1}\right)\end{array}$ & $\left(\begin{array}{c}q_{n} \\
\left(\mathrm{~m} \mathrm{yr}^{-1}\right)\end{array}\right.$ & $\theta_{o}$ & $\theta_{n}$ & $\begin{array}{c}D_{h o} \\
\left(\mathrm{~m}^{2} \mathrm{yr}^{-1}\right)\end{array}$ & $\begin{array}{c}T \\
(\mathrm{~m})\end{array}$ & $\begin{array}{c}t_{w f} \\
\text { (years) }\end{array}$ & $\varphi$ & $n$ \\
\hline clay & 0.010 & 0.020 & 0.3474 & 0.3539 & 1.7723 & 3.0 & 19.680 & 25.804 & 10 \\
\hline clay & 0.010 & 0.040 & 0.3474 & 0.3602 & 1.7723 & 2.3077 & 12.880 & 39.427 & 13 \\
\hline clay & 0.010 & 0.060 & 0.3474 & 0.3638 & 1.7723 & 2.0 & 9.846 & 51.576 & 15 \\
\hline clay & 0.010 & 0.100 & 0.3474 & 0.3679 & 1.7723 & 1.5 & 6.830 & 74.352 & 20 \\
\hline clay & 0.040 & 0.150 & 0.3602 & 0.3708 & 4.1256 & 1.429 & 2.869 & 76.034 & 21 \\
\hline clay & $2.089 \times 10^{-4}$ & 0.002 & 0.3090 & 0.3311 & 0.2134 & 7.5 & 371.338 & 11.356 & 4 \\
\hline clay & 0.010 & 0.050 & 0.3474 & 0.3623 & 1.7723 & 2.40 & 22.20 & 91.46 & 25 \\
\hline clay & $2.089 \times 10^{-4}$ & $4.96 \times 10^{-4}$ & 0.3089 & 0.3173 & 0.2134 & 10 & 873.6 & 4.827 & 3 \\
\hline clay & $2.089 \times 10^{-4}$ & $2.287 \times 10^{-4}$ & 0.3089 & 0.3098 & 0.2134 & 15 & 1318 & 3.199 & 2 \\
\hline sandy clay loam & 0.010 & 0.011 & 0.1997 & 0.2014 & 0.3323 & 1.6667 & 41.129 & 61.488 & 18 \\
\hline sandy clay loam & 0.010 & 0.015 & 0.1997 & 0.2058 & 0.3323 & 1.4286 & 36.600 & 69.097 & 21 \\
\hline sandy clay loam & 0.010 & 0.020 & 0.1997 & 0.2104 & 0.3323 & 1.2500 & 32.100 & 78.783 & 24 \\
\hline sandy clay loam & 0.010 & 0.040 & 0.1997 & 0.2223 & 0.3323 & 1.0000 & 22.600 & 111.900 & 30 \\
\hline sandy clay loam & 0.010 & 0.060 & 0.1997 & 0.2297 & 0.3323 & 0.8330 & 18.000 & 140.496 & 36 \\
\hline sandy clay loam & 0.010 & 0.100 & 0.1997 & 0.2397 & 0.3323 & 0.6383 & 13.333 & 189.670 & 47 \\
\hline sandy clay loam & 0.010 & 0.200 & 0.1997 & 0.2544 & 0.3323 & 0.4286 & 8.637 & 292.808 & 70 \\
\hline sand & 0.010 & 0.020 & 0.0619 & 0.0654 & 0.1570 & 0.2400 & 10.452 & 548.454 & 125 \\
\hline sand & 0.00209 & 0.004 & 0.0561 & 0.0582 & 0.0643 & 0.2857 & 33.136 & 422.187 & 105 \\
\hline sand & 0.010 & 0.012 & 0.0619 & 0.06278 & 0.1570 & 0.2777 & 6.645 & 215.67 & 54 \\
\hline sand & 0.00209 & 0.002386 & 0.0561 & 0.0565 & 0.06433 & 0.333 & 20.45 & 171 & 45 \\
\hline
\end{tabular}




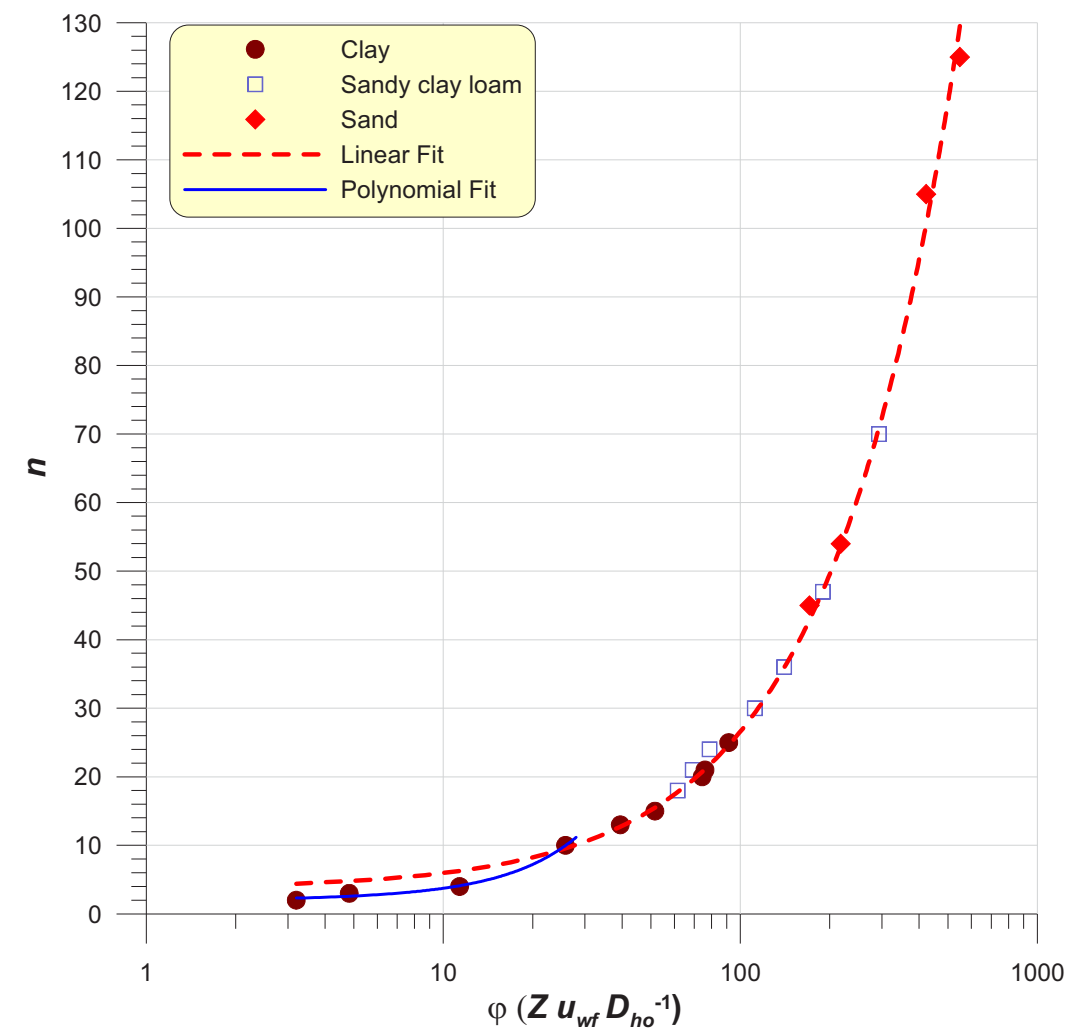

Figure 6 . The number of mixing cells (n) versus the dimensionless variable $\varphi$ required to approximate the behavior of the water-flux profile at $\mathrm{z}=\mathrm{Z}$. The abscissa was plotted in log-scale so as to better visualize the points for $\varphi<100$.

Equation 35 provides guidance on the number of mixing cells to use in a model simulation under the extreme situation of a step increase in the input water flux. Ultimately, model discretization should consider the assessment question and overall uncertainty accompanying a contaminant fate and transport estimate in the unsaturated zone. That is, how sensitive is the assessment question to model discretization? As shown in Figure 4A and 4B, adequate solutions to the water flow problem are obtained with relatively few mixing cells for an assessment question involving the mean wetting-front travel time and the maximum water flux.

\subsection{Coupling Water Flow and Solute Transport}

The transport model requires the water flux as a function of time for each mixing cell. However, the number of mixing cells required to simulate transient flow behavior may not match the number of cells required to simulate dispersion effects. In most cases, the number of cells required to simulate transient flow behavior exceeds the number of cells required to simulate dispersive effects. In these cases, the mixing-cell model with interchange is used because dispersive effects can be simulated through cell interchange. In some cases, the number of mixing cells required to simulate transient flow behavior is less than the number of cells required to simulate dispersive processes. For example, clays exhibit a relatively high hydraulic diffusivity resulting in diffuse infiltration fronts and therefore require relatively few mixing cells to simulate transient flow. In these cases, the mixing-cell model without interchange can be used. The water flux assigned to each transport cell is based on the water flux in the cell that occupies the same space as the transport cell. 


\section{NUMERICAL SOLUTION}

The numerical solution uses a fifth-order Runge-Kutta algorithm coupled with adaptive stepsize-control described in Press et al. (1992). The adaptive stepsize algorithm adjusts the time step according to a user-provided tolerance of the local truncation error. The time step shortens when integrating the stiffer portions of the derivative function and lengthens when integrating the smoother portions. The fifth-order algorithm described in Press et al. (1992) has an embedded forth-order method that is used for error estimation. Beginning with an initial value of the state variable, $y_{n}$ at time $t_{n}$, the general form of the fifth-order Runge-Kutta method is (Press et al. 1992):

$$
\begin{aligned}
& k_{1}=h f\left(t_{n}, y_{n}\right) \\
& k_{2}=h f\left(t_{n}+a_{2} h, y_{n}+b_{21} k_{1}\right) \\
& \cdots \\
& k_{6}=h f\left(t_{n}+a_{6} h, y_{n}+b_{61} k_{1}+\ldots+b_{65} k_{5}\right) \\
& y_{n+1}=y_{n}+c_{1} k_{1}+c_{2} k_{2}+c_{3} k_{3}+c_{4} k_{4}+c_{5} k_{5}+c_{6} k_{6}+O\left(h^{6}\right)
\end{aligned}
$$

where

$$
\begin{array}{ll}
y_{n} & =\text { value of the state (dependent) variable at the } n^{\text {th }} \text { time step } \\
t_{n} & \left.=\text { value of time (independent variable) at the } n^{\text {th }} \text { time step (Note: } t_{n+1} \equiv t_{n}+h\right) \\
f\left(t_{n}, y_{n}\right) & =\text { right-hand side of the derivative } \\
h & =\text { value of time in the time step } \\
n & =\text { time step number } \\
O\left(h^{6}\right) & =\text { the error correction term } \\
a, b, c & =\text { Cash-Karp parameters for the embedded Runge-Kutta method. }
\end{array}
$$

The embedded forth-order method is:

$$
y_{n+1}^{*}=y_{n}+c_{1}^{*} k_{1}+c_{2}^{*} k_{2}+c_{3}^{*} k_{3}+c_{4}^{*} k_{4}+c_{5}^{*} k_{5}+c_{6}^{*} k_{6}+O\left(h^{5}\right)
$$

and the error $(\Delta)$ estimate is:

$$
\Delta \equiv y_{n+1}-y_{n+1}^{*}=\sum_{i=1}^{n}\left(c_{i}-c_{i}^{*}\right) k_{i}
$$

The Cash-Karp parameters are provided in Press et al. (1992). The overall error is scaled to a user-provided tolerance level which is also used to estimate the starting time step of the next step. The desired accuracy of the solution for the ith equation $\left(\Delta_{\mathrm{o}}\right)$ is estimated by:

$$
\Delta_{o}=e p s \times\left(\left|y_{i}\right|+\left|h \times \frac{d y_{i}}{d t}\right|\right)
$$


where eps is the user-provided tolerance level. The optimal time step $\left(h_{o}\right)$ to achieve the desired accuracy is then computed based on the error estimate from the actual time step taken $\left(h_{1}\right)$ :

$$
h_{o}= \begin{cases}S h_{1}\left|\frac{\Delta_{o}}{\Delta_{1}}\right|^{0.20} & \Delta_{o} \geq \Delta_{1} \\ S h_{1}\left|\frac{\Delta_{o}}{\Delta_{1}}\right|^{0.25} & \Delta_{o}<\Delta_{1}\end{cases}
$$

where

$$
\begin{array}{ll}
\Delta_{1} & =\text { the error estimate for the time step, } h_{l} \\
S & =\text { a "safety factor" that is a few percent smaller than unity. }
\end{array}
$$

The exponents 0.20 , and 0.25 essentially grow and shrink the time step depending on the ratio of $\Delta_{\mathrm{o}} / \Delta_{1}$

The code uses a linear interpolation routine to interpolate tabulated values of water flux and contaminant flux as a function of time. If radionuclides are modeled, radionuclide inventories and fluxes are entered in the activity units of Curies or Becquerels. Activities are converted to mass units (i.e., grams) for all computations, and are then converted back to activity units before output. Activity is converted to mass using

$$
Q_{\text {mass }}=\frac{Q_{\text {activity }}(A P D) M W}{\lambda N_{A}}
$$

where

$$
\begin{aligned}
& M W=\text { molecular weight }\left(\mathrm{g} \mathrm{mol}^{-1}\right) \\
& N_{\mathrm{A}}=\text { Avogadro's number }\left(6.023 \times 10^{23} \text { atoms } \mathrm{mol}^{-1}\right) \\
& A P D=\text { disintegrations per second }(\mathrm{dps}) \text { per activity unit }\left(3.7 \times 10^{10} \mathrm{dps} / \mathrm{Ci} \text {, or } 1 \mathrm{dps} / \mathrm{Bq}\right) \\
& Q_{\text {mass }}=\text { number of atoms of a radionuclide (atoms) } \\
& Q_{\text {activity }}=\text { activity of a radionuclide }(\mathrm{Ci} \text { or } \mathrm{Bq}) \\
& \lambda \quad=\text { decay rate constant }\left(\mathrm{s}^{-1}\right) .
\end{aligned}
$$




\section{CODE IMPLEMENTATION}

The MCM model was coded into two FORTRAN programs; one to solve for water fluxes in each cell (MCMF), and the other to solve for solute transport (MCMT). The water flow code is only required if transient infiltration is considered. For transient infiltration problems, the MCMF (water flow code) is run first followed by the solute transport code (MCMT). The output from MCMF is stored either in an ASCII or binary file that is later read by MCMT. Input to both codes is provided through ASCII files whose construction is described later in this section. Both programs perform the same general tasks that include: (1) read user input from ASCII input files, (2) compute unit conversions and internal parameter values, (3) solve the ODEs, and (4) writes output to ASCII or binary files. Input to both MCMF and MCMT is through several ASCII files. The primary input file is termed the parameter definition file and defines model options, cell properties, contaminant properties (MCMT only), and initial inventories of water or contaminant in each cell. The parameter definition file also identifies auxiliary files that may be required. These files include the MCMF water flux file, name of the output file, and release rate history file. Both codes use the same general input file structure, which consists of a series of records that are read in sequential order.

Each code writes a list file (MCMF.LST and MCMT.LST) that: (1) identifies the version of the code, (2) echoes back all input data, (3) presents computed intermediate parameter values, and (4) summarizes time steps taken, execution time, and mass balance. The primary MCMF output file contains the water fluxes, moisture content, and water inventory as a function of time for each cell. The primary MCMT output files contains contaminant inventories, pore water concentrations, and contaminant fluxes as a function of time for each cell. MCMF generates an additional file that contains water fluxes as a function of time for each cell. This file is formatted to be read by MCMT. The primary MCMF output file and water flux file can be written in either binary or ASCII format. A binary file is recommended if the number of cells in the simulation exceed about 60. A utility program has also been written to extract time histories and profiles from the MCMF and MCMT primary output files. MCMT also produces a file for each contaminant (or decay chain member) of contaminant flux leaving the base of the model domain. This is file is useful for quick examination of contaminant fluxes and may be used as input for an aquifer transport model.

Although the model formulation does not specify the units of calculation, both MCMF and MCMT have adhered to convenient units for computations. Parameter units are identified in the input file structure in the next section.

\subsection{Input File Structures for MCMF}

File structure for the MCMF parameter definition file is described in Table 3. All input files are free-form ASCII and may be created and edited in any standard text editor. Each record in the file represents one or more lines of input. Records must be placed in ascending order and the order of each of variable comprising the record must be in the same order as prescribed in Table 3. Blank lines between records are permitted. The code ignores lines where a dollar sign (\$) is placed in the first column, thereby facilitating comments in the file. Comments may also be placed after the last value present on a line.

Suggested default values (when applicable) are put in the description column of Table 3 in parentheses. Further explanation of some of the code variables follows. 
Table 3. Format for the MCMF parameter definition file.

\begin{tabular}{|c|c|c|c|c|}
\hline Record & Code Variable & Type/Format & Units & Description \\
\hline 1 & Title & CHAR/A80 & & Title of run \\
\hline 2 & fileout & CHAR/A80 & & $\begin{array}{l}\text { Name of the water flux file that will be read by } \\
\text { MCMT }\end{array}$ \\
\hline 3 & fileppt & CHAR/A80 & & $\begin{array}{l}\text { File containing the net water flux into the first cell as } \\
\text { a function of time }\end{array}$ \\
\hline 4 & eps & $\mathrm{REAL} / *$ & & Desired accuracy of solution $\left(1 \times 10^{-6}\right)$ \\
\hline 4 & h1 & $\mathrm{REAL} / *$ & $\mathrm{yr}$ & Beginning time step $(0.0001 \mathrm{yr})$ \\
\hline 4 & hmin & $\mathrm{REAL} / *$ & $\mathrm{yr}$ & Minimum time step $\left(1 \times 10^{-60} \mathrm{yr}\right)$ \\
\hline 5 & mlayer & $\mathrm{INT} / *$ & & Number of cells in the simulation $(250 \geq$ mlayer $\geq 1)$ \\
\hline 5 & nmat & $\mathrm{INT} / *$ & & Number of material types (must be $\leq$ mlayer) \\
\hline 5 & nkt & $\mathrm{INT} / *$ & & $\begin{array}{l}\text { Number of points to store that describe hydraulic } \\
\text { conductivity curve as a function of moisture content } \\
(100)\end{array}$ \\
\hline 5 & qmax & $\mathrm{REAL} / *$ & $\mathrm{~m} \mathrm{yr}^{-1}$ & Maximum infiltration rate for simulation \\
\hline 5 & qmin & $\mathrm{REAL} / *$ & $\mathrm{~m} \mathrm{yr}^{-1}$ & Minimum infiltration for simulation \\
\hline 5 & iflag & $\mathrm{INT} / *$ & & $\begin{array}{l}\text { Flag variable for initial moisture option: (0) Initial } \\
\text { moisture content based on first record in fileppt; } \\
\text { (1) user will provide initial moisture contents. }\end{array}$ \\
\hline 5 & abin & $\mathrm{CHAR} / *$ & & $\begin{array}{l}\text { Flag variable for ASCII or binary output: (A) for } \\
\text { ASCII output or, (B) for binary output. All output is } \\
\text { written in the specified format (ASCII or binary) } \\
\text { except for the .LST file, which is always in ASCII } \\
\text { format. }\end{array}$ \\
\hline
\end{tabular}

\section{NOTE: Record 6 is read only if iflag $=1$}
6
theta $(i)$
$\mathrm{REAL} / * \quad \mathrm{~m}^{3} \mathrm{~m}^{-3}$
Initial moisture content in each cell. Twenty values are read per line until all cells are defined.

NOTE: Record 7, 8, and 9 define the cell property range and the cell properties. These records are repeated nmat number of times. Cells must be defined in ascending order

$\begin{array}{ccc}7 & \text { h } & \text { INT/* } \\ 7 & \text { j } & \text { INT/* }\end{array}$

Beginning cell number to define cell properties (inclusive).

Ending cell number to define cell properties (inclusive).

\section{NOTE: Cell properties in records 8 and 9 for each material type apply to cells $h$ through $j$ (inclusive)}

\begin{tabular}{|c|c|c|c|c|}
\hline 8 & thick & $\mathrm{REAL} / *$ & $\mathrm{~m}$ & Thickness of all cells in the range from $\mathrm{h}$ to $\mathrm{j}$. \\
\hline 9 & $\operatorname{sk}(i)$ & $\mathrm{REAL} / *$ & $\mathrm{~m} \mathrm{yr}^{-1}$ & $\begin{array}{l}\text { Saturated hydraulic conductivity of all cells in the } \\
\text { range from } \mathrm{h} \text { to } \mathrm{j} \text {. }\end{array}$ \\
\hline 9 & ths(i) & $\mathrm{REAL} / *$ & $\mathrm{~m}^{-3} \mathrm{~m}^{-3}$ & Saturated porosity of all cells in the range from $\mathrm{h}$ to $\mathrm{j}$. \\
\hline 9 & $\operatorname{thr}(i)$ & $\mathrm{REAL} / *$ & $\mathrm{~m}^{-3} \mathrm{~m}^{-3}$ & $\begin{array}{l}\text { Residual moisture content of all cells in the range } \\
\text { from } \mathrm{h} \text { to } \mathrm{j} \text {. }\end{array}$ \\
\hline
\end{tabular}


Table 3. (continued).

\begin{tabular}{|c|c|c|c|c|}
\hline Record & Code Variable & Type/Format & Units & Description \\
\hline 9 & alpha $(i)$ & REAL/* & $\mathrm{m}^{-1}$ & $\begin{array}{l}\text { van Genuchten fitting parameter, } \alpha \text { for all cells in the } \\
\text { range from } h \text { to } j \text {. }\end{array}$ \\
\hline 9 & $\operatorname{rn}(i)$ & REAL/* & & $\begin{array}{l}\text { van Genuchten fitting parameter } n \text { for all cells in the } \\
\text { range from } h \text { to } j \text {. }\end{array}$ \\
\hline 9 & $\mathrm{rm}$ & REAL/* & & $\begin{array}{l}\text { van Genuchten fitting parameter } m \text { for all cells in the } \\
\text { range from } \mathrm{h} \text { to } \mathrm{j} \text {. See note below }\end{array}$ \\
\hline 9 & $\mathrm{rl}$ & REAL/* & & $\begin{array}{l}\text { van Genuchten fitting parameter } l \text { for all cells in the } \\
\text { range from } \mathrm{h} \text { to } \mathrm{j} \text {. See note below }\end{array}$ \\
\hline
\end{tabular}

NOTE: If rm and/or rl are missing from Record 9, then the default values for $\mathbf{r m}$ and $\mathrm{rl}$ are used

$10 \quad$ ntimes $\quad \mathrm{INT} / * \quad$ Number of output time periods (1)

NOTE: Record 11 is repeated for each output time period. Total number of output time periods = ntimes

\begin{tabular}{|c|c|c|c|c|}
\hline 11 & $\mathrm{t} 1(k)$ & $\mathrm{REAL} / *$ & yrs & Begin time of output time $k$ \\
\hline 11 & $\mathrm{t} 2(k)$ & $\mathrm{REAL} / *$ & yrs & End time of output time $k$ \\
\hline 11 & $\operatorname{tp}(k)$ & $\mathrm{REAL} / *$ & yrs & Print step of output time $k$ \\
\hline 12 & $\operatorname{tmax}$ & REAL/* & yrs & Maximum time of simulation \\
\hline 13 & ncout & $\mathrm{INT} / *$ & & $\begin{array}{l}\text { Number of cells to produce time histories of water } \\
\text { flux }(0, \text { maximum value of } 10)\end{array}$ \\
\hline
\end{tabular}

NOTE: Record 14 read only if ncout $>0$

$14 \quad \operatorname{ncoutput}(k) \quad \mathrm{INT} / *$

15 dline CHAR/a7 or

Cell numbers for each time history (ncout number of values read)

Record 15 is optional. If dline $=$ RESTART, then a restart file is written. If dline $=$ CONTINUE, then the code will expect a repeat of records $13,14,18$ and 19

\subsubsection{Record 2 (fileout)}

The fileout variable stores the name of the water flux file (and complete or relative path to the file) that will later be read by MCMT. This file contains the water flux in each cell as a function of time and can either be binary or ASCII depending on the value of the variable abin.

\subsubsection{Record 3 (fileppt)}

The fileppt variable stores the name of the file (and complete or relative path to the file) containing the net infiltration rate as a function of time that is fed into the first (uppermost) cell of the model. The structure for the file is described in Table 4. 
Table 4. Format of the water flux file for MCMF.

\begin{tabular}{cll}
\hline Line Number & Code Variable & \multicolumn{1}{c}{ Description } \\
\hline 1 & junk & Column headers and comments (discarded) \\
2 to $n+1^{\text {a }}$ & $\operatorname{precip}(k, 1)$ & Time in years from the start of the simulation for the $k^{\text {th }}$ record \\
2 to $n+1^{\text {a }}$ & $\operatorname{precip}(k, 2)$ & $\begin{array}{l}\text { Water flux }\left(\mathrm{m} \mathrm{y}^{-1}\right) \text { entering the first compartment of the model domain } \\
\text { for the } k^{\text {th }} \text { time record }\end{array}$ \\
& & a. $n$ is the number of time and water flux records. A minimum of two records are required. \\
\hline
\end{tabular}

\subsubsection{Record 4 (eps, h1, hmin)}

The code variables, eps, h1, and hmin all control time stepping and iteration of the Runge-Kutta solver. The code variable eps is defined in terms of Equation 39 and has a default value of $10^{-6}$. The variable $\mathbf{h} 1$ defines the initial time step to be taken. A relatively large value (say 1 year) can result in faster simulation times, but a user runs the risk of an inaccurate solution. A default value of $0.0001 \mathrm{yr}$ is recommended. The code variable, hmin defines the minimum time step to be taken. The code will abort if the estimated time step is less than $\mathbf{h m i n}$. If this occurs, the user should set $\mathbf{h m i n}$ to a smaller value step.

\subsubsection{Record 5 (mlayer, nmat, nkt, qmax, qmin, iflag, and abin)}

The variable mlayer defines the total number of cells to discretize the model domain into. The variable nmat defines the number of material-type definitions that will be used to assign material properties to each cell. Materials are defined in increasing order, starting with the cell nearest the ground surface and ending with the cell at the aquifer-unsaturated zone interface (see Figure 1 and 3). For example, if a $50 \mathrm{~m}$ thick unsaturated zone is composed (from top to bottom) of $20 \mathrm{~m}$ of sandstone, $10 \mathrm{~m}$ of clay, and $20 \mathrm{~m}$ of sandstone, then nmat is set to $\mathbf{3}$, because there are three material definitions required to define the unsaturated zone. Material properties are defined in records 7, 8, and 9.

In MCMF, the moisture characteristic curve, (which is the relationship between $\theta$ and $K$ and given by Equation 8 and 9), is computed first and stored in an array. Evaluation of the $\theta-K$ function is then performed by linear interpolation. The number of points that comprise the tabulated function is specified by the code variable, nkt. Naturally, one would only want to compute the function over the range of hydraulic conductivities expected to be encountered. The range of hydraulic conductivities to compute the $\theta-K$ function over is specified by the code variables qmin (the minimum value of $K$ ) and qmax (maximum value of $K$ ). Inaccurate interpolation can occur if too few points are specified for the range of qmin and qmax, however, this also depends largely on the shape of the $\theta-K$ curve in the region bounded by qmin and qmax. The MCMF list file prints the $\theta-K$ values that are used for interpolation. The user should be aware of the shape of the $\theta-\mathrm{K}$ curve in the region bounded by qmin and qmax and adjust $\mathbf{n k t}$ accordingly.

The iflag variable selects whether the user provides the initial moisture profile or the initial moisture profile is defined by the first record in the net infiltration file (fileppt). An initial moisture profile is required if iflag $=1$. Otherwise, if iflag $=0$, then the initial moisture content is calculated from the first record in the net infiltration file. If iflag $=1$, then the initial moisture content is read in Record 6 .

The abin variable defines whether an ASCII (abin=A) or binary $(\mathbf{a b i n}=\mathrm{B})$ output file is written. A binary file is recommended if the number of cells exceeds about 60 . The corresponding value of abin in the MCMT parameter definition file must also be the same. The abin variable should always be in upper case. 


\subsubsection{Record 6 (theta)}

The code variable theta is an array that holds the current moisture content in each cell. The initial moisture content values are read from the parameter definition file in Record 6 if iflag=1. Twenty values are read per line until all cells are defined. Values are assigned in ascending order. That is, the first theta value read is assigned to cell 1 (uppermost cell), the next value read is assigned to cell 2 , and so on until the last (lowermost) cell is assigned the last value provided. For example, if a problem had a total of 43 cells, and theta was 0.2 for the first 10 cells, 0.1 for the next 30 cells, and 0.3 for the last three cells, then the input file for the 6th record would look like

$\begin{array}{llllllllllllllllllllllllllllllllll}0.2 & 0.2 & 0.2 & 0.2 & 0.2 & 0.2 & 0.2 & 0.2 & 0.2 & 0.2 & 0.1 & 0.1 & 0.1 & 0.1 & 0.1 & 0.1 & 0.1 & 0.1 & 0.1 & 0.1 & \text { ! cells } & 1-20 \\ 0.1 & 0.1 & 0.1 & 0.1 & 0.1 & 0.1 & 0.1 & 0.1 & 0.1 & 0.1 & 0.1 & 0.1 & 0.1 & 0.1 & 0.1 & 0.1 & 0.1 & 0.1 & 0.1 & 0.1 & \text { ! } & \text { cells } & 21-40 \\ 0.3 & 0.3 & 0.3 & & & & & & & & & & & & & & & & & & & \end{array}$

If iflag is zero, then the 6th record is omitted from the parameter definition file.

\subsubsection{Records 7, 8, and 9 (h, j thick, sk ths, thr, alpha, rn, rm, rl)}

The code variables $\mathbf{h}$ and $\mathbf{j}$ define the beginning and ending cells (inclusive) to include in a material definition. Each material is defined in terms of its thickness and hydraulic properties (saturated hydraulic conductivity, porosity, etc.) as defined in the variables thick, sk, ths, thr, alpha, rn, rm, and rl. The variables, $\mathrm{rm}$ and $\mathrm{rl}$ are optional and if missing, the default values of $\mathrm{rl}=0.5$ and $\mathrm{rm}=1-1 / \mathrm{rn}$ will be used. These properties are read in records 8 and 9 and are repeated for each material type. For example, suppose that a $45 \mathrm{~m}$ thick unsaturated zone is composed of (from top to bottom) $10 \mathrm{~m}$ of sandy clay loam, $15 \mathrm{~m}$ of sandy clay, and $20 \mathrm{~m}$ of sand. The code variable, nmat should be set to 3 . Assuming 45 cells of $1 \mathrm{~m}$ thickness and the hydraulic properties in Table 1, records 7, 8, and 9 would then be:

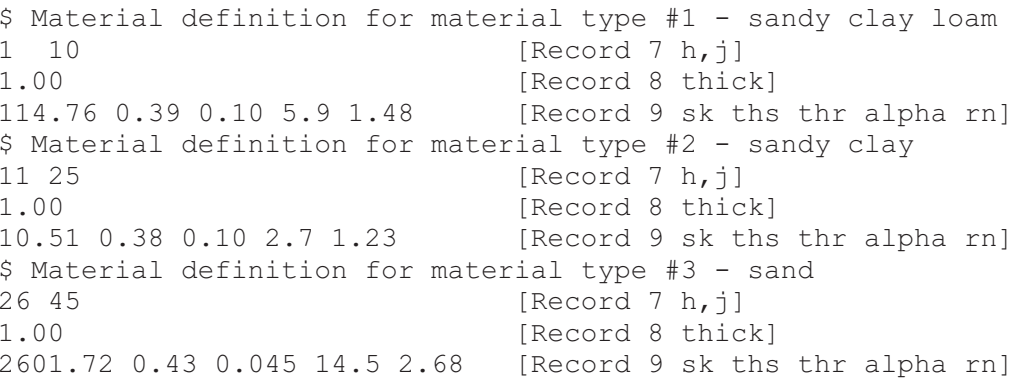

Note that records 7, 8, and 9 are repeated nmat number of times (nmat $=3$ ). Comments are placed on lines that begin with a dollar sign (\$), and additional comments may be placed after the last value on each line. Also note that $\mathrm{rm}$ and $\mathrm{rl}$ are missing in record 9. If these values are missing, the the default values $(\mathrm{rl}=0.5, \mathrm{rm}=11 / \mathrm{rn})$ will be used in the computation. The user is cautioned that any two real values placed after $\mathrm{rn}$ in record 9 will be interpreted as $\mathrm{rl}$ and $\mathrm{rn}$ respectively, so make sure either both values are missing (to use the default values), or valid values for each parameter are present. An invalid real value (i.e., a character) will registar as a missing value.

\subsubsection{Records 10, 11, and 12 (ntimes, t1, t2, tp, and tmax)}

The code variable, ntimes defines how many time-history output periods are printed in fileout. Each output period is defined by a beginning time (t1), an ending time (t2), and a print intervals (tp). In this way, different time resolutions can be applied to various time periods of the simulation. Record 11 is repeated ntimes. It is important to apply proper time resolution for transient flows because these data are used by MCMT to estimate the time-variable Darcy velocity and moisture content in each cell. Suppose 
for example that one wants to capture the transient water fluxes during the first 100 years of a simulation, and extend the simulation out to 1000 years. A possible choice for records 10 and 11 would be:

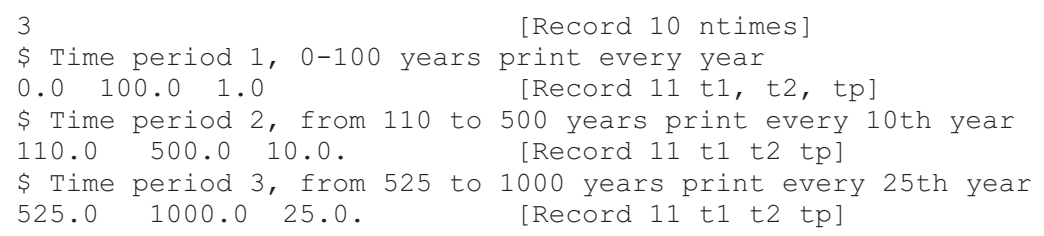

The code variable, tmax is the maximum time of the simulation. The water flow equations are not actually solved at tmax, rather the water inventory and flux at $\mathbf{t} 2$ (ntimes) values are printed to the output file at the time, tmax. This variable should be greater than $\mathbf{t} 2$ (ntimes) and is used to extend the simulation in time once steady-state conditions are achieved.

\subsubsection{Records 13 and 14 (ncout, ncoutput)}

The code variables ncout and ncoutput are used to define cells for which time histories are output in separate files. The variable ncout defines how many cells to output time histories for (maximum of 10), and the variable ncoutput defines an array of cell numbers for which to provide water flux time histories. Cell 1 is defined as the uppermost cell near at the top of the model domain. Cell numbers should be separated by spaces or commas. For example, suppose a user wants to output water flux histories for cells 5, 10, 15, and 20. Records 13 and 14 would read:

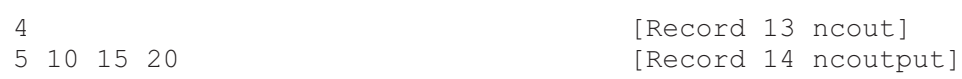

Water fluxes are written to predefined file names in the default working directory and named $\mathrm{qXX}$.dat where $\mathrm{XX}$ is the sequential number of the cell read in the array ncoutput. Using the previous example, the code would write the flux histories to the files q01.dat, q02.dat, q03.dat, and q04.dat.

\subsubsection{Record 15 (Restart and Continue options)}

Record 15 is optional and is a keyword that is either RESTART or CONTINUE (case sensitive). The keywords should have no leading blanks on the line. If record 15 is RESTART, then a restart file is written to the working directory. The restart file is named RESTART.DAT and contains the moisture contents at the end of the simulation. The values can be pasted into a new MCMF file to initialize the moisture content. If record 15 is CONTINUE, them MCMF will expect a new set of parameters beginning with record 7 and ending with record 12 . The total number of cells and number of material types must remain the same. However, the properties of materials may change. This allows for property changes over time while retaining the water balance of the system. That is, the volume of water in each cell remains the same but the moisture content in the cell may change based on the redefined material properties. The time variables should start from the last output time of the first run. Also, it is up to the user to make sure that the water in each cell at the end of the first simulation does not exceed the moisture content in the redefined cell.

\subsubsection{Water Flux File}

Water fluxes entering the top of the model domain are provided to MCMF via an external ASCII file. The water flux file is specified in the parameter definition file (Record 3) and the name of the file is stored in the code variable, fileppt. The file can be any name the user chooses. The file format is described in Table 4. 


\subsection{Code Execution and MCMF Output Files and Utilities}

Execution of the MCMF code is performed on the command line by typing:

[path]MCMF [parameter definition file]

where path is the full or relative path to the MCMF executable from the current operating directory, and parameter definition file is the name of the parameter definition file (Table 3). If the parameter definition file is left off, then MCMF will look for the default parameter definition file named MCMF.PAR in the current working directory. If the default parameter definition file is not found, or the user fails to provide a valid parameter definition file, the code will abort.

MCMF produces three output files: (1) the water flux output file read by MCMT and specified by record 2 in the parameter definition file, (2) the general output file, and (3) the list file. The general output file and list file are assigned named based on the parameter definition file name. For example, if the parameter definition file is named PROB.PAR, then the list file is PROB.LST and the general output file is named PROB.OUT. These files are written to the current operating directory each time MCMF is executed. If the default name of the parameter definition file is used (MCMF.PAR), then the list and output file names are MCMF.LST and MCMF.OUT recpectively. The MCMF.OUT file contains the time histories of water inventory, moisture content, and water flux for each cell in the simulation. The MCMF.LST file contains the model input data, calculated intermediate values, the number of converged and unconverged time steps, code execution time, and mass balance information. The MCMF.LST file is always written in ASCII whereas the MCMF.OUT file is written in binary if the code variable abin is set to "B". A utility program (MCMFPRT) was written to allow access to the binary (or ASCII) data stored in the MCMF.OUT file. The MCMFPRT utility is executed by typing on the command line:

\section{[path]MCMFPRT [parameter definition file]}

where path is the full or relative path to the MCMFPRT executable from the current operating directory, followed by the name of the parameter definition file. If the parameter definition file is left off, then MCMFPRT will look for the default parameter definition file (MCMFPRT.PAR) in the current working directory. If the default parameter definition file is not found, or the user fails to provide a valid parameter definition file name, the code will abort. The format for the MCMFPRT parameter definition file is described in Table 5.

Table 5. Format for the MCMFPRT parameter definition file.

\begin{tabular}{|c|c|c|c|}
\hline Record & Code Variable & Type/Format & Description \\
\hline 1 & Title & CHAR/A80 & Title of run \\
\hline 2 & filedat & CHAR/A80 & MCMF general output file (MCMF.OUT) \\
\hline 3 & abin & $\mathrm{CHAR} / *$ & $\begin{array}{l}\text { Flag variable for ASCII or binary output: (A) for ASCII output or, } \\
\text { (B) for binary output. }\end{array}$ \\
\hline 3 & aqnt & $\mathrm{CHAR} / *$ & $\begin{array}{l}\text { Quantity to extract: } \mathrm{M}=\text { moisture content, } \mathrm{I}=\text { water inventory, } \mathrm{Q}= \\
\text { water flux }\end{array}$ \\
\hline 3 & pfix & $\mathrm{CHAR} * 4 / *$ & A four character prefix to identify each output file name. \\
\hline 4 & nout & $\mathrm{INT} / *$ & Number of cells to output time histories $($ maximum $=50)$ \\
\hline 4 & tout & $\mathrm{INT} / *$ & Number of times to output spatial profiles $($ maximum $=50)$ \\
\hline 4 & $\mathrm{cf}$ & $\mathrm{REAL} / *$ & User-provided conversion factor to multiply output by (1.0) \\
\hline
\end{tabular}




\begin{tabular}{ccll}
\hline Record & Code Variable & Type/Format & \multicolumn{1}{c}{ Description } \\
\hline 5 & noutput $(i)$ & $\mathrm{INT} / *$ & $\begin{array}{l}\text { The cell numbers for each of the nout time histories. All values are } \\
\text { read from one line and each value is separated by a space or } \\
\text { comma. If nout is zero, this record should be blank. }\end{array}$ \\
& toutput $(i)$ & $\mathrm{REAL} / *$ & $\begin{array}{l}\text { The time of each of the tout spatial profiles. All values are read } \\
\text { from one line and each value is separated by a space or comma. If } \\
\text { tout is zero, this record should be blank. }\end{array}$ \\
& &
\end{tabular}

Output files for MCMFPRT are defined by the concatenation of a four character prefix (variable pfix in Record 3), a file sequence number, and a ".dat" file extension. The sequence number is a concatenation of the output quantity symbol ( $\mathrm{M}$ for moisture content, I for water inventory, or $\mathrm{Q}$ for water flux), a time output $(\mathrm{T})$ or profile output $(\mathrm{P})$ symbol, and a sequence number. For example, if moisture time histories are requested for two different cells and the user defines the pfix variable as "test", then two files will be created. The file for the first cell requested will be called testMT001.dat and the file for the second cell requested will be testMT002.dat.

\subsection{Input File Structures for MCMT}

File structure for the MCMT parameter definition file is similar to the MCMF and is described in Tables 6. All MCMT input files are free-form ASCII, with the exception of binary water flux files generated by MCMF. Each record in the parameter definition file represents one or more lines of input. Records must be placed in ascending order and the order of each of variable comprising the record must be in the same order as prescribed in Table 6. Blank lines between records are permitted. The code ignores lines where a dollar sign (\$) in placed in the first column, thereby facilitating comments in the file. Comments may also be placed after the last value on a line. Suggested default values (where applicable) are put in the description column of Table 6 in parentheses. Further explanation of some of the code variables follows. 
Table 6. Format for the MCMT parameter definition file.

\begin{tabular}{|c|c|c|c|c|}
\hline Record & Code Variable & Type/Format & Units & Description \\
\hline 1 & title & CHAR/A80 & & Title of run \\
\hline 2 & fileppt & CHAR/A80 & & $\begin{array}{l}\text { Name of the MCMF water flux file. If } \\
\text { fileppt=NONE (case sensitive) then a steady-state } \\
\text { water flux is assumed. The steady-state water flux } \\
\text { is read from the saturated } K(\text { ksat) and moisture } \\
\text { content is read from the saturated } \theta \text { (thetas) that } \\
\text { are defined in record } 18 \text {. }\end{array}$ \\
\hline 3 & filerel & CHAR/A80 & & $\begin{array}{l}\text { Name of file containing the contaminant release } \\
\text { rate into the first cell as a function of time. If } \\
\text { filerel=NONE (case sensitive), then no external } \\
\text { source of contaminant is assumed. }\end{array}$ \\
\hline 4 & eps & REAL/* & & Desired accuracy of solution $\left(1 \times 10^{-6}\right)$ \\
\hline 4 & h1 & REAL/* & $\mathrm{yr}$ & Beginning time step $(0.0001 \mathrm{yr})$ \\
\hline 4 & hmin & REAL/* & $\mathrm{yr}$ & Minimum time step $\left(1 \times 10^{-60} \mathrm{yr}\right)$ \\
\hline 5 & mlayer & $\mathrm{INT} / *$ & & $\begin{array}{l}\text { Number of cells in the simulation }(250 \geq \text { mlayer } \geq \\
\text { 1) }\end{array}$ \\
\hline 5 & nprog & $\mathrm{INT} / *$ & & $\begin{array}{l}\text { Number of contaminants or members in the } \\
\text { decay-series }(10 \geq \text { nprog } \geq 1)\end{array}$ \\
\hline 5 & nmat & $\mathrm{INT} / *$ & & Number of material types (must be $\leq$ mlayer) \\
\hline 5 & iunits & $\mathrm{INT} / *$ & & $\begin{array}{l}\text { Flag variable that sets the units of the calculation: } \\
\text { (1) Curies; (2) Becquerel; (3) mg }\end{array}$ \\
\hline 5 & abin & CHAR/* & & $\begin{array}{l}\text { Flag variable for ASCII or binary output: (A) for } \\
\text { ASCII output or, (B) for binary output. Only the } \\
\text { general output file is written in binary when binary } \\
\text { is specified. The format (ASCII or binary) of the } \\
\text { water fluxes generated with MCMF must match } \\
\text { the format specified in MCMT }\end{array}$ \\
\hline 6 & cname $(i)$ & $\mathrm{CHAR}^{*} 6 / *$ & & $\begin{array}{l}\text { A six character name (no spaces in name) for each } \\
\text { contaminant or decay chain member (nprog } \\
\text { number of values expected). }\end{array}$ \\
\hline 7 & $\mathrm{mw}(i)$ & REAL/* & $\mathrm{g} \mathrm{mol}^{-1}$ & $\begin{array}{l}\text { Molecular weight of each contaminant or decay } \\
\text { chain member (nprog number of values expected). }\end{array}$ \\
\hline 8 & $\operatorname{sol}(i)$ & REAL/* & $\mathrm{mg} \mathrm{m}^{-3}$ & $\begin{array}{l}\text { Solubility in water for each contaminant or decay } \\
\text { chain member (nprog number of values expected). }\end{array}$ \\
\hline 9 & thalf $(i)$ & REAL/* & years & $\begin{array}{l}\text { Half life of contaminant or decay chain member } \\
\text { (nprog number of values expected). }\end{array}$ \\
\hline 10 & bratio $(i)$ & REAL/* & - & $\begin{array}{l}\text { Branching ratio of the fraction of decay product } \\
j-1 \text {, that decays to decay product } j \text { (nprog number } \\
\text { of values expected, last value is not used if it is the } \\
\text { last contaminant in the list) }\end{array}$ \\
\hline 11 & dwater $(i)$ & REAL/* & $\mathrm{m}^{2} \mathrm{yr}^{-1}$ & $\begin{array}{l}\text { Free-water molecular diffusion coefficient (nprog } \\
\text { number of values expected). }\end{array}$ \\
\hline
\end{tabular}


Table 6. (continued).

\begin{tabular}{|c|c|c|c|c|}
\hline Record & Code Variable & Type/Format & Units & Description \\
\hline \multicolumn{5}{|c|}{ NOTE: Record 12, 13, and 14 are repeated for each contaminant or decay chain member } \\
\hline 12 & $\mathrm{y}(i, j)$ & REAL/* & $\mathrm{Ci}, \mathrm{Bq}$, or mg & $\begin{array}{l}\text { Initial contaminant inventories in cell } i \text { for } \\
\text { contaminant } j \text {. Twenty values are read per line } \\
\text { until all cells for a given contaminant are defined. } \\
\text { The first contaminant is read first followed by the } \\
\text { remaining contaminants. }\end{array}$ \\
\hline 13 & $\operatorname{kd}(i, j)$ & REAL/* & $\mathrm{mL} \mathrm{g}^{-1}$ & $\begin{array}{l}\text { Linear sorption coefficient for cell } i \text { and } \\
\text { contaminant } j \text {. Twenty values are read per line } \\
\text { until all cells for a given contaminant are defined. } \\
\text { The first contaminant is read first followed by the } \\
\text { remaining contaminants. }\end{array}$ \\
\hline 14 & $\mathrm{kx}(i, j)$ & REAL/* & $\mathrm{yr}^{-1}$ & $\begin{array}{l}\text { Optional rate constant describing transfer of } \\
\text { contaminant } j \text { from cell } i \text { to cell } i+1 \text {. Twenty } \\
\text { values are read per line until all cells for a given } \\
\text { contaminant are defined. The first contaminant is } \\
\text { read first followed by the remaining contaminants } \\
\text { (Default is } 0 \text { ) }\end{array}$ \\
\hline
\end{tabular}

NOTE: Record 15, 16, and 17 define the cell property range and the cell properties. These records are repeated nmat number of times. Cells must be defined in ascending order.
$15 \mathrm{~h} \quad \mathrm{INT} / *$
$15 \mathrm{j} \quad \mathrm{INT} / *$
Beginning cell number to define cell properties (inclusive).
Ending cell number to define cell properties (inclusive).

NOTE: Cell properties assigned in records 16 and 17 for each material type apply to cells $h$ through $j$ (inclusive)

$\begin{array}{llll}16 & \text { thick } & \mathrm{REAL} / * & \mathrm{~m} \\ 16 & \text { rho } & \mathrm{REAL} / * & \mathrm{~g} \mathrm{~cm}^{-3} \\ 17 & \text { sk } & \mathrm{REAL} / * & \mathrm{~m} \mathrm{yr}^{-1} \\ 17 & \text { ths } & \mathrm{REAL} / * & \mathrm{~m}^{-3} \mathrm{~m}^{-3} \\ 17 & \text { thr } & \mathrm{REAL} / * & \mathrm{~m}^{-3} \mathrm{~m}^{-3} \\ 17 & \text { alpha } & \mathrm{REAL} / * & \mathrm{~m}^{-1} \\ 17 & \text { rn } & \mathrm{REAL} / * & \\ 17 & \mathrm{rm} & \mathrm{REAL} / * & \\ 17 & \mathrm{rl} & \mathrm{REAL} / * & \end{array}$

Thickness of all cells in the range from $\mathrm{h}$ to $\mathrm{j}$

Bulk density of all cells in the range from $\mathrm{h}$ to $\mathrm{j}$

Saturated hydraulic conductivity of all cells in the range from $h$ to $j$

Saturated porosity of all cells in the range from $\mathrm{h}$ to $\mathrm{j}$.

Residual moisture content of all cells in the range from $h$ to $j$.

van Genuchten fitting parameter, $\alpha$ for all cells in the range from $h$ to $j$.

van Genuchten fitting parameter $n$ for all cells in the range from $h$ to $j$.

van Genuchten fitting parameter $m$ for all cells in the range from $\mathrm{h}$ to $\mathrm{j}$. See note below

van Genuchten fitting parameter $l$ for all cells in the range from $\mathrm{h}$ to $\mathrm{j}$. See note below

NOTE: If rm and/or $\mathrm{rl}$ are missing from Record 17, then the default values for $\mathbf{r m}$ and $\mathrm{rl}$ are used

18 ntimes INT/* Number of output time periods

NOTE: Record 19 is repeated for each output time period. Total number of output time periods $=$ ntimes 
Table 6. (continued).

\begin{tabular}{|c|c|c|c|c|}
\hline Record & Code Variable & Type/Format & Units & Description \\
\hline 19 & $\mathrm{t} 1(k)$ & REAL/* & yrs & Begin time of output time $k$ \\
\hline 19 & $\mathrm{t} 2(k)$ & REAL/* & yrs & End time of output time $k$ \\
\hline 19 & $\operatorname{tp}(k)$ & REAL/* & yrs & Print step of output time $k$ \\
\hline 20 & dline & $\begin{array}{c}\text { CHAR/a7 or } \\
\text { a8 }\end{array}$ & & $\begin{array}{l}\text { Record } 15 \text { is optional. If dline }=\text { RESTART, then a } \\
\text { restart file is written. If dline }=\text { CONTINUE, then } \\
\text { the code will expect a repeat of the input file } \\
\text { starting with record } 7 \text { and ending with record } 12\end{array}$ \\
\hline
\end{tabular}

\subsubsection{Record 2 (fileppt)}

The fileppt variable stores the name of the MCMF-generated water flux file. The file format (ASCII or binary) must correspond to the setting of the variable, abin. Setting fileppt to NONE (case sensitive) allows MCMT to be run in steady-state mode without an MCMF file. The variables sk and theta define the water flux and moisture content of each material. The theta value must be set to negative(theta) for this option to take effect.

\subsubsection{Record 3 (filerel)}

The filerel variable stores the name (and complete or relative path to the file) of the contaminant release rate file. If the file name is NONE (case sensitive), then no external contaminant flux is considered. The structure for the file is described in Section 6.3.8.

\subsubsection{Record 4 (eps, h1, hmin)}

The code variables, eps, h1, and hmin all control time stepping and iteration of the Runge-Kutta solver. The code variable eps is defined in terms of Equation 39 and has a default value of $10^{-6}$. The variable $\mathbf{h} \mathbf{1}$ defines the initial time step to be taken. A relatively large value (say 1 year) can result in faster simulation times, but a user runs the risk of an inaccurate solution. A default value of $0.0001 \mathrm{yr}$ is recommended. The code variable, hmin defines the minimum time step to be taken. The code will abort if the estimated time step is less than hmin. If this occurs, the user should set hmin to a smaller value. A value of $10^{-60} \mathrm{yr}$ is recommended.

\subsubsection{Record 5 (mlayer, nprog, nmat, iunits, and abin)}

The variable mlayer defines the total number of cells to discretize the model domain into. The variable nprog defines how many contaminants to simulate. If a radioactive decay chain is considered, nprog should be set to the number of progeny plus the parent. The variable nmat defines the number of different material definitions that will be used to assign material properties to each cell. Materials are defined in increasing order, starting with the cell nearest the ground surface and ending with the cell at the aquifer-unsaturated zone interface (see Figures 1 and 3). For example, if a $50 \mathrm{~m}$ thick unsaturated zone is composed (from top to bottom) of $20 \mathrm{~m}$ of sandstone, $10 \mathrm{~m}$ of clay, and $20 \mathrm{~m}$ of sandstone, then nmat is set to 3 , because there are three material definitions required to define the unsaturated zone. Material properties are defined in records 15, 16, and 17.

The iunits variable define the units of the calculation. Both radiological (i.e., $\mathrm{Ci}$ or $\mathrm{Bq}$ ) and mass units are included. The abin variable defines whether an ASCII (abin=A) or binary $(\mathbf{a b i n}=\mathrm{B})$ output file is written. A binary file is recommended if the number of cells exceeds about 60 . The format of the MCMF file must corresponding to the format defined by abin in the MCMT parameter definition file. 


\subsubsection{Record 6, 7, 8, 9, 10, and 11 (cname, mw, sol, thalf, bratio, dwater)}

The variables read in records 6 through 10 are the material-independent contaminant properties. Each record contains nprog values. Decay chains are modeled by setting bratio to a value greater than zero (typically 1.0). If bratio(i) is zero, then the fraction of contaminant (i) that decays to contaminant $\mathrm{i}+1$ is zero. In this way, a single MCMT simulation can include a decay chain and several contaminants that are not connected to the chain. The procedure is illustrated in the example below. Six radionuclides are modeled; Th-230, Ra-226, $\mathrm{Pb}-210, \mathrm{H}-3$, Tc-99, and $\mathrm{C}-14$. The first three radionuclides comprise a decay chain (Th-230 $\rightarrow$ Ra-226 $\rightarrow$ Pb-210) with a branching ratio of 1.0 between Th-230 and Ra-226 (bratio(1)=1.0) and Ra-226 and $\mathrm{Pb}-210$ (bratio(2)=1.0). The remainder of the radionuclides are independent, and therefore, bratio is set to zero.

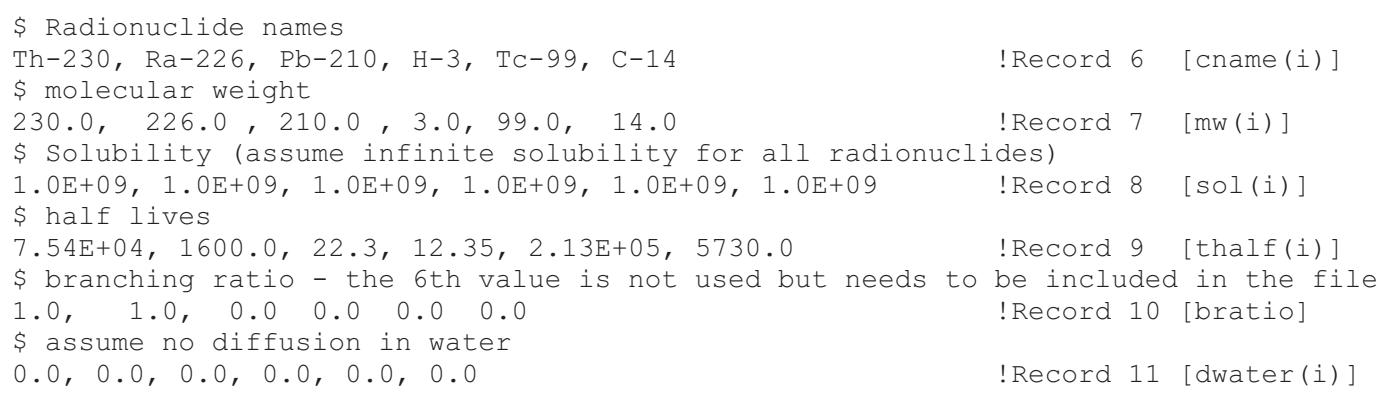

The variable, dwater is the free-water molecular diffusion coefficient in water. The code calculates the effective diffusion coefficient in pore water using the empirical expression given by Millington and Quirk (1961).

$D_{m}=D_{o} \frac{\theta^{10 / 3}}{\theta_{s}^{2}}$

Where $D_{o}$ is the contaminant diffusion coefficient in free-water, $D_{m}$ is the effective diffusion coefficient in pore water $\left(\mathrm{L}^{2} \mathrm{~T}^{-1}\right), \theta$ is the moisture content, and $\theta_{s}$ is the saturated porosity.

Mixing radionuclide activity with nonradionuclide mass in an input file is not allowed because of unit conversion problems. However, if radionuclide activities are expressed as isotope mass (in $\mathrm{mg}$ ), then radionuclides and nonradionuclides can be simulated in a single MCMT run.

\subsubsection{Records 15, 16, and 17 (h, j thick, rho, sk ths, thr, alpha, rn, rl, rm)}

The code variables $\mathbf{h}$ and $\mathbf{j}$ define the beginning and ending cells (inclusive) to include in a material definition. Each material is defined in terms of its physical (thickness and bulk density) and hydraulic (saturated hydraulic conductivity, porosity, etc.) properties as defined in the variables thick, rho, sk, ths, thr, alpha, rn, rl, and rm. The variables, $\mathrm{rl}$ and $\mathbf{r m}$ are optional and if missing, the default values of $\mathrm{rl}=$ 0.5 and $\mathrm{rm}=11 / \mathrm{rn}$ are used. These properties are read in records 16 and 17 and are repeated for each material type. For example, suppose that a $45 \mathrm{~m}$ thick unsaturated zone is composed of (from top to bottom) $10 \mathrm{~m}$ of sandy clay loam, $15 \mathrm{~m}$ of sandy clay, and $20 \mathrm{~m}$ of sand. The code variable, nmat should be set to 3 . Assuming a 45 cell problem, a cell thickness of $1 \mathrm{~m}$, a bulk density of $1.5 \mathrm{~g} \mathrm{~cm}^{-3}$ for all materials, and hydraulic properties listed in Table 1, records 15, 16, and 17 would be:

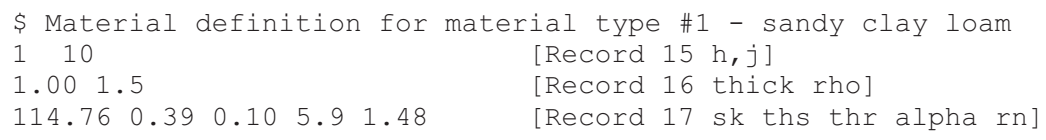




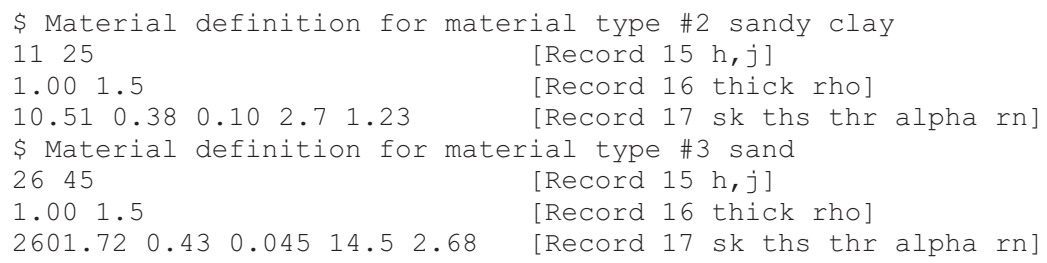

Note that records 15, 16, and 17 are repeated nmat number of times (nmat $=3$ ). Also note that $\mathbf{r m}$ and $\mathrm{rl}$ are missing in record 17 . If these values are missing, the the default values $(\mathrm{rl}=0.5, \mathrm{rm}=11 / \mathrm{rn})$ will be used in the computation. The user is cautioned that any two real values placed after $\mathrm{rn}$ in record 17 will be interpreted as $\mathrm{rl}$ and $\mathrm{rn}$ respectively, so make sure either both values are missing (to use the default values), or valid values for each parameter are present. An invalid real value (i.e., a character) will registar as a missing value.

\subsubsection{Records 18, and 19 (ntimes, t1, t2, and tp)}

The code variable, ntimes defines how many time-history output periods are requested. Each output period is defined by an array of beginning times (t1), ending times (t2), and print intervals (tp). In this way, different time resolutions can be applied to various time periods of the simulation. Record 19 is repeated ntimes. Suppose for example that one wants to capture the transient during the first 100 years of a simulation, and extend the simulation out to 1000 years. A possible choice for records 18 and 19 would be:

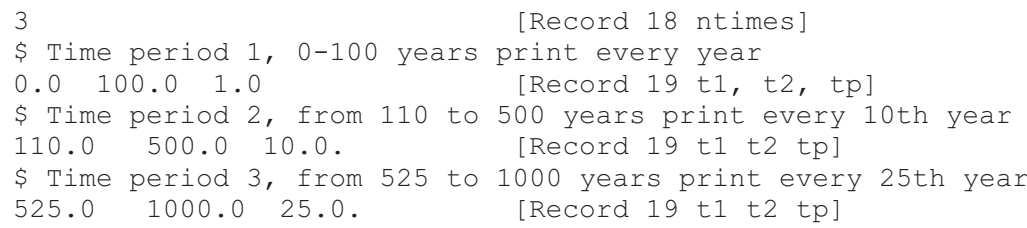

\subsubsection{Record 20 (Restart and Continue options)}

Record 20 is optional and is a keyword that is either RESTART or CONTINUE (case sensitive). The keywords should have no leading blanks on the line. If record 15 is RESTART, then a restart file is written to the working directory. The restart file is named RESTART.DAT and contains the contaminant inventories at the end of the simulation. These values can be pasted into a new MCMT file to initialize the contaminant inventories. If record 20 is CONTINUE, them MCMT will expect a new set of $\mathrm{K}_{\mathrm{d}}$ values (record 13), kx values (record 14), and output time values (records 18 and 19). The total number of cells and number of material types must remain the same. This allows for changes in the $\mathrm{K}_{\mathrm{d}}$ and $\mathrm{kx}$ values during the simulation. The time variables should start from the last output time of the first run.

\subsubsection{Contaminant Release Rate File}

The contaminant release rate entering the top of the model domain is provided to MCMT via an external ASCII file. The contaminant release rate file is specified in the parameter definition file (Record 3) and the name of the file is stored in the code variable, filerel. The file can be any name the user chooses. The file format is described in Table 7. 
Table 7. Format of the contaminant release rate file.

\begin{tabular}{lll}
\hline Line Number & \multicolumn{1}{c}{ Code Variable } & \multicolumn{1}{c}{ Description } \\
\hline 1 & junk & Column headers and comments (discarded) \\
2 to $n+1^{\text {a }}$ & $\operatorname{rel}(k, 1)$ & Time in years from the start of the simulation for the $k^{\text {th }}$ record \\
2 to $n+1^{\text {a }}$ & $\begin{array}{l}\operatorname{rel}(k, 2), \operatorname{rel}(\mathrm{k}, 3), \operatorname{rel}(k, 4) \\
\ldots \operatorname{rel}(k, \mathbf{n p r o g}+1)\end{array}$ & $\begin{array}{l}\text { Contaminant release rate }\left(\mathrm{Ci}, \mathrm{Bq}, \text { or } \mathrm{mg} \mathrm{y}^{-1}\right) \text { for each of the } \\
\text { nprog contaminants }\end{array}$ \\
\hline
\end{tabular}

a. $n$ is the number of time and contaminant release rate records. A minimum of two records are needed.

\subsection{Code Execution and MCMT Output Files and Utilities}

Execution of the MCMT code is performed on the command line by typing: [path]MCMT [parameter definition file]

where path is the full or relative path to the MCMT executable from the current operating directory, and parameter definition file is the name of the parameter definition file (Table 6). If the parameter definition file is left off, then MCMT will look for the default parameter definition file named MCMT.PAR in the current working directory. If the default parameter definition file is not found, or the user fails to provide a valid parameter definition file, the code will abort.

MCMT produces multiple output files: (1) a general output file (MCMT.OUT), (2) a list file (MCMT.LST), and (3) contaminant flux files for each contaminant simulated. The contaminant flux file names are automatically generated from a concatenation of the contaminant name with the ".rel" extension. The general output file and list file have hardwired file names and are written in the default directory each time MCMT is executed. The MCMT.OUT file contains the time histories of contaminant inventories, pore water concentrations, and fluxes for each cell in the simulation. The MCMT.LST file contains the model input data, calculated intermediate values, the number of converged and unconverged time steps, and the code execution time. The MCMT.LST file is always written in ASCII whereas the MCMT.OUT file is written in binary if the code variable abin=B. A utility program (MCMTPRT) was written to allow a user to access the binary (or ASCII) data stored in the MCMT.OUT file. The MCMTPRT utility is executed by typing on the command line:

\section{[path]MCMTPRT [parameter definition file]}

where path is the full or relative path to the MCMTPRT executable from the current operating directory, and parameter definition file is the name of the MCMTPRT parameter definition file. If the parameter definition file is left off, then MCMTPRT will look for the default parameter definition file (MCMTPRT.PAR) in the current working directory. If the default parameter definition file is not found, or the user fails to provide a valid parameter definition file, the code will abort. The format for the MCMTPRT parameter definition file is described in Table 8. 
Table 8. Format for the MCMTPRT parameter definition file.

\begin{tabular}{|c|c|c|c|}
\hline Record & Code Variable & Type/Format & Description \\
\hline 1 & title & CHAR/A80 & Title of run \\
\hline 2 & filedat & CHAR/A80 & MCMT general output file (MCMT.OUT) \\
\hline 3 & abin & CHAR/* & $\begin{array}{l}\text { Flag variable for ASCII or binary output: (A) for ASCII } \\
\text { output or, (B) for binary output. }\end{array}$ \\
\hline 3 & aqnt & CHAR/* & $\begin{array}{l}\text { Quantity to extract: } \mathrm{I}=\text { contaminant inventory, } \\
\mathrm{C}=\text { contaminant pore water concentration, } \\
\mathrm{F}=\text { contaminant flux }\end{array}$ \\
\hline 3 & pfix & $\mathrm{CHAR} * 4 / *$ & A four character prefix to identify output file names. \\
\hline 4 & nout & $\mathrm{INT} / *$ & Number of cells to output time histories $(\operatorname{maximum}=50)$ \\
\hline 4 & tout & $\mathrm{INT} / *$ & $\begin{array}{l}\text { Number of times to output spatial profiles } \\
(\text { maximum }=50)\end{array}$ \\
\hline 4 & $\mathrm{cf}$ & $\mathrm{REAL} / *$ & User-provided conversion factor (1.0) \\
\hline 5 & noutput $(i)$ & $\mathrm{INT} / *$ & $\begin{array}{l}\text { The cell numbers for each of the nout time histories. All } \\
\text { values are read from one line and each value is separated } \\
\text { by a space or comma. If nout is zero, this record should } \\
\text { be blank. }\end{array}$ \\
\hline 6 & toutput $(i)$ & $\mathrm{REAL} / *$ & $\begin{array}{l}\text { The time of each of the tout spatial profiles. All values } \\
\text { are read from one line and each value is separated by a } \\
\text { space or comma. If tout is zero, this record should be } \\
\text { blank. }\end{array}$ \\
\hline
\end{tabular}

\section{SOFTWARE MANAGEMENT}

Software management requirements for the INL are stated in Management Control Procedure 550 (MCP-550). The MCM codes are classified as Quality Level C software as defined in MCP-550. The required elements of software management for Level C software are listed in Table 9. Fulfillment of these requirements is stated in column two of Table 9.

Table 9. MCP-550 software quality assurance requirements and where they are addressed in the MCM documentation.

\begin{tabular}{ll}
\hline \multicolumn{1}{c}{ MCP-550 Requirement } & \multicolumn{1}{c}{$\begin{array}{c}\text { Section/Appendix/Form where } \\
\text { MCP-550 requirement is fulfilled }\end{array}$} \\
\hline Software Management Plan (SMP) & Form 562.26 ID No. \\
Software Quality Assurance Plan (SQAP) & Form 562.27 ID No. \\
Software Configuration Management Plan (SCMP) & Appendix A \\
Software Requirements Specification (SRS) & Section 1 - 5 \\
Requirements Traceability Matrix (RTM) & Form 562.31 ID No. \\
Design Description for Software & Appendix A \\
Software Test Plan and Results & Appendix B \\
User Documentation & Section 6 \\
\hline
\end{tabular}




\section{SAMPLE APPLICATION}

This section illustrates application of the MCM codes to a hypothetical problem regarding clean-up of a decommissioned infiltration pond that was used to dispose of low-level liquid radioactive waste. The problem is illustrated in Figure 7. A $100 \mathrm{~m} \times 100 \mathrm{~m}$ infiltration basin operated for a period of 40 years during which liquid radioactive waste was disposed. During its operations, it was estimated that $100 \mathrm{Ci} / \mathrm{yr}$ year of Sr-90 and $1 \mathrm{Ci} / \mathrm{yr}$ of Ra-226 were disposed in the basin. Much of the contamination currently resides in the surface alluvium and in a $21.45 \mathrm{~m}$ thick sedimentary interbed located $66 \mathrm{~m}$ below the surface. The aquifer lies $144 \mathrm{~m}$ below the surface. Because of the depths of contamination, complete site remediation is impractical. The site may be put under administrative control and not accessible to the public for the next 100 years. Groundwater will be monitored in wells downgradient from the facility during this time.

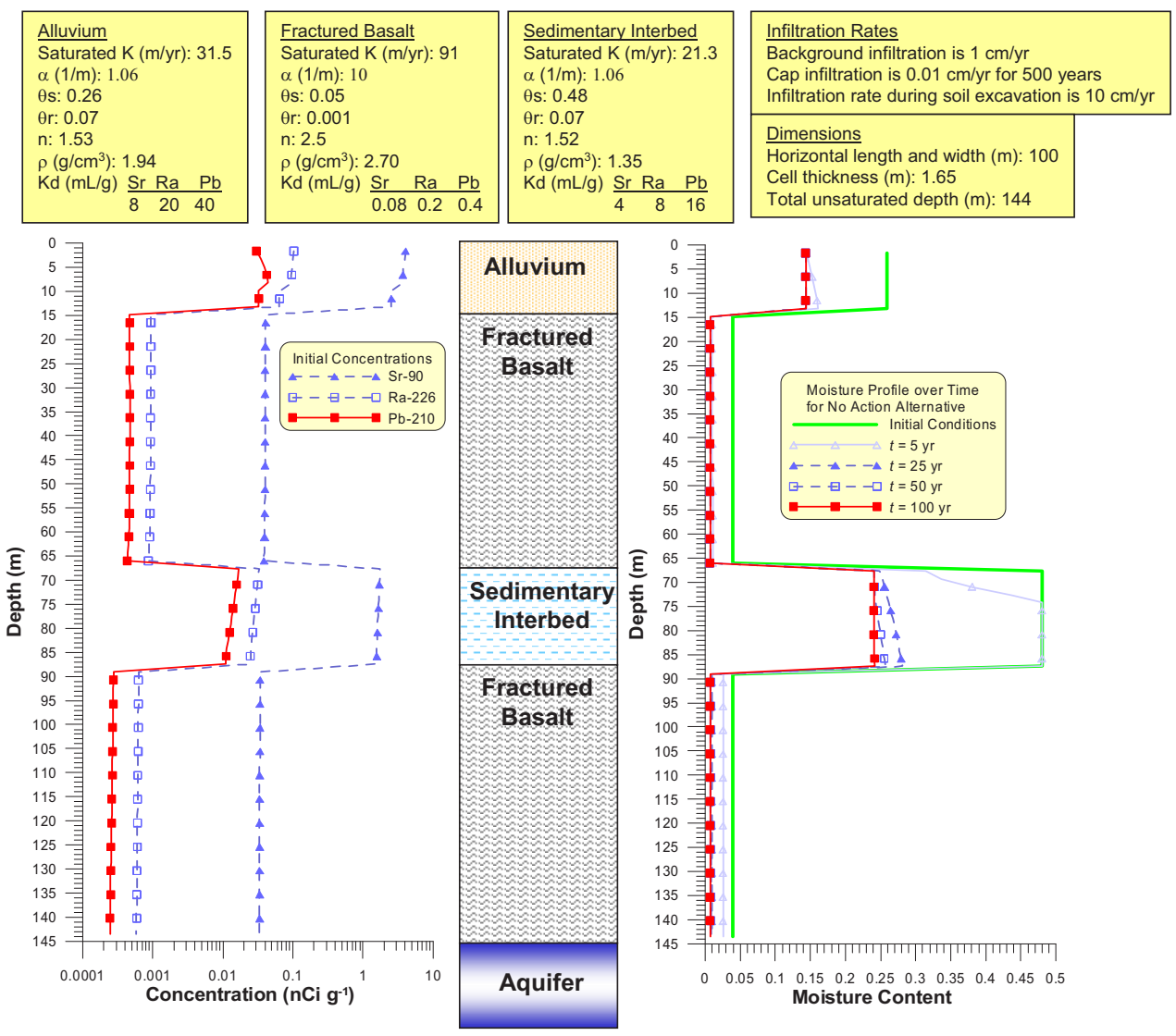

Figure 7. Problem description, model domain, and input parameters for the sample application of the MCM models. Initial concentrations of each radionuclide after the end facility operations is illustrated on the left graph. The initial moisture content and moisture content profile in subsequent years for the no action alternative is shown in the graph on the right.

Three remediation options are considered: (1) no action, (2) remove contaminated soils down to fractured basalt and refill with clean soil, and (3) leave contaminated soil in place and cover site with an engineered barrier (capping). Remedial Option 2 will result in enhanced infiltration over the infiltration basin during the time excavation takes place and until native vegetation reestablishes itself over the disturbed soil. The infiltration during remediation and before native vegetation reestablishes itself is estimated to be about an order of magnitude greater than that for undisturbed soil. Enhanced infiltration is estimated to persist for 10 years. 
The engineered barrier is designed for a 500-year lifetime and result in a two-orders of magnitude reduction in the infiltration rate relative to background infiltration through undisturbed soils. After 500 years, the infiltration is assumed to return to its background conditions.

Residual concentrations of Sr-90 and Ra-226 in surface soils present an unacceptable risk from surface exposure pathways (i.e., external exposure, soil resuspension/inhalation, and soil ingestion). Therefore some remediation of the surface soils will be necessary. Both source removal and capping will reduce the surface pathway risks to acceptable levels. The question is, which remediation strategy will also minimize groundwater impacts?

The MCMF and MCMT codes were first run to provide the moisture content and radionuclide concentration profiles at the end of operation of the infiltration basin. The radionuclide and moisture profiles at the end of operations were the initial conditions used in each remediation option simulation. Initial conditions could also have been provided by measured radionuclide concentrations and moisture contents in the subsurface. The model domain was discretized into 87 cells each having a thickness of $1.65 \mathrm{~m}$. It was not particularly important to capture the shape of the wetting front in the MCMF code. Therefore, cell size was chosen based on the level of lithologic detail for the unsaturated zone. Water flow rates into infiltration basin were $180,000 \mathrm{~m}^{3} \mathrm{yr}^{-1}$ and spread out over an area of $10,000 \mathrm{~m}^{2}$. It was assumed that all water entering the basin infiltrated into the subsurface. Radionuclide release rates into the

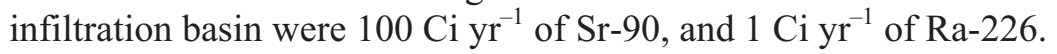

Radium-226 has numerous daughter products, but only $\mathrm{Pb}-210$ has a long enough half life (22.3 years) such that it can exist in the environment without the presence of $\mathrm{Ra}-226$. Therefore, $\mathrm{Pb}-210$ was modeled as the only daughter of Ra-226. Infiltration basin effluent did not include $\mathrm{Pb}-210$ and therefore, all $\mathrm{Pb}-210$ was derived from the decay of Ra-226. The MCMF and MCMT input files for the no action alternative are presented in Figure 8.

The results of the simulation are summarized in Figure 9. The radionuclide fluxes are relatively insensitive to the different remediation options during the 0 to 50 year time frame following cessation of infiltration basin operations. Therefore, some administrative control will probably be necessary for at least 50 years. Option 2 results in slightly higher radionuclide fluxes at 100 years because infiltration is enhanced while soil is being excavated. However, radionuclide fluxes for Option 2 drop off faster after about 500 years compared to the fluxes for the Option 1 (no action alternative). Option 3 yields the lowest radionuclide aquifer flux after the 100 year administrative control period until about the year 700 . The water and radionuclide flux for Option 3 drops over an order of magnitude between the years $\sim 100$ to $\sim 700$ as a result of the emplacement of the engineered barrier.

This sample application illustrates how MCM may be used for assessment of transient flow problems. Comparison of the graphs for the three remediation options with the one labeled "Steady-State" in Figure 9 illustrates the importance of transient flow on the outcome of the assessment. The graph labeled "Steady-State" in Figure 9 shows the radionuclide flux as a function of time assuming the initial moisture profile and transient flow effects are ignored. The MCM simulation for the Steady-State problem assumed the same vertical distribution of radionuclides in the unsaturated zone, a steady-state water infiltration flux of $1 \mathrm{~cm} \mathrm{yr}^{-1}$, and an initial moisture content in all cells that corresponds to a $1 \mathrm{~cm} \mathrm{yr}^{-1}$ steady-state water flux. The radionuclide flux for the steady-state simulation is substantially lower than the radionuclide flux for Options 1-3, which may lead to the conclusion that no action needs to be taken. Without considering drainage of the water present in the unsaturated zone after the end of operations, potentially incorrect conclusions could be drawn about the mobility of radionuclides present in the unsaturated zone. The MCM model represents a relatively simple model to address these processes. Based on the results presented in Figure 9, it appears that Option 3 would provide the best overall protection for groundwater for foreseeable future. However, other considerations, such as public perception and cost may weigh into the ultimate decision of what remediation option to select. 


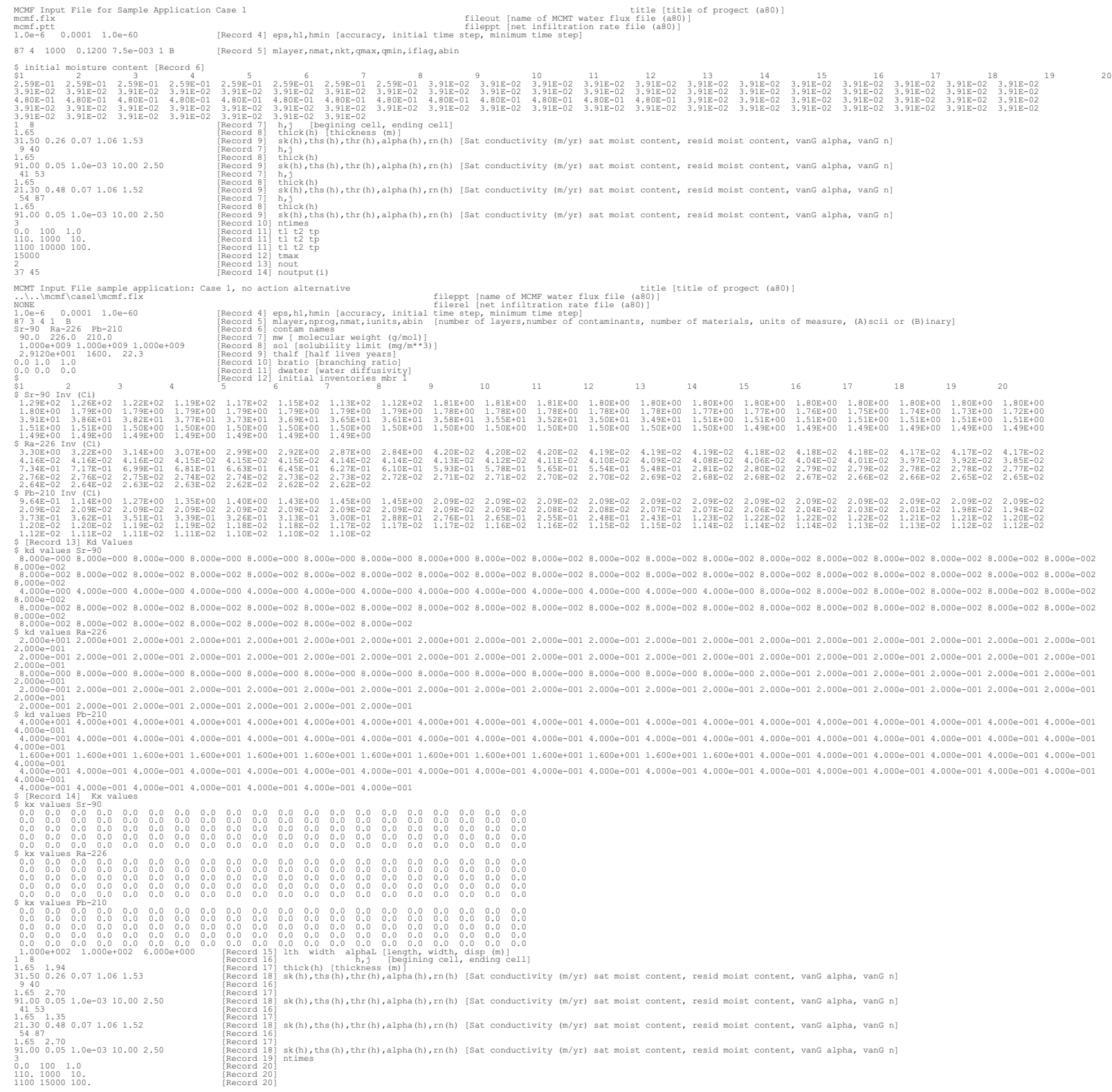

Figure 8. MCMF (top) and MCMT (bottom) input files for the no action alternative of the sample application. 

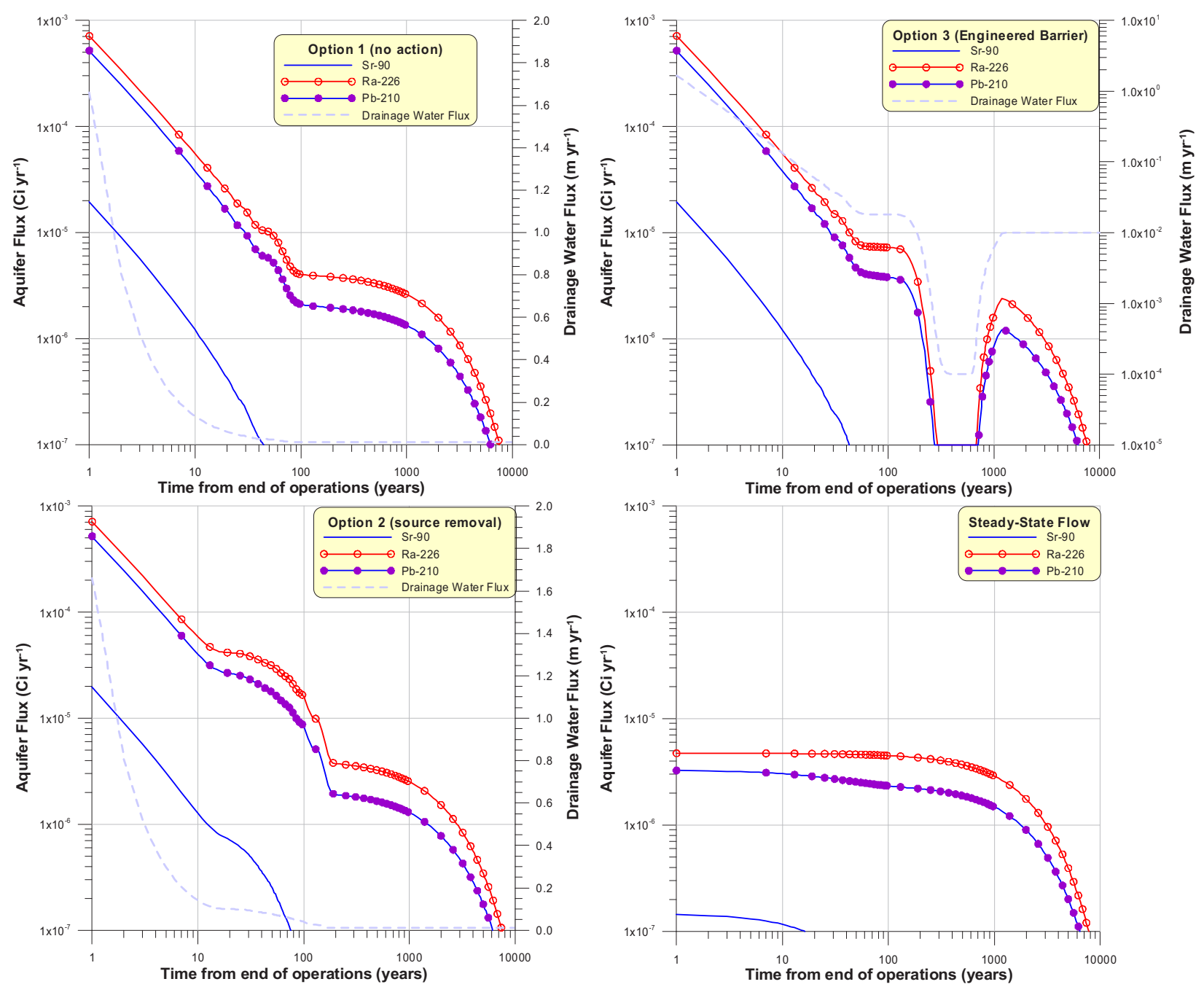

Figure 9. Radionuclide flux to the aquifer as a function of time for the three remediation options and the Steady-State case for the sample application of MCM. 


\section{REFERENCES}

ACRI, 1996, "PORFLOW: A Software Tool for Multiphase Fluid Flow, Heat and Mass Transport in Fractured Porous Media," Analytical \& Computational Research, Inc., Bel Air, CA, 1996.

Appelo, C. A. J. and A. Willemsen, 1987, "Geochemical Calculations and Observations on Salt Water Intrusions, I. A Combined Geochemical/Mixing Cell Model," Journal of Hydrology, 94, pp. 313-330.

Baes, C. F., III and R. D. Sharp, 1983, “A proposal for estimation of soil leaching and leaching constants for use in assessment models," Journal of Environmental Quality, 12(1), pp. 17-28.

Brooks, R. H., and A. T. Corey, 1964, "Hydraulic Properties of Porous Media," Hydrologic Paper 3, Colorado State University, Fort Collins, CO.

Campbell, G. S., 1974, A "Simple Method for Determining Unsaturated Conductivity from Moisture Retention Data," Soil Science 117, 311-314.

Carsel, R. F. and R. S. Parrish, 1988, Developing joint probability distributions of soil water retention characteristics Water Resources Research, 25(5), 755-769.

Codell, R. B., K. T. Key, and G. Whelan, 1983, "Transport of Radionuclides in Groundwater," in Radiological Assessment, NUREG/CR-3332, J. E. Till and H. R. Meyer, eds., U.S. Nuclear Regulatory Commission, Washington, DC, 1983.

EPA, 1992, MMSOILS: Multimedia Contaminant Fate, Transport, and Exposure Model. Documentation and User's Manual,. U.S. Office of Research and Development, Washington, DC, 1992.

Fayer, M. J., 2000, UNSAT-H Version 3.0: Unsaturated Soil Waste and Heat Flow Model, Theory, User's Manual, and Examples. PNNL 13249, Pacific Northwest National Laboratories, Richland, Washington, 2000.

Gardner, W. R., 1960, "Soil Water Relations in Arid and Semi-arid Conditions," UNESCO 15, 37-61.

Hillel, D., 1998, Environmental Soil Physics. Academic Press, San Diego, CA.

Levenspiel, O. and K. B. Bischoff, 1963, "Patterns of Flow in Chemical Process Vessels" In T. B. Drew, J. W. Hoopes, Jr., and T. Vermeulen Eds., Advances in Chemical Engineering, Vol. 4, Academic Press, New York, 95-198.

MCP-550, 2004, “Software Management,” Rev. 8, November 9, 2004.

Millington, R. J., and J. M. Quirk, 1961, "Permeability of Porous Solids" Trans Faraday Soc. 57:12001207.

Philip, J. R., 1957, “Theory of Infiltration 2. The Profile of Infinity.” Soil Science, 83(6), 435-448.

PNNL, 1996, Subsurface Transport Over Multiple Phase Description "STOMP” Theory Guide, PNNL-11217, Pacific Northwest National Laboratories, Richland, WA, 1996. 
Press, W. H., B. P. Flannery, S. A. Teukolsky, and W. T. Vetterling, 1992, Numerical Recipes: The Art of Scientific Computing. Cambridge: Cambridge University Press.

Rao, B. K. and D. L. Hathaway, 1989, “A Three Dimensional Mixing Cell Solute Transport Model and its Application,” Ground Water, 27(4), 509-516.

Rood, A. S., 1999, GWSCREEN: A Semi-Analytical Model for Assessment of the Groundwater Pathway from Surface or Buried Contamination, Theory and User's Manual, Version 2.5. INEEL/EXT-98-00750, Idaho National Engineering and Environmental Laboratory, 1999.

Rood, A. S., 2004, “A Mixing-Cell Model for Assessment of Contaminant Transport in the Unsaturated Zone Under Steady-State and Transient Flow Conditions," Environmental Engineering Science, 21(6).

Schroeder, P. R., T. S. Dozier, P. A. Zappi, B. M. McEnroe, J. W. Sjostrom, and R. L. Peyton, 1994, The Hydrologic Evaluation of Landfill Performance (HELP) Model. EPA/600/R-94/168b. U.S. Environmental Protection Agency, Office of Research and Development, Cincinnati, Ohio, 1994.

Scott, S. J. and D. M. Hetrick, 1994, The New SESOIL User's Guide. PUBL-SW-200-94. Science \& Technology Management Inc., Brookfield, WI 53005. Distributed by the Radiation Safety Information Computational Center, Oak Ridge National Laboratory, Oak Ridge, Tennessee, 1994.

Shanahan, P. and D. R. F. Harleman, 1984, “Transport in Lake Water Quality Modeling," Journal of Environmental Engineering, 110(1), pp. 42-57.

Simunek, J., M. Sejna, M. and M. Th. van Genuchten, 1999, HYDRUS-2D/MESHGEN-2D Simulating Water Flow and Solute Transport in Two-Dimensional Variably Saturated Media, IGWMC-TPS 53C, Version 2.0, International Ground Water Modeling Center, Colorado School of Mines, Golden, Colorado, 1999.

Smith, R. E., K. R. J. Smetten, and D. A. Woolhiser, 2002, Infiltration Theory for Hydrologic Applications, American Geophysical Union, Washington DC.

Sullivan, T. M. 1996, DUST Disposal Unit Source Term, Data Input Guide. NUREG/CR-6041, BNL-NUREG-52375, Brookhaven National Laboratory, Upton, New York, 1996.

van Genuchten, M. Th., 1980, “A Closed-form Equation for Predicting the Hydraulic Conductivity of Unsaturated Soils,” Soil Sci. Soc. Am J., 44, 892-898.

Van Ommen, H. C., 1985, “The Mixing Cell Concept Applied to Transport of Non-Reactive and Reactive Components in Soils and Groundwater," Journal of Hydrology, 78, pp. 201-213.

Whelan, G., J. P. McDonald, and C. Sato, 1996, Multimedia Environmental Pollutant Assessment System (MEPAS) Groundwater Pathway Formulations, PNNL-10907, Pacific Northwest National Laboratory, Richland, Washington, 1996.

Whicker, F. W. and V. Schultz, 1982, Radioecology: Nuclear Energy and the Environment, CRC Press, Boca Raton, Florida. 
Yu, C., A. J. Zielen, J. J. Cheng, Y. C. Yuan, L. G. Jones, D. L. Lepoire, Y. Y. Wang, C. O. Loureiro, E. Gnanapragasam, E. Failance, A. Wallo III, W. A. Williams, and H. Peterson, 2000, Manual for Implementing Residual Radioactive Material Guidelines Using RESRAD Version 6.0, ANL/EAD/LD-2 Argonne National Laboratory, Argonne, Illinois, 2000.

Zvirin, T., and R. Shinnar, 1976, "Interpretation of Internal Tracer Experiments and Local Sojourn Time Distributions,” International Journal of Multiphase Flow, 2, pp. 495-520. 
Appendix A

Software Design Description and Configuration Management Plan 


$$
\text { A-2 }
$$




\section{Appendix A}

\section{Software Design Description and Configuration Management Plan}

\section{A-1. SOFTWARE DESIGN DESCRIPTION}

The software design description depicts how the software is structured to satisfy the requirements of the software, and the components and subcomponents of the software. The MCM software is written in FORTRAN 77 with some use of language extensions as provided by the Lahey LF95 Compiler. Less than 15 modules comprise both MCMT and MCMF. Each module is described in Table A-1. The calling sequence and functional relationships are described in Table A-2.

Table A-1. Description of each subroutine and function in MCMF and MCMT.

\begin{tabular}{|c|c|c|c|}
\hline \multirow[b]{2}{*}{ Module } & \multicolumn{2}{|c|}{ Included in? } & \multirow[b]{2}{*}{ Description } \\
\hline & MCMT & MCMF & \\
\hline main & $\mathrm{x}$ & $\mathrm{x}$ & $\begin{array}{l}\text { Main program unit that: (1) reads the command line arguments, opens and } \\
\text { reads the input files, calls the ODE solver, and writes output to files and screen }\end{array}$ \\
\hline derivs & $\mathrm{x}$ & $\mathrm{x}$ & Subroutine that contains the ODEs to be solved \\
\hline quantity & $\mathrm{x}$ & & $\begin{array}{l}\text { Subroutine for calculating retardation, pore water concentrations, and } \\
\text { dispersive fluxes for each cell }\end{array}$ \\
\hline odeint & $\mathrm{x}$ & $\mathrm{x}$ & Subroutine for control of Runge-Kutta ODE solver \\
\hline lint & $\mathrm{x}$ & $\mathrm{x}$ & Subroutine for linear interpolation \\
\hline vang & $\mathrm{x}$ & $\mathrm{x}$ & Subroutine for calculating the moisture characteristic curve \\
\hline readline & $\mathrm{x}$ & $\mathrm{x}$ & Subroutine for reading a line of input from the parameter definition file \\
\hline numvaline & $\mathrm{x}$ & $\mathrm{x}$ & Subroutine for determining the number of expected values on a line \\
\hline checkfile & $\mathrm{x}$ & $\mathrm{x}$ & Subroutine to check for valid file names \\
\hline filcase & $\mathrm{x}$ & $\mathrm{x}$ & Subroutine to convert the case of file names to lower or upper case \\
\hline convert & $\mathrm{x}$ & & Subroutine to calculate conversion factors from mass to activity \\
\hline rkqs & $\mathrm{x}$ & $\mathrm{x}$ & Subroutine for QA checks for Runge-Kutta ODE solver \\
\hline rkck & $\mathrm{x}$ & $\mathrm{x}$ & Subroutine of main Runge-Kutta ODE solver \\
\hline timsscale & $\mathrm{x}$ & & Subroutine for calculating advective and dispersive time scales \\
\hline readmat & & $\mathrm{x}$ & Subroutine for reading material properties \\
\hline readkdkx & $\mathrm{x}$ & & Subroutine for reading $\mathrm{Kd}$ and $\mathrm{kx}$ values \\
\hline wheader & & $\mathrm{x}$ & Subroutine for writing output header to list file \\
\hline wquantity & $\mathrm{x}$ & & Subroutine for writing calculated values to list file \\
\hline wkdkx & $\mathrm{x}$ & & Subroutine for writing $\mathrm{Kd}$ and $\mathrm{kx}$ values to list file \\
\hline writevang & & $\mathrm{x}$ & Subroutine for writing van Genuchten parameters to the output file \\
\hline
\end{tabular}

Table A-2. Functional relationship and subroutine calling sequence for MCMT and MCMF.

\begin{tabular}{|c|c|c|c|c|c|c|}
\hline Level 0 & Level 1 & Level 2 & Level 3 & Level 4 & Level 5 & Level 6 \\
\hline \multicolumn{7}{|c|}{ Program MCMT } \\
\hline
\end{tabular}


Table A-2. (continued).

\begin{tabular}{|c|c|c|c|c|c|c|}
\hline Level 0 & Level 1 & Level 2 & Level 3 & Level 4 & Level 5 & Level 6 \\
\hline$\bullet$ & checkfile & & & & & \\
\hline • & readline & & & & & \\
\hline • & numvaline & & & & & \\
\hline$\bullet$ & convert & & & & & \\
\hline • & odeint & & & & & \\
\hline - & - & derivs & & & & \\
\hline$\bullet$ & - & - & lint & & & \\
\hline$\bullet$ & • & - & quantity & & & \\
\hline$\bullet$ & $\bullet$ & $\bullet$ & $\bullet$ & lint & & \\
\hline$\bullet$ & $\bullet$ & rkqs & & & & \\
\hline$\bullet$ & $\bullet$ & $\bullet$ & derivs & & & \\
\hline$\bullet$ & $\bullet$ & - & $\bullet$ & lint & & \\
\hline • & • & • & • & quantity & & \\
\hline - & - & • & - & • & lint & \\
\hline$\bullet$ & $\bullet$ & • & rkck & & & \\
\hline$\bullet$ & $\bullet$ & $\bullet$ & - & derivs & & \\
\hline$\bullet$ & $\bullet$ & - & $\bullet$ & - & lint & \\
\hline • & $\bullet$ & $\bullet$ & • & $\bullet$ & quantity & \\
\hline$\bullet$ & $\bullet$ & $\bullet$ & $\bullet$ & $\bullet$ & - & lint \\
\hline$\bullet$ & timsscale & & & & & \\
\hline$\bullet$ & lint & & & & & \\
\hline$\bullet$ & vang & & & & & \\
\hline - & quantity & & & & & \\
\hline$\bullet$ & readkdkx & & & & & \\
\hline - & wquantity & & & & & \\
\hline$\bullet$ & wkdkx & & & & & \\
\hline$\bullet$ & $\bullet$ & lint & & & & \\
\hline \multicolumn{7}{|c|}{ Program MCMF } \\
\hline$\bullet$ & filcase & & & & & \\
\hline - & checkfile & & & & & \\
\hline • & readline & & & & & \\
\hline$\bullet$ & numvaline & & & & & \\
\hline - & odeint & & & & & \\
\hline - & • & derivs & & & & \\
\hline$\bullet$ & $\bullet$ & $\bullet$ & lint & & & \\
\hline$\bullet$ & $\bullet$ & rkqs & & & & \\
\hline$\bullet$ & • & • & derivs & & & \\
\hline$\bullet$ & • & • & • & lint & & \\
\hline$\bullet$ & $\bullet$ & • & rkck & & & \\
\hline - & • & • & • & derivs & & \\
\hline
\end{tabular}


Table A-2. (continued).

\begin{tabular}{ccccccc}
\hline Level 0 & Level 1 & Level 2 & Level 3 & Level 4 & Level 5 & Level 6 \\
\hline$\bullet$ & $\bullet$ & $\bullet$ & $\bullet$ & $\bullet$ & lint & \\
$\bullet$ & lint & & & & & \\
$\bullet$ & readmat & & & & \\
$\bullet$ & wheader & & & & \\
$\bullet$ & writevang & & & & \\
- & vang & & & & \\
\hline
\end{tabular}

\section{A-2. SOFTWARE CONFIGURATION MANAGEMENT PLAN}

Software configuration management provides the mechanism to identify, document, and control changes to the software. Software configuration management for MCM is addressed within the module headers and the version date. Each module in the MCM codes contain a header that documents: (1) The name and purpose of the module, (2) the code author, (3) the date it was written, (4) a change history to the module, (5) arguments and returned values, and (5) calls to and from the module. The module header forms the basis for most of the code documentation. An example module header is provided in Figure A-1. 


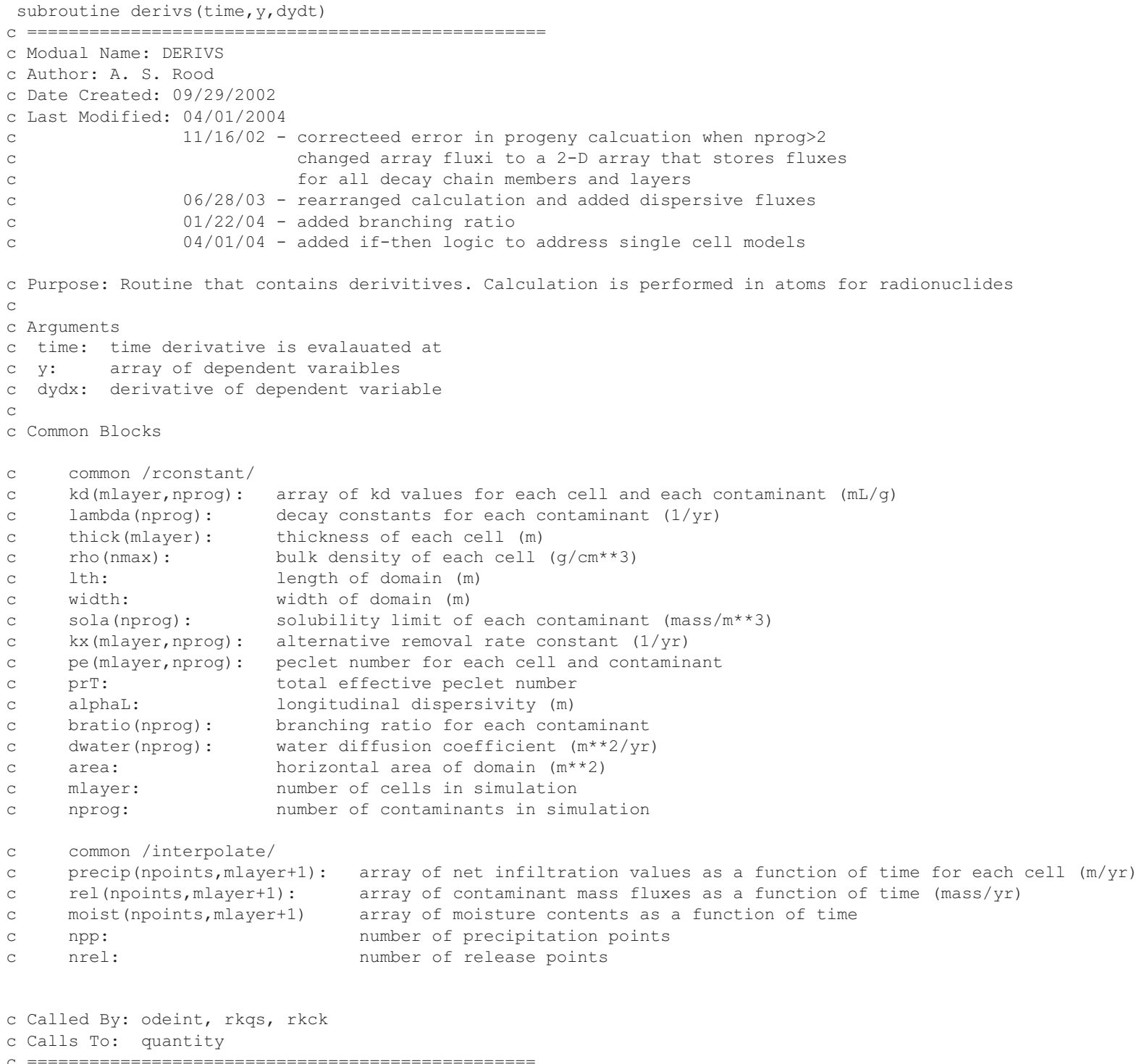

Figure A-1. Module header for subroutine derives in MCMT.

Version control is primarily handled in MCM through the version date instead of a version number. The version date can be thought of as essentially a version number and is stored in the variable vdate in the main program unit. The version date is a six digit number where the first two numbers represent the month, the second two the day, and the last two the year. The version date is in the header of the .LST file generated by MCMT and MCMF and in all ancillary output files generated by both codes. The version date is identified as the "Level" in the ancillary output files. In this way, results from old version of the code can be identified.

Old versions of the code are identified by a concatenation of either "mf" for MCMF or " $m$ t" for MCMT and the version date. For example, mf010404.for would represent the MCMF code with a version date of January 4, 2004. Old versions of the code archived on the code custodian's computer in the $\mathrm{c}: \backslash \mathrm{mcm} \backslash \mathrm{mcmflf77}$ directory for MCMF and c: $\backslash \mathrm{mcm} \backslash \mathrm{mcmt} \backslash \mathrm{f} 77$ directory for MCMT. Only the most recent version is sent when distributing the code to other users. 
The code custodian has the responsibility of maintaining and updating the code, identifying and archiving code versions, verifying new versions of the code operate correctly, and distributing the software to end users. 
Appendix B

Code Verification and Benchmark Problems 
B-2 


\section{Appendix B}

\section{Code Verification and Benchmark Problems}

Code verification is defined here as confirmation that the model was written and implemented in the computer code correctly. To do this, quantities output from the MCM codes (such as pore water concentrations, contaminant fluxes, water fluxes, and moisture contents) were compared with like quantities calculated using other codes or analytical solutions to the governing equations. MCMF and MCMT input files for each of the verification exercises are attached to the end of this appendix.

\section{B-1. MCMT VERIFICATION PROBLEMS}

Four verification problems and one benchmark problem were constructed to verify the MCMT code. Verification problems compare code output to analytical solutions to the governing equations. Benchmark problems compare code output to that of other codes that solve essentially the same type of problem. Differences between MCMT output and verification/benchmark output were expressed as the percent difference $(\% d)$ as given by Equation B-1:

$\% d=\frac{V_{v}-V_{m}}{V_{v}} \times 100$

where $V_{v}=$ the value calculated by verification/benchmark code output, and $V_{m}=$ the value calculated by MCMT. Analytical solutions to the governing equations are developed first followed by the results of the verification exercises. An additional verification problem is also presented in Section 3.1 in the main body of the report.

\section{B-1.1 Analytical Solutions for Governing Equations}

For the case where dispersion is ignored (i.e., no cell interchange) the transport equation takes the form a unidirectional catenary system of equations. A general solution has been developed by Skrable et al. (1974) for the limiting case of an initial amount in each cell and where all leach rate constants are different. For other cases, analytical solutions to the first and second cell in a system are developed. For the case of no cell interchange, the governing equation is:

$\frac{d Q_{i, j}}{d t}=\kappa_{i-1, j} Q_{i-1, j}-\kappa_{i, j} Q_{i, j}-\lambda_{j} Q_{i, j}+S_{i, j}+B R_{j} \lambda_{j-1} Q_{i, j-1}$

where

$Q_{i, j}=$ the mass of contaminant $j$ in cell $i(\mathrm{M})$

$i=$ the cell index

$j \quad=\quad$ the index for the decay chain member

$B R_{j}=$ the fraction of decay product $j-1$ that decays to product $j$

$\kappa_{i, j} \quad=$ the leach rate constant describing transfer from cell $i$ to cell $i+1$ for decay product $j\left(\mathrm{~T}^{-1}\right)$ 


$$
\begin{aligned}
& S_{i, j}=\text { is the source term }\left(\mathrm{M} \mathrm{T}^{-1}\right) \\
& \lambda=\text { decay rate constant }\left(\mathrm{T}^{-1}\right) .
\end{aligned}
$$

For the originating contaminant containing a series of degradation products, the term, $B R_{j} . \lambda_{\mathrm{j}-1} Q_{i, j-1}$ is omitted. Equation B-2 has three solutions for the first and second cell depending on the initial conditions and whether there is an external source involved. For the case where $Q_{1,1}=Q o_{1,1}$ at $t=0$, $S(t)=0$ for all time, and $C_{11} \leq \mathrm{C}_{S l}$, the solution is:

$Q_{1,1}(t)=Q o_{1,1} \exp \left(-\left(\kappa_{1,1}+\lambda_{1}\right) t\right)$

For the case where $Q_{1,1}=0$ at $t=0$, and $S(t)$ is a constant, $R$, for all time, the solution is:

$$
Q_{1,1}(t)=\frac{R}{\kappa_{1,1}+\lambda}\left(1-\exp \left[-\left(\kappa_{1,1}+\lambda_{1}\right) t\right]\right)
$$

The solution to the second cell for the conditions in Equation B-4 and $Q_{2,1}=0$ at $\mathrm{t}=0$ can be found using Laplace transforms. The governing differential equation is given by:

$$
\frac{d Q_{2,1}}{d t}=\frac{\kappa_{1,1} R}{\gamma}[1-\exp (-\gamma t)]-\delta Q_{2,1}
$$

where

$$
\begin{aligned}
& \gamma=\kappa_{1,1}+\lambda_{1} \\
& \delta=\kappa_{2,1}+\lambda_{1 .}
\end{aligned}
$$

The solution is

$$
Q_{2,1}(t)=\kappa_{1,1} R\left(\frac{1}{\gamma \delta}+\frac{\gamma \mathrm{e}^{-\delta t}-\delta \mathrm{e}^{-\gamma t}}{\gamma \delta(\delta-\gamma)}\right) .
$$

For a decay chain of more than one member, a generalized solution to the multi-cell catenary system has been developed by Skrable et al. 1974 and implemented in a computer algorithm by Birchall (1986) for the limiting conditions, $S(t)=0$ for all times, $\kappa_{i} \neq \kappa_{i+1}$ for all $i$, and $Q_{i, j}=Q o_{i, j}$ at $t=0$.

$$
Q_{n}(t)=\sum_{i=1}^{n}\left[\left(\prod_{j=1}^{n-1} K_{j}\right) \sum_{j=i}^{n} \frac{Q o_{i} e^{-K T_{j} t}}{\prod_{\substack{p \neq j \\ p=i}}^{n}\left(K T_{p}-K T_{j}\right)}\right]
$$

where

$$
Q_{n}(t)=\quad \text { mass in the } n t h \text { cell in the system }(\mathrm{M})
$$


$Q_{o}=\quad$ the initial amount in the $n t h$ cell in the system (M)

$K_{j} \quad=\quad$ the rate constant from cell $j$ to cell $j+1\left(\mathrm{~T}^{-1}\right)$

$K T_{j}=$ the total transfer rate constant out of cell $j\left(\mathrm{~T}^{-1}\right)$.

When the pore water concentration exceeds the solubility limit of the contaminant, then a solubility-limited release is calculated. The solubility-limited release in the first cell where $S(t)=0$ for all times is described by the differential equation:

$\frac{d Q_{1,1}}{d t}=-\lambda_{1} Q_{1,1}-R_{s}$

where

$$
\begin{array}{ll}
R_{s} & =S_{\mathrm{L}} \times q \times A \\
S_{L} & =\text { solubility limit }\left(\mathrm{M} \mathrm{L}^{-3}\right) \\
q & =\text { water flux }\left(\mathrm{L} \mathrm{T}^{-1}\right) \\
A & =\text { area of source }\left(\mathrm{L}^{2}\right) .
\end{array}
$$

The solution to Equation B-8 for the initial conditions, $Q_{1,1}=Q o_{1,1}$ at $t=0$, is:

$Q_{1,1}(t)=Q o_{1,1} \exp \left(-\lambda_{1} t\right)-\frac{R_{s}}{\lambda_{1}}\left[1-\exp \left(-\lambda_{1} t\right)\right]$

When the pore water concentration is less than the solubility limit, then $Q(t)$ is described by:

$Q_{1,1}(t)=Q_{1,1}\left(t_{s l}\right) \exp \left[-\left(\kappa_{1,1}+\lambda_{1}\right)\left(t-t_{s l}\right)\right]$

where $t \geq t_{s l}$, and $t_{s l}$ is the time when the pore water concentration drops below the solubility limit.

\section{B-1.2 Verification Problem 1}

Verification Problem 1 considers a two-cell model with an initial radioactivity inventory of zero in all cells and a constant release rate of $1 \mathrm{Ci} \mathrm{y}^{-1}$ into the first cell. A hypothetical radionuclide having a half-life of 100 years and a molecular weight of $138 \mathrm{~g} \mathrm{~mol}^{-1}$ is simulated. Water flux is assumed to be at steady state and different for each cell. Input data are presented in Table B-1. Radionuclide inventories were converted to pore water concentrations using Equation B-10. Radioactive inventories were calculated using Equation B-4 for the first cell and Equation B-6 for the second cell. 
Table B-1. Parameter Values used in Verification Test Problems 1, 2, and 4.

\begin{tabular}{|c|c|c|}
\hline Parameter & Cell 1 & Cell 2 \\
\hline Thickness (m) & $1.00 \mathrm{E}+00$ & $1.00 \mathrm{E}+00$ \\
\hline Length (m) & $1.00 \mathrm{E}+01$ & $1.00 \mathrm{E}+01$ \\
\hline Width (m) & $1.00 \mathrm{E}+01$ & $1.00 \mathrm{E}+01$ \\
\hline Bulk Density $\left(\mathrm{g} \mathrm{cm}^{-3}\right)$ & $1.50 \mathrm{E}+00$ & $1.50 \mathrm{E}+00$ \\
\hline Saturated hydraulic conductivity $\left(\mathrm{m} \mathrm{y}^{-1}\right)$ & $1.71 \mathrm{E}+03$ & $1.71 \mathrm{E}+03$ \\
\hline Total porosity $\left(\mathrm{m}^{3} \mathrm{~m}^{-3}\right)$ & $2.72 \mathrm{E}-01$ & $2.72 \mathrm{E}-01$ \\
\hline Residual moisture content $\left(\mathrm{m}^{3} \mathrm{~m}^{-3}\right)$ & $3.21 \mathrm{E}-02$ & $3.21 \mathrm{E}-02$ \\
\hline van Genuchten alpha $\left(\mathrm{m}^{-1}\right)$ & $7.51 \mathrm{E}+00$ & $7.51 \mathrm{E}+00$ \\
\hline van Genuchten $n$ & $2.30 \mathrm{E}+00$ & $2.30 \mathrm{E}+00$ \\
\hline Water flux $\left(\mathrm{m} \mathrm{y}^{-1}\right)$ & $1.00 \mathrm{E}-01$ & $5.00 \mathrm{E}-02$ \\
\hline Half-life (y) & $1.00 \mathrm{E}+02$ & $1.00 \mathrm{E}+02$ \\
\hline Molecular weight $\left(\mathrm{g} \mathrm{mol}^{-1}\right)$ & $1.38 \mathrm{E}+02$ & $1.38 \mathrm{E}+02$ \\
\hline Solubility limit $\left(\mathrm{mg} \mathrm{L}^{-1}\right)$ & $1.00 \mathrm{E}+00$ & $1.00 \mathrm{E}+00$ \\
\hline Partition coefficient $\left(\mathrm{mL} \mathrm{g}^{-1}\right)$ & $1.00 \mathrm{E}-01$ & $5.00 \mathrm{E}-01$ \\
\hline Initial moisture content $\mathrm{t}^{\mathrm{a}}$ & $6.06 \mathrm{E}-02$ & $5.61 \mathrm{E}-02$ \\
\hline Leach rate constants ${ }^{\mathrm{a}}\left(\mathrm{y}^{-1}\right)$ & $4.75 \mathrm{E}-01$ & $6.20 \mathrm{E}-02$ \\
\hline Solubility limit ${ }^{\mathrm{a}}\left(\mathrm{Ci} \mathrm{m}^{-3}\right)$ & $2.59 \mathrm{E}+01$ & $2.59 \mathrm{E}+01$ \\
\hline
\end{tabular}

Results of Verification Problem 1 (Table B-2) for the first two cells indicate good agreement between MCMT and the analytical solution. The differences are $\leq 0.004 \%$.

\section{B-1.3 Verification Problem 2}

Verification Problem 2 considers the same model as Verification Problem 1 but $R(t)=0$ and $Q_{1,1}(0)=1.0 \mathrm{Ci}$. Radionuclide inventories and pore water concentrations for cell 1 were calculated using Equations B-2 and 10, respectively. The results (Table B-3) indicate very little difference between the analytical solution and MCMT. Differences between the analytical solution and MCMT increase as the inventory decreases. However, differences are still less than 0.05 percent, and the inventory at those times (42 and 54 years) is nine orders of magnitude smaller than the initial inventory.

\section{B-1.4 Verification Problem 3}

Verification Problem 3 uses the general solution developed Skrable et al. (1974) and implemented by Birchall (1986) to solve a four cell model with a two member decay chain consisting of Pu-241 $(T 1 / 2=14.4$ years) and Am-241 $(T 1 / 2=432$ years). Parameters values (Table B-4) include the initial inventories of $\mathrm{Pu}-241$ and $\mathrm{Am}-241$ in each of the cells, cell-specific partition coefficients, and a constant water flux. 
Table B-2. Results of Verification Problem 1.

\begin{tabular}{|c|c|c|c|c|c|c|c|c|c|}
\hline \multirow[b]{2}{*}{$\begin{array}{l}\text { Time } \\
(y)\end{array}$} & \multicolumn{6}{|c|}{ Cell 1} & \multicolumn{3}{|c|}{ Cell 2} \\
\hline & $\begin{array}{c}\text { MCMT } \\
\text { Inventory } \\
\text { (Ci) }\end{array}$ & $\begin{array}{l}\text { Analytical } \\
\text { Solution } \\
\text { (Ci) }\end{array}$ & $\begin{array}{c}\% \\
\text { Difference }\end{array}$ & $\begin{array}{l}\text { MCMT Conc. } \\
\left(\mathrm{Ci} \mathrm{m}^{-3}\right)\end{array}$ & $\begin{array}{l}\text { Analytical } \\
\text { Solution } \\
\left(\mathrm{Ci} \mathrm{m}^{-3}\right)\end{array}$ & $\begin{array}{c}\% \\
\text { Difference }\end{array}$ & $\begin{array}{l}\text { MCMT } \\
\text { Inventory } \\
(\mathrm{Ci})\end{array}$ & $\begin{array}{l}\text { Analytical } \\
\text { Solution } \\
(\mathrm{Ci})\end{array}$ & $\begin{array}{c}\% \\
\text { Difference }\end{array}$ \\
\hline 2 & $1.28 \mathrm{E}+00$ & $1.28 \mathrm{E}+00$ & $0.003 \%$ & $6.10 \mathrm{E}-02$ & $6.10 \mathrm{E}-02$ & $0.002 \%$ & $6.723 \mathrm{E}-01$ & $6.723 \mathrm{E}-01$ & $0.001 \%$ \\
\hline 6 & $1.96 \mathrm{E}+00$ & $1.96 \mathrm{E}+00$ & $0.002 \%$ & $9.31 \mathrm{E}-02$ & $9.31 \mathrm{E}-02$ & $0.001 \%$ & $3.397 \mathrm{E}+00$ & $3.397 \mathrm{E}+00$ & $0.001 \%$ \\
\hline 10 & $2.06 \mathrm{E}+00$ & $2.06 \mathrm{E}+00$ & $0.002 \%$ & $9.78 \mathrm{E}-02$ & $9.78 \mathrm{E}-02$ & $0.002 \%$ & $5.942 \mathrm{E}+00$ & $5.942 \mathrm{E}+00$ & $0.000 \%$ \\
\hline 14 & $2.07 \mathrm{E}+00$ & $2.07 \mathrm{E}+00$ & $0.000 \%$ & $9.84 \mathrm{E}-02$ & $9.84 \mathrm{E}-02$ & $0.002 \%$ & $7.943 \mathrm{E}+00$ & $7.943 \mathrm{E}+00$ & $0.001 \%$ \\
\hline 20 & $2.08 \mathrm{E}+00$ & $2.08 \mathrm{E}+00$ & $0.000 \%$ & $9.86 \mathrm{E}-02$ & $9.86 \mathrm{E}-02$ & $0.001 \%$ & $1.009 \mathrm{E}+01$ & $1.009 \mathrm{E}+01$ & $0.002 \%$ \\
\hline 28 & $2.08 \mathrm{E}+00$ & $2.08 \mathrm{E}+00$ & $0.002 \%$ & $9.86 \mathrm{E}-02$ & $9.86 \mathrm{E}-02$ & $0.002 \%$ & $1.187 \mathrm{E}+01$ & $1.187 \mathrm{E}+01$ & $0.000 \%$ \\
\hline 36 & $2.08 \mathrm{E}+00$ & $2.08 \mathrm{E}+00$ & $0.002 \%$ & $9.86 \mathrm{E}-02$ & $9.86 \mathrm{E}-02$ & $0.002 \%$ & $1.290 \mathrm{E}+01$ & $1.290 \mathrm{E}+01$ & $-0.002 \%$ \\
\hline 42 & $2.08 \mathrm{E}+00$ & $2.08 \mathrm{E}+00$ & $0.002 \%$ & $9.86 \mathrm{E}-02$ & $9.86 \mathrm{E}-02$ & $0.002 \%$ & $1.337 \mathrm{E}+01$ & $1.337 \mathrm{E}+01$ & $0.000 \%$ \\
\hline 54 & $2.08 \mathrm{E}+00$ & $2.08 \mathrm{E}+00$ & $0.002 \%$ & $9.86 \mathrm{E}-02$ & $9.86 \mathrm{E}-02$ & $0.002 \%$ & $1.389 \mathrm{E}+01$ & $1.389 \mathrm{E}+01$ & $0.004 \%$ \\
\hline
\end{tabular}


Table B-3. Results of Verification Problem 2 for Cell 1.

\begin{tabular}{rcccccc}
\hline $\begin{array}{c}\text { Time } \\
(\mathrm{y})\end{array}$ & $\begin{array}{c}\text { MCMT } \\
\text { Inventory } \\
(\mathrm{Ci})\end{array}$ & $\begin{array}{c}\text { Analytical } \\
\text { Solution } \\
(\mathrm{Ci})\end{array}$ & $\begin{array}{c}\% \\
\text { Difference }\end{array}$ & $\begin{array}{c}\text { MCMT Conc. } \\
\left.(\mathrm{Ci} \mathrm{m})^{-3}\right)\end{array}$ & $\begin{array}{c}\text { Analytical } \\
\text { Solution } \\
\left(\mathrm{Ci} \mathrm{m}^{-3}\right)\end{array}$ & $\begin{array}{c}\% \\
\text { Difference }\end{array}$ \\
\hline 2 & $3.82 \mathrm{E}-01$ & $3.82 \mathrm{E}-01$ & $-0.002 \%$ & $1.81 \mathrm{E}-02$ & $1.81 \mathrm{E}-02$ & $0.002 \%$ \\
6 & $5.55 \mathrm{E}-02$ & $5.55 \mathrm{E}-02$ & $-0.005 \%$ & $2.64 \mathrm{E}-03$ & $2.64 \mathrm{E}-03$ & $0.005 \%$ \\
10 & $8.09 \mathrm{E}-03$ & $8.09 \mathrm{E}-03$ & $-0.008 \%$ & $3.84 \mathrm{E}-04$ & $3.84 \mathrm{E}-04$ & $-0.08 \%$ \\
14 & $1.18 \mathrm{E}-03$ & $1.18 \mathrm{E}-03$ & $-0.010 \%$ & $5.59 \mathrm{E}-05$ & $5.59 \mathrm{E}-05$ & $-0.010 \%$ \\
20 & $6.54 \mathrm{E}-05$ & $6.54 \mathrm{E}-05$ & $-0.016 \%$ & $3.10 \mathrm{E}-06$ & $3.10 \mathrm{E}-06$ & $-0.016 \%$ \\
28 & $1.39 \mathrm{E}-06$ & $1.39 \mathrm{E}-06$ & $-0.019 \%$ & $6.58 \mathrm{E}-08$ & $6.58 \mathrm{E}-08$ & $-0.019 \%$ \\
36 & $2.94 \mathrm{E}-08$ & $2.94 \mathrm{E}-08$ & $-0.029 \%$ & $1.39 \mathrm{E}-09$ & $1.39 \mathrm{E}-09$ & $-0.029 \%$ \\
42 & $1.63 \mathrm{E}-09$ & $1.63 \mathrm{E}-09$ & $-0.031 \%$ & $7.75 \mathrm{E}-11$ & $7.74 \mathrm{E}-11$ & $-0.031 \%$ \\
54 & $5.03 \mathrm{E}-12$ & $5.03 \mathrm{E}-12$ & $-0.044 \%$ & $2.39 \mathrm{E}-13$ & $2.39 \mathrm{E}-13$ & $-0.044 \%$ \\
\hline
\end{tabular}

Table B-4. Parameters Values for Verification Problem 3.

\begin{tabular}{lllll}
\hline \multicolumn{1}{c}{ Parameter } & Cell 1 & Cell 2 & Cell 3 & Cell 4 \\
\hline Length $(\mathrm{m})$ & 1.0 & 1.0 & 1.0 & 1.0 \\
Width $(\mathrm{m})$ & 1.0 & 1.0 & 1.0 & 1.0 \\
Thickness $(\mathrm{m})$ & 0.02 & 0.13 & 0.15 & 0.2 \\
Bulk density $\left(\mathrm{g} \mathrm{cm}^{-3}\right)$ & 1.2 & 1.5 & 1.5 & 1.8 \\
Saturated hydraulic conductivity $\left(\mathrm{m} \mathrm{y}^{-1}\right)$ & 1710 & 1710 & 1710 & 1710 \\
Porosity & 0.2724 & 0.2724 & 0.2724 & 0.2724 \\
Residual moisture content & 0.0321 & 0.0321 & 0.0321 & 0.0321 \\
Alpha $\left(\mathrm{m}^{-1}\right)$ & 7.71 & 7.71 & 7.71 & 7.71 \\
$r n$ & 2.28 & 2.28 & 2.28 & 2.28 \\
Calculated moisture content & 0.0659 & 0.0659 & 0.0659 & 0.0659 \\
Water flux, $t=0$ to $t=\infty\left(\mathrm{m} \mathrm{y}^{-1}\right)$ & 0.2 & 0.2 & 0.2 & 0.2 \\
Pu-241 partition coefficient $\left(\mathrm{mL} \mathrm{g}^{-1}\right)$ & 10 & 15 & 22 & 22 \\
Am-241 partition coefficient $\left(\mathrm{mL} \mathrm{g}^{-1}\right)$ & 50 & 60 & 70 & 70 \\
Pu-241 solubility (mg L $\left.{ }^{-1}\right)$ & infinite & infinite & infinite & infinite \\
Am-241 solubility $\left(\mathrm{mg} \mathrm{L}^{-1}\right)$ & infinite & infinite & infinite & infinite \\
Pu-241 initial inventory $(\mathrm{Ci})$ & $2.40 \mathrm{E}-05$ & $5.46 \mathrm{E}-04$ & $6.75 \mathrm{E}-05$ & $2.72 \mathrm{E}-11$ \\
Am-241 initial inventory $(\mathrm{Ci})$ & $4.80 \mathrm{E}-07$ & $2.93 \mathrm{E}-06$ & $2.25 \mathrm{E}-07$ & $2.86 \mathrm{E}-14$ \\
\hline
\end{tabular}

As shown in Figure B-1 (for Pu-241) and Figure B-2 (for Am-241), there is excellent agreement between the analytical solution and MCMT. Differences between the analytical expression and MCMT for the maximum inventory beyond 1-year ranged from $0.0000 \%$ for $\mathrm{Pu}-241$ in cell 3, to $0.1277 \%$ for Am-241 in cell 4. 


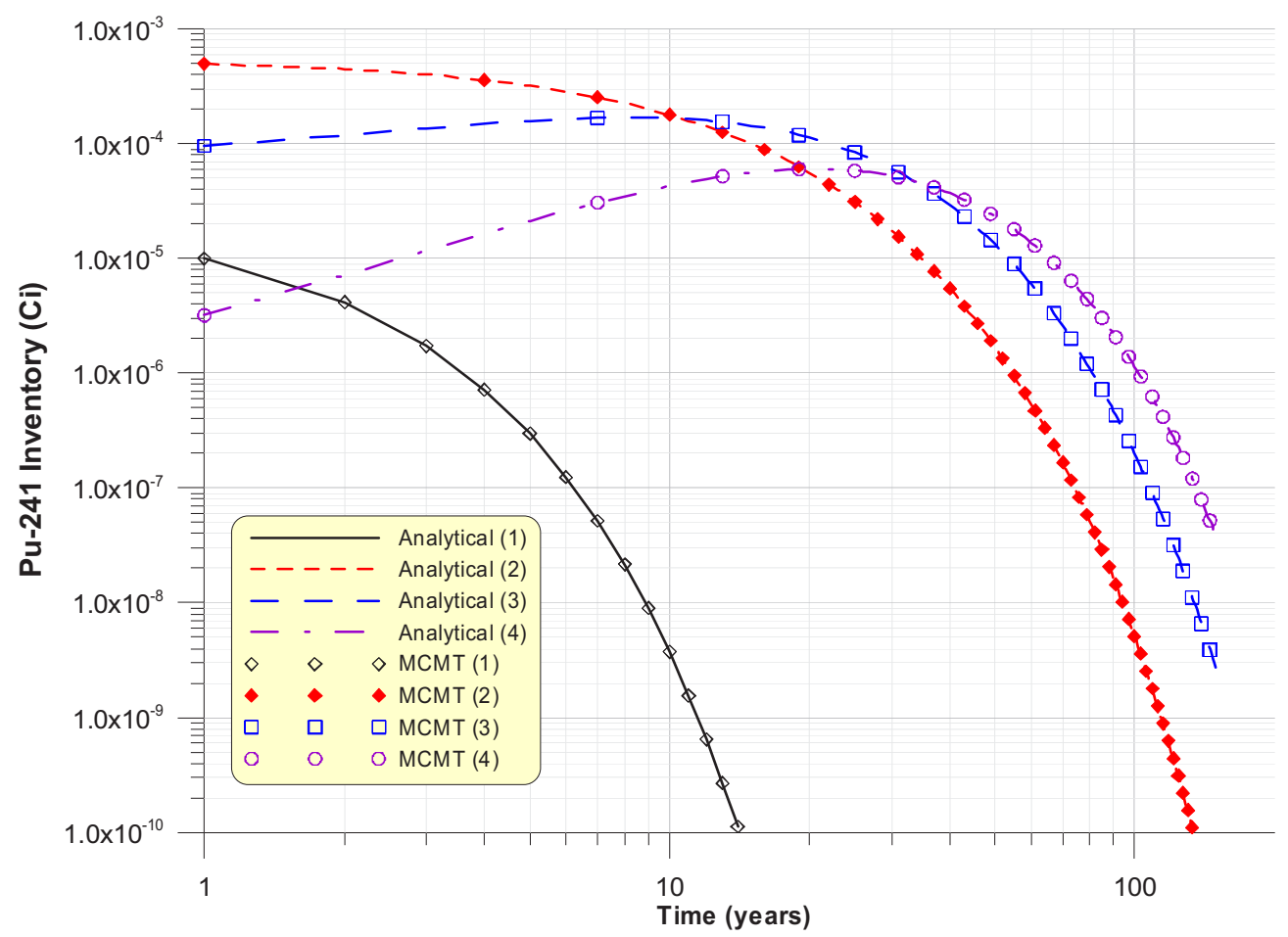

Figure B-1. Plutonium-241 inventory as a function of time calculated with the analytical solution developed by Birchall (1986) and MCMT. The numbers in parentheses in the legend refer to the cell number.

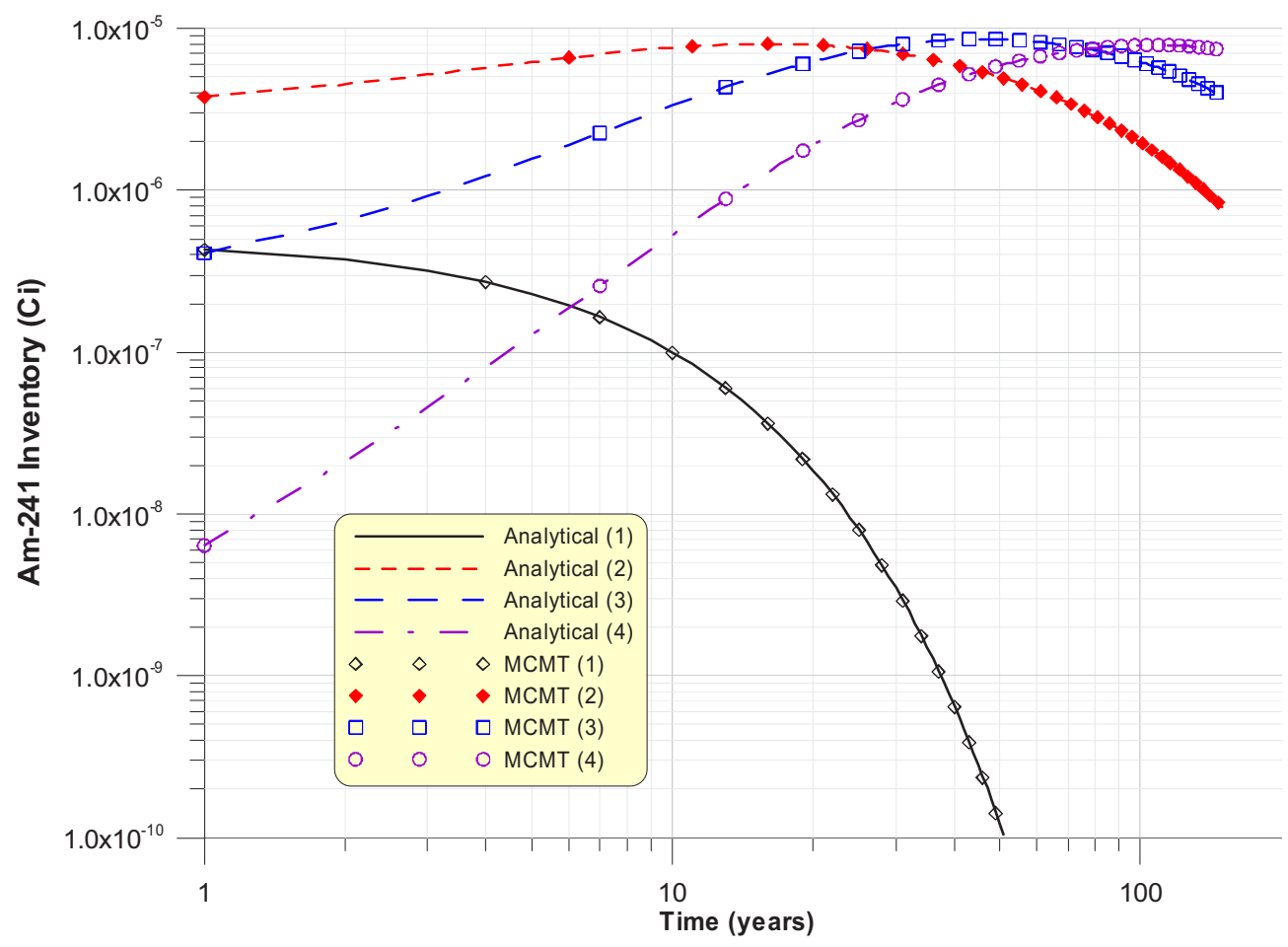

Figure B-2. Americium-241 inventory as a function of time calculated with the analytical solution developed by Birchall (1986) and MCMT. The numbers in parentheses in the legend refer to the cell number. 


\section{B-1.5 Verification Problem 4}

Verification Problem 4 checks the solubility limited release function in MCMT with the analytical solution expressed by Equations B-9 and B-10. The problem uses the same parameters used in Verification Problem 2, except the initial inventory is set to $1 \times 10^{4} \mathrm{Ci}$. The flux from cell 1 was also output and compared with output from the GWSCREEN model (Rood 1999), which includes the solubility release model described in Equations B-9 and B-10. Results (Table B-5) show good agreement between MCMT, the analytical solution, and GWSCREEN. Differences are no greater than 0.163 percent.

Table B-5. Inventory and Flux from Cell 1 for Verification Problem 4.

\begin{tabular}{ccccccc}
\hline $\begin{array}{c}\text { Time } \\
(\mathrm{y})\end{array}$ & $\begin{array}{c}\text { MCMT } \\
\text { Inventory } \\
(\mathrm{Ci})\end{array}$ & $\begin{array}{c}\text { Analytical } \\
\text { Solution } \\
(\mathrm{Ci})\end{array}$ & $\begin{array}{c}\% \\
\text { Difference }\end{array}$ & $\begin{array}{c}\text { MCMT Flux } \\
\left(\mathrm{Ci} \mathrm{y}^{-1}\right)\end{array}$ & $\begin{array}{c}\text { GWSCREEN } \\
\text { Flux } \\
\left(\mathrm{Ci} \mathrm{y}^{-1}\right)\end{array}$ & $\begin{array}{c}\% \\
\text { Difference }\end{array}$ \\
\hline 2 & $9.35 \mathrm{E}+03$ & $9.35 \mathrm{E}+03$ & $-0.001 \%$ & $2.59 \mathrm{E}+02$ & $2.59 \mathrm{E}+02$ & $0.012 \%$ \\
6 & $8.07 \mathrm{E}+03$ & $8.07 \mathrm{E}+03$ & $-0.002 \%$ & $2.59 \mathrm{E}+02$ & $2.59 \mathrm{E}+02$ & $0.012 \%$ \\
10 & $6.83 \mathrm{E}+03$ & $6.83 \mathrm{E}+03$ & $-0.005 \%$ & $2.59 \mathrm{E}+02$ & $2.59 \mathrm{E}+02$ & $0.012 \%$ \\
14 & $5.62 \mathrm{E}+03$ & $5.62 \mathrm{E}+03$ & $-0.008 \%$ & $2.59 \mathrm{E}+02$ & $2.59 \mathrm{E}+02$ & $0.012 \%$ \\
20 & $3.86 \mathrm{E}+03$ & $3.86 \mathrm{E}+03$ & $-0.015 \%$ & $2.59 \mathrm{E}+02$ & $2.59 \mathrm{E}+02$ & $0.012 \%$ \\
28 & $1.64 \mathrm{E}+03$ & $1.64 \mathrm{E}+03$ & $-0.048 \%$ & $2.59 \mathrm{E}+02$ & $2.59 \mathrm{E}+02$ & $0.012 \%$ \\
36 & $8.30 \mathrm{E}+01$ & $8.29 \mathrm{E}+01$ & $-0.162 \%$ & $3.94 \mathrm{E}+01$ & $3.95 \mathrm{E}+01$ & $0.119 \%$ \\
42 & $4.61 \mathrm{E}+00$ & $4.60 \mathrm{E}+00$ & $-0.162 \%$ & $2.19 \mathrm{E}+00$ & $2.19 \mathrm{E}+00$ & $0.146 \%$ \\
54 & $1.42 \mathrm{E}-02$ & $1.42 \mathrm{E}-02$ & $-0.163 \%$ & $6.76 \mathrm{E}-03$ & $6.76 \mathrm{E}-03$ & $0.115 \%$ \\
\hline
\end{tabular}

\section{B-2. MCMT BENCHMARK PROBLEM}

The primary output of MCMT is the radionuclide flux from the unsaturated zone to the aquifer. In this section, the radionuclide flux to the aquifer calculated with MCMT is compared to the radionuclide flux calculated using the Disposal Unit Source Term (DUST) (Sullivan 1996) model. The DUST model solves the one-dimensional transport equation for parent and progeny using an implicit finite difference scheme. Temporal changes in water fluxes and spatial distribution of moisture content are specified by the user in DUST and not calculated within the code; hence transient water flux is not modeled in DUST but rather is specified.

The benchmark exercise with DUST considered a $11.5 \mathrm{~m}$ of contaminated soil containing $6.42 \mathrm{Ci}$ of U-238. The soil contamination covers an area of $\sim 0.2 \mathrm{~km}^{2}(382 \mathrm{~m} \times 512 \mathrm{~m})$. An $81 \mathrm{~m}$ thick unsaturated zone underlies the contaminated soil. Model parameters are described in Table B-6. Moisture contents in DUST are not allowed to change over time. Therefore, a fixed value of 0.05 was used throughout the model domain. Uranium-238 has several important radioactive daughters that will grow in over time and are therefore, also modeled. These daughters are (in descending order) U-234 (T1/2 = 245,000 yr), Th-230 (T1/2 = 75,400 yr), and Ra-226 (T1/2 =- $1600 \mathrm{yr})$. Uranium-238 has a long half life $(4.47 \mathrm{E}+09 \mathrm{yr})$ and little will decay during transport in the unsaturated zone. Therefore, if the simulation is run for sufficient time, the integrated U-238 flux at the bottom of the model domain should equal the total initial activity at the beginning of the simulation. 
Table B-6. Parameter values used in the DUST benchmark exercise.

\begin{tabular}{|c|c|}
\hline Parameter & Value \\
\hline Thickness of source cell (m) & 11.5 \\
\hline Finite difference node spacing in DUST (m) & 0.5 \\
\hline Length of source (m) & 382 \\
\hline Width of source and unsaturated cells (m) & 518 \\
\hline Initial $\mathrm{U}-238$ activity $(\mathrm{Ci})^{\mathrm{a}}$ & 6.42 \\
\hline Bulk density of contaminated soil $\left(\mathrm{g} \mathrm{cm}^{-3}\right)$ & 1.26 \\
\hline Moisture content throughout model domain $\left(\mathrm{m}^{3} \mathrm{~m}^{-3}\right)$ & 0.05 \\
\hline Uranium partition coefficient, $0 \mathrm{~m}$ to $23.14 \mathrm{~m}\left(\mathrm{~mL} \mathrm{~g}^{-1}\right)$ & 0.2 \\
\hline Thorium partition coefficient, $0 \mathrm{~m}$ to $23.14 \mathrm{~m}\left(\mathrm{~mL} \mathrm{~g}^{-1}\right)$ & 5.0 \\
\hline Radium partition coefficient, $0 \mathrm{~m}$ to $23.14 \mathrm{~m}\left(\mathrm{~mL} \mathrm{~g}^{-1}\right)$ & 0.4 \\
\hline Uranium partition coefficient, $23.14 \mathrm{~m}$ to $92.5 \mathrm{~m}\left(\mathrm{~mL} \mathrm{~g}^{-1}\right)$ & 3 \\
\hline Thorium partition coefficient, $23.14 \mathrm{~m}$ to $92.5 \mathrm{~m}\left(\mathrm{~mL} \mathrm{~g}^{-1}\right)$ & 1000 \\
\hline Radium partition coefficient, $23.14 \mathrm{~m}$ to $92.5 \mathrm{~m}\left(\mathrm{~mL} \mathrm{~g}^{-1}\right)$ & 20 \\
\hline Water flux $\left(\mathrm{m} \mathrm{y}^{-1}\right)$ & 0.02 \\
\hline Dispersivity & 4.1 \\
\hline Number of MCMT cells & 24 \\
\hline Thickness of each cell (m) & 3.854 \\
\hline Total thickness of domain (m) & 92.5 \\
\hline
\end{tabular}

Results of the simulation are presented in Table B-7 and Figure B-3. In general, differences in the three essential quantities (maximum flux, time of maximum flux, and integrated flux) differ by less than about $5 \%$ between the two models, although MCMT consistently calculates higher fluxes and longer travel times relative to DUST. The total integrated flux out the bottom of the model domain for MCMT agrees well with the total initial amount $(6.42 \mathrm{Ci})$ of U-238 present at the start of the simulation. However, DUST only calculated $6.36 \mathrm{Ci}$ released, which equates to about a $1 \%$ mass balance error.

Table B-7. Results of MCMT benchmark with DUST.

\begin{tabular}{lllllc}
\hline Model & \multicolumn{1}{c}{ Quantity } & U-238 & U-234 & Th-230 & Ra-226 \\
\hline MCMT & Maximum Flux $\left(\mathrm{Ci} \mathrm{yr}^{-1}\right)$ & $5.03 \mathrm{E}-04$ & $2.17 \mathrm{E}-05$ & $7.22 \mathrm{E}-09$ & $3.51 \mathrm{E}-07$ \\
MCMT & Time of maximum & $1.47 \mathrm{E}+04$ & $1.63 \mathrm{E}+04$ & $3.18 \mathrm{E}+04$ & $3.43 \mathrm{E}+04$ \\
MCMT & Cumulative Flux $(\mathrm{Ci})$ & $6.42 \mathrm{E}+00$ & $3.04 \mathrm{E}-01$ & $7.36 \mathrm{E}-04$ & $3.59 \mathrm{E}-02$ \\
DUST & Maximum Flux $\left(\mathrm{Ci} \mathrm{yr}^{-1}\right)$ & $4.90 \mathrm{E}-04$ & $2.06 \mathrm{E}-05$ & $7.03 \mathrm{E}-09$ & $3.43 \mathrm{E}-07$ \\
DUST & Time of maximum & $1.42 \mathrm{E}+04$ & $1.58 \mathrm{E}+04$ & $3.17 \mathrm{E}+04$ & $3.41 \mathrm{E}+04$ \\
DUST & Cumulative Flux $(\mathrm{Ci})$ & $6.36 \mathrm{E}+00$ & $2.99 \mathrm{E}-01$ & $7.27 \mathrm{E}-04$ & $3.55 \mathrm{E}-02$ \\
& \% Difference maximum flux & $-2.68 \%$ & $-5.30 \%$ & $-2.64 \%$ & $-2.41 \%$ \\
& \% Difference time of maximum & $-3.59 \%$ & $-3.23 \%$ & $-0.35 \%$ & $-0.62 \%$ \\
& \% difference cumulative flux & $-0.94 \%$ & $-1.58 \%$ & $-1.29 \%$ & $-1.04 \%$ \\
\hline
\end{tabular}




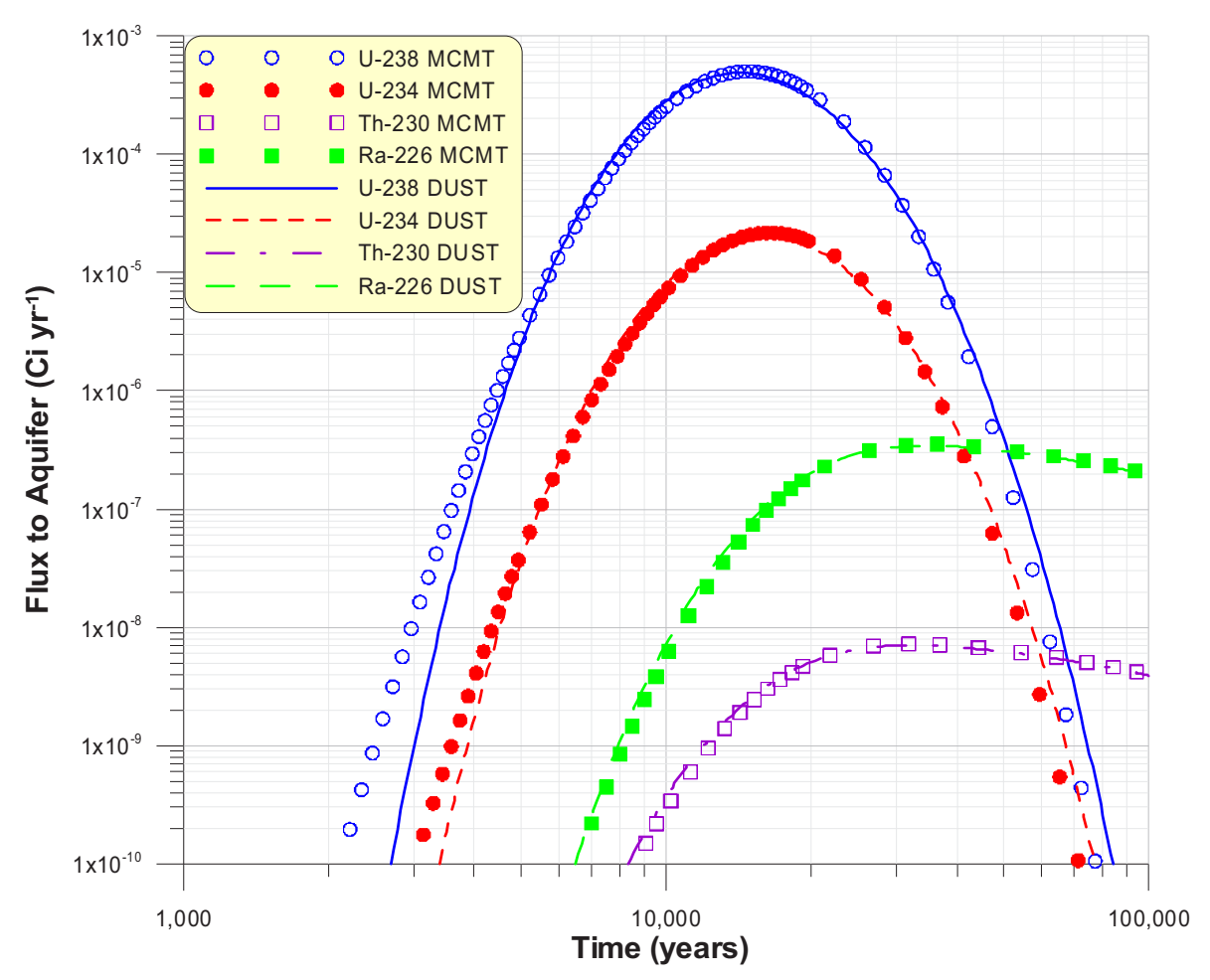

Figure B-3. Comparison of the aquifer flux calculated by MCMT and DUST.

The benchmark illustrates that the MCMT model produces results that are comparable to those derived from finite difference solutions of the advection-dispersion equation, and that the mixing-cell model is a good approximation to advection-dispersion behavior.

\section{B-3. MCMF VERIFICATION PROBLEMS}

The primary verification problem for MCMF is in Section 4 in the main body of the report. Figure 4 in the main body of the report illustrates the sensitivity of the number of cells to the water flux profile. Figure 5 illustrates the passage of a wetting front as a function of time as estimated by MCMF and the HYDRUS-2D finite element code. Excellent agreement between the two codes is found by fitting a proper number of cells to the problem. The number of cells needed to fit the water flux profile is defined by Equation 35 .

In this section, MCMF is benchmarked against HYDRUS-2D for an arbitrary problem. Equation 35 is used to estimate the number of cells needed for the simulation. The water flux output is then used with MCMT to estimate solute fluxes at the base of the model domain. Solute fluxes calculated with MCMT are then compared to solute fluxes calculated with HYDRUS-2D.

\section{B-3.1 Problem Description}

The benchmark problem considered a 30-m thick homogeneous unsaturated zone consisting of sandy clay loam with an initial water flux $\left(q_{o}\right)$ of $0.01 \mathrm{~m} \mathrm{yr}^{-1}$ and an initial solute mass of $\sim 0.25 \mathrm{~g}$ that occupied the first $1.5 \mathrm{~m}(z=0 \mathrm{~m}$ to $z=1.5 \mathrm{~m})$ of the model domain. The van Genuchten fitting parameters for sandy clay loam are found in Table 1 in the main body of the report. The system is subject to a new water flux $\left(q_{n}\right)$ of 10-year duration after which it returns to its baseline value of $q_{o}$. Three cases were considered: $q_{n}=0, q_{n}=6 \times q_{o}$, and $q_{n}=10 \times q_{o}$. The solute was assumed to have an infinite half-life 
and a sorption coefficient of zero $\mathrm{mL} \mathrm{g}^{-1}$. A dispersivity of $1.1 \mathrm{~m}$ was used in all three cases resulting in a scale-length Peclet number of $30 \mathrm{~m} \div 1.1 \mathrm{~m}=27.27$. Because Case 1 involved steady-state flow conditions, the number of cells were chosen such that $n>P e / 2$. Cases 2 and 3 are transient flow simulations; therefore, Equations 34 and 35 were used to determine the number of mixing cells needed to simulate transient flow behavior.

The number of cells needed to simulate transient flow behavior used Equation 34 to calculate the value $\varphi$ and the Equation 35 to calculate $n$. Calculation of the number of cells is organized in Table B- 8 . The hydraulic diffusivity is determined using the utility program, DHYD.FOR.

Table B-8. Data and calculations to determine the number of mixing cells.

\begin{tabular}{lccc}
\multicolumn{1}{c}{ Quantity } & Steady State & $q_{n}=6 \times q_{0}$ & $q_{n}=10 \times q_{0}$ \\
\hline Initial solute mass, $Q_{0}(\mathrm{~g})$ & 0.254 & 0.252 & 0.252 \\
$q_{o}\left(\mathrm{~m} \mathrm{yr}^{-1}\right)$ & $1.00 \mathrm{E}-02$ & $1.00 \mathrm{E}-02$ & $1.00 \mathrm{E}-02$ \\
$q_{n}\left(\mathrm{~m} \mathrm{yr}^{-1}\right)$ & $1.00 \mathrm{E}-02$ & $6.00 \mathrm{E}-02$ & $1.00 \mathrm{E}-01$ \\
Duration of new flux $(\mathrm{yr})$ & $\mathrm{N} / \mathrm{A}$ & 10 & 10 \\
Initial moisture content, $\theta o$ & $1.9966 \mathrm{E}-01$ & $1.9966 \mathrm{E}-01$ & $1.9966 \mathrm{E}-01$ \\
New moisture content, $\theta n$ & N/A & $2.2973 \mathrm{E}-01$ & $2.3974 \mathrm{E}-01$ \\
Wetting front speed, $u_{w f}\left(\mathrm{~m} \mathrm{yr}^{-1}\right)$ & N/A & $1.663 \mathrm{E}+00$ & $2.246 \mathrm{E}+00$ \\
Time of arrival, $t_{w f}(\mathrm{yr})$ & N/A & $1.804 \mathrm{E}+01$ & $1.336 \mathrm{E}+01$ \\
Initial hydraulic diffusivity, $D_{h o}\left(\mathrm{~m}^{2} \mathrm{yr}^{-1}\right)$ & $3.3246 \mathrm{E}-01$ & $3.3246 \mathrm{E}-01$ & $3.3246 \mathrm{E}-01$ \\
$\varphi$ & N/A & $1.432 \mathrm{E}+02$ & $1.934 \mathrm{E}+02$ \\
$n$ & 30 & 36 & 48 \\
Cell thickness $(\mathrm{m})$ & 1.0 & 0.83333 & 0.63830 \\
\hline
\end{tabular}

The HYDRUS domain was discretized into sixty, 0.5-m thick elements and a maximum time step of 100 days was specified for Cases 1 and 2, and 50 days for Case 3. The results of the simulation show that there is little difference between the water fluxes calculated by the two models (Figure B-4). The solute fluxes are illustrated in Figure B-5. While there are differences between the solute flux estimated by HYDRUS and that of the mixing-cell model, those differences are not meaningful when the overall uncertainty in an unsaturated flow and transport model are considered. The percent difference between the maximum solute flux estimated with HYDRUS and that of the mixing-cell model was $1.03 \%$ for Case 1, 1.26\% for Case 2, and 1.78\% for Case 3. However, what is more important is that the mixing-cell model mimics the behavior of HYDRUS for the three cases. That is, a pulse of water entering the top of the unsaturated zone results in shorter solute travel times and greater solute dilution. Consequently, solute fluxes are slightly lower for higher values of $q_{n}$. 


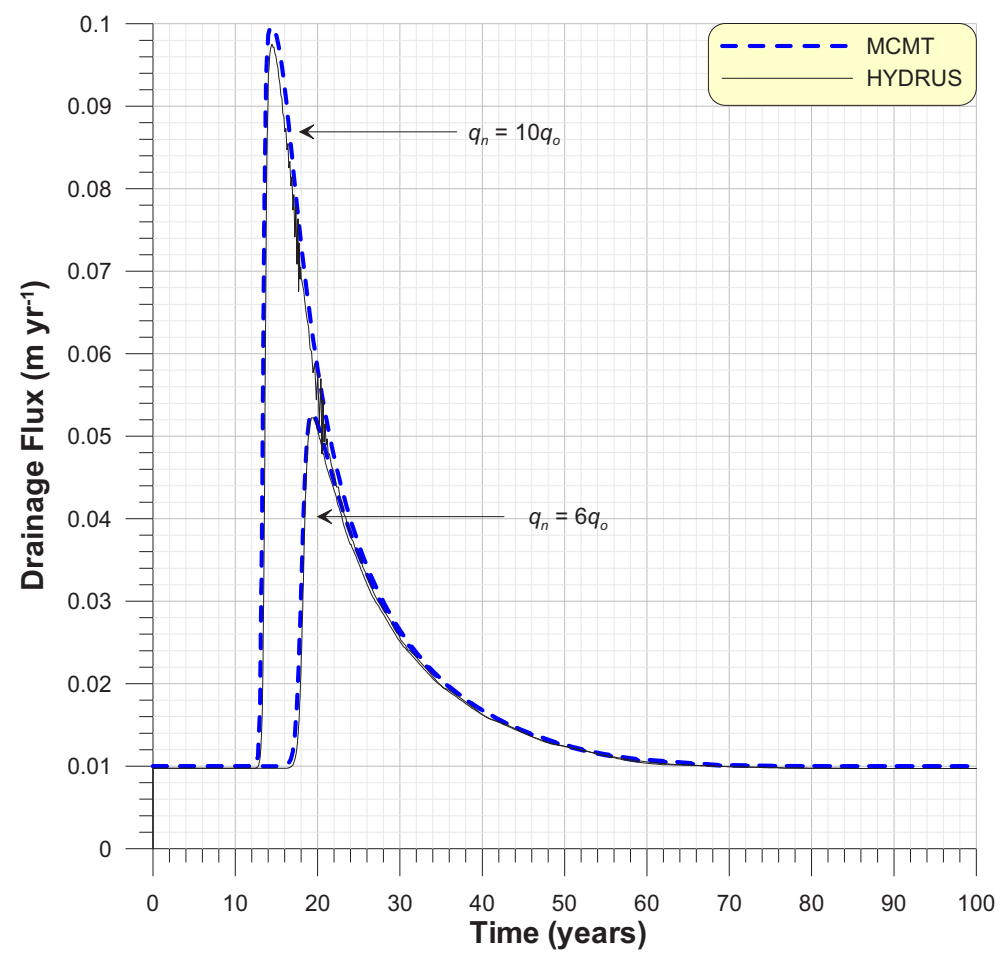

Figure B-4. Water fluxes as a function of time at $z=Z$ for Cases 2 and 3.

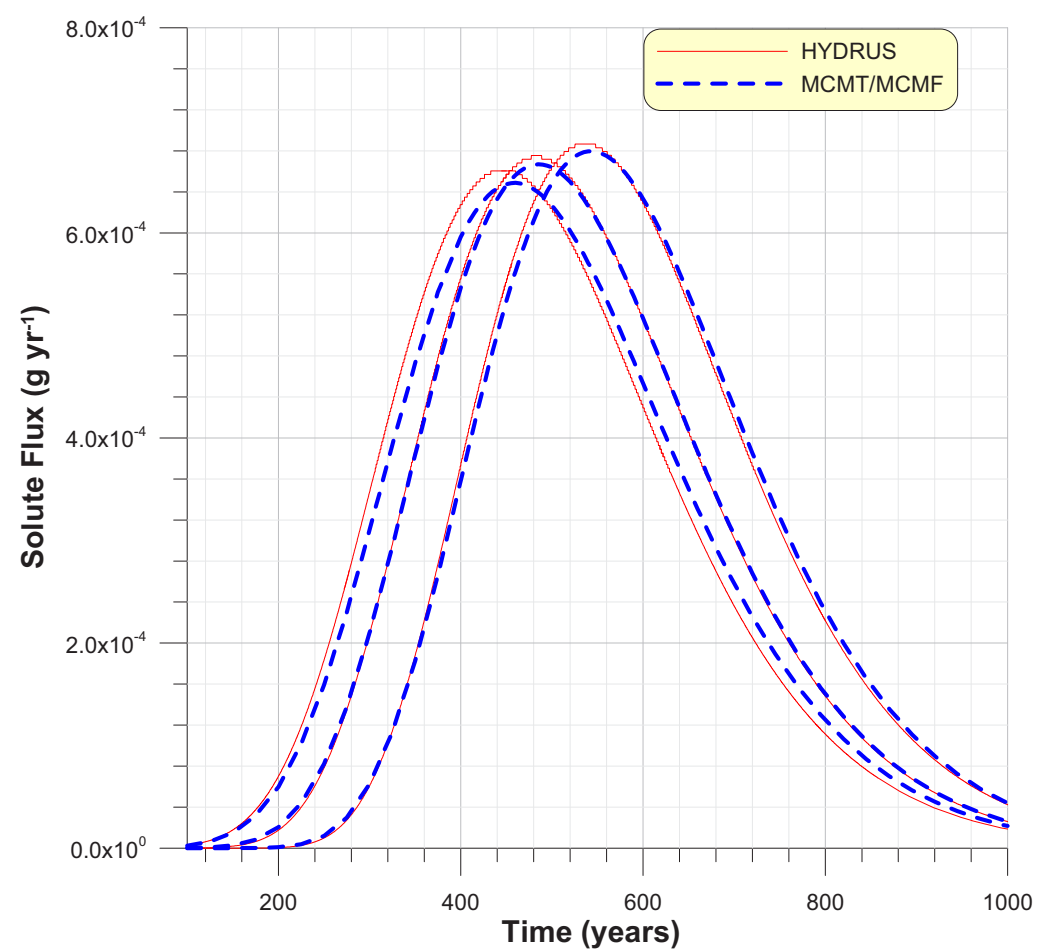

Figure B-5. Solute fluxes as a function of time for Cases 1, 2, and 3. 


\section{B-4. MCMT INPUT FILES}

Verification Problem 1 for MCMP water. flx
verify1.inv
$1.0 \mathrm{e}-6$. $1.0 \mathrm{e}-3.31 .00-6$

title [title of project]
fileppt [water flux file from MCMF]

$\begin{array}{llll}3 & 1 & 1 & 1 \\ \$[a b i n: & \text { A } & \text { (A) scii or } & \text { (B) inary] }\end{array}$ S[iunits: (1) Ci (2) Bq (3) $\mathrm{mg}$

138
1000
100

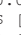

eps, hi, hmin faccuracy, initial time step, minimum time step/

(B) scii or (B) inary

[contaminant names $(6$ characters)

mw $[$ molecular weight $(\mathrm{g} / \mathrm{m} / \mathrm{l})]$
sol $\left[\right.$ [solubility $1 \mathrm{mit}\left(\mathrm{mg} / \mathrm{m}^{* * 3}\right)$

bratio [branching ratio]

awater lwater diffus

\$ [kd values in each cell, 20. values per $y(1)$ ine are read begining with the uppermost cell]

\$ [ $k$ values in each cell, 20 values per line are read begining with the uppermost cell]
[a11 values for the 1 st member are read first, then the second and so on]

10. 10. $0.0 \quad 0.0 \quad 0.0 \quad k x(1) \quad 1$ th, width, alphat [length (m), width (m), longitudinal dispersivity (mil

\$ [Material properities are input by defining the range of cells where they apply]

1.01 .5

h, lbegining cell, ending cell

$1710,0.2724,0.0321,7.51,2.298$
$\$[T i m e$ output parameters $]$

(G)

$\$$ [Repeat for each ntime]

ntimes [number or output time periods]

[End of Parameter Definition File]

E1(i),t2(i),tp(i) [begining time of output ending time of output, print step]

$\frac{1}{4}$

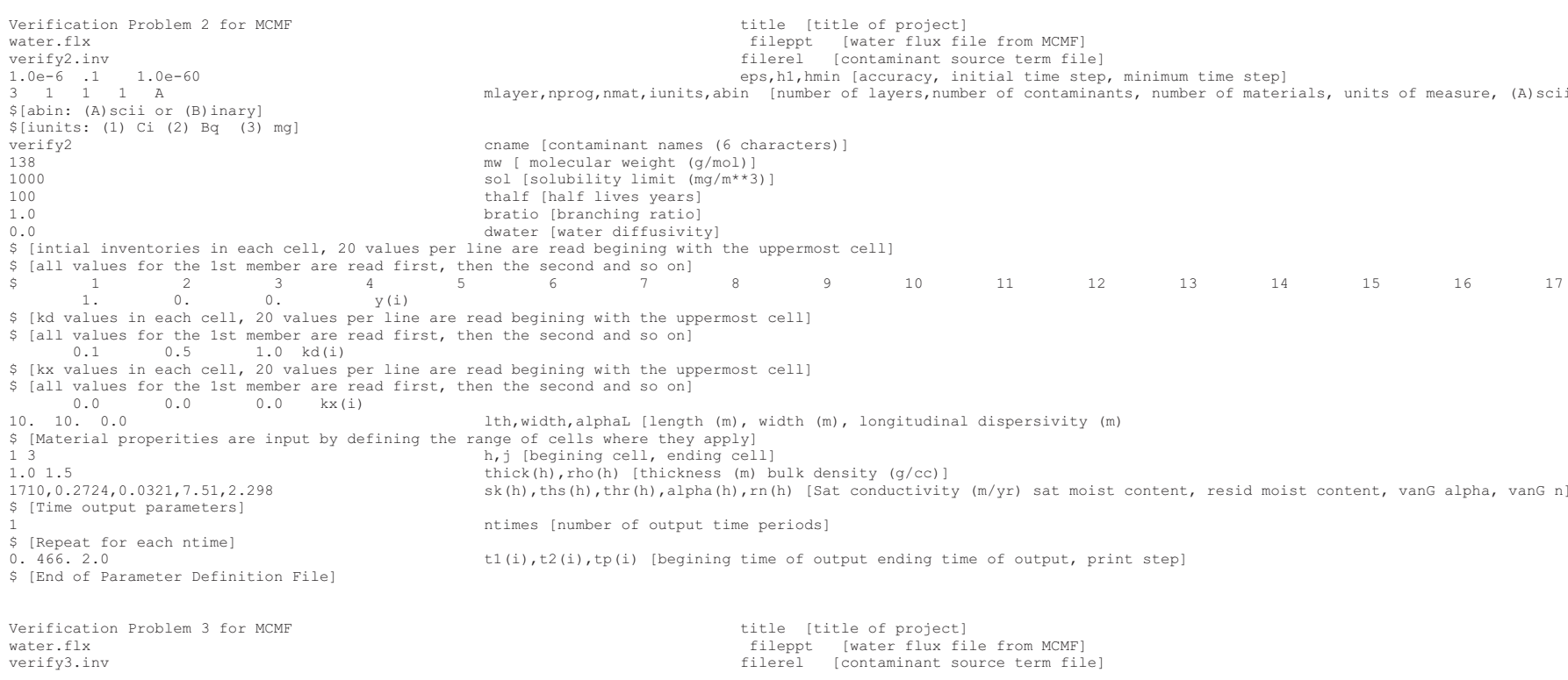




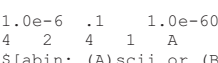

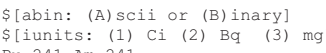

$\mathrm{Pu}-241, \mathrm{Am}-24$
241

$14.4 \quad 432$

$\begin{array}{ll}1.0 & 1.0 \\ 0.0 & 0.0\end{array}$

$\$$ [intial inventories

[all values for the 1st member are read first,

$\begin{array}{llll}.40 \mathrm{E}-05 & 5.46 \mathrm{E}-04 & 6.75 \mathrm{e}-5 & 2.72 \mathrm{e}-11 \\ 80 \mathrm{E}-07 & 2.93 \mathrm{E}-06 & 2.25 & \end{array}$

Initial am241 layer 1-4

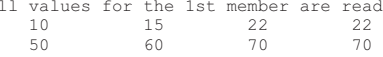

$70 \quad \begin{aligned} & k d(i) \\ & k d ~ a m 241 \\ & 70\end{aligned}$

[ $k \mathrm{kx}$ values in each cell, 20 values per line are read begining with the uppen
[all values for the 1 .

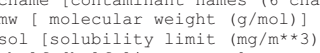

thalf [half lives years]

bratio tbranching yatiol

es, hi, hmin laccuracy, initial time step, minimum time step

$\begin{array}{ccccc}0.0 & 0.0 & 0.0 & 0.0 & k x(1) \\ 0.0 & 0.0 & 0.0 & 0.0 & k x(1)\end{array}$

1. 1.0 .0 [Material properities are input by defining the rth, width, alphat [length (m), width ( $\mathrm{m}$ ), longitudinal dispersivity (m)

11

$1710,0.2724,0.0321,7.51,2.298$

${ }_{2}$ layer

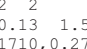

$710,0.2724,0.0321,7.51,2.298$

3

0.15
$1710,0.2724,0.0321,7.51,2.298$

$\$$ layer 4

${ }_{0.2}^{4} 4.8$

$1710,0.2724,0.0321,7.51,2.298$

$\$$ [Time output parameters]

$\$$ [Repeat for each ntime]

0. 150 . 1.0
[End of Parameter Definition File

$h, j$ [begining cell, ending cell]

sk(1), ths (1), thr (1), alpha (1), rn (1)

$h, j$ [begining cell, ending cell]

thick (2), rho (2)
sk (2), ths (2), thr (2), alpha (2), rn (2)

$h, j$ [begining cell, ending cell]

sk (3), ths (3), thr (3), alpha (3), rn (3)

$\mathrm{h}, \mathrm{j}$ [begining cell, ending cell]
thick (3), rho (3)

sk (3), ths (3), thr (3), alpha (3), rn (3)

ntimes [number of output time periods]

$\mathrm{t} 1(\mathrm{i}), \mathrm{t} 2(\mathrm{i}), \mathrm{tp}(\mathrm{i})$ [begining time of output ending time of output, print step.

Verification Problem 4 for MCMF

verify2.iny

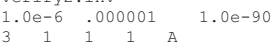

\$labin: (A) scii or (B) inary]
\$[iunits: (1) $\mathrm{Ci}$ (2) $\mathrm{Bq}$ (3) $\mathrm{mg}$ ]

ver 138

1000
100

1.0
0.0

0.0
$\$[$ inti
$\$$ lall
$\$$

values for the 1 st member are read first, then the second and so onj

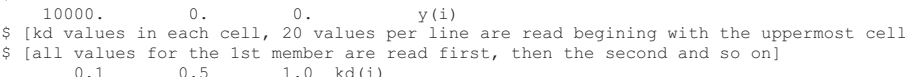

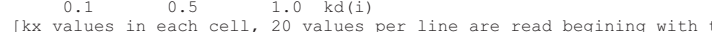

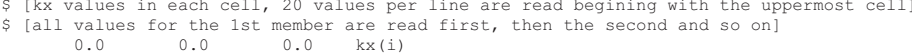

10. 10. 0.0 lth, width, alphat [length ( $\mathrm{m}$ ), width ( $\mathrm{m}$ ), longitudinal dispersivity (

[Material properities are input by defining the range of cells where they apply]

$1.011 .5,0.2724,0.0321,7.51,2.298$

thick (h), rho (h) [thickness (m) bulk density (g/cc)
$\mathrm{sk}(\mathrm{h})$, ths $(\mathrm{h})$, thr (h), alpha $(\mathrm{h})$,

[Repeat for each ntime]

(

[End of Parameter Definition File]

t1(i), t2(i), tp(i) [begining time of output ending time of output, print step] 


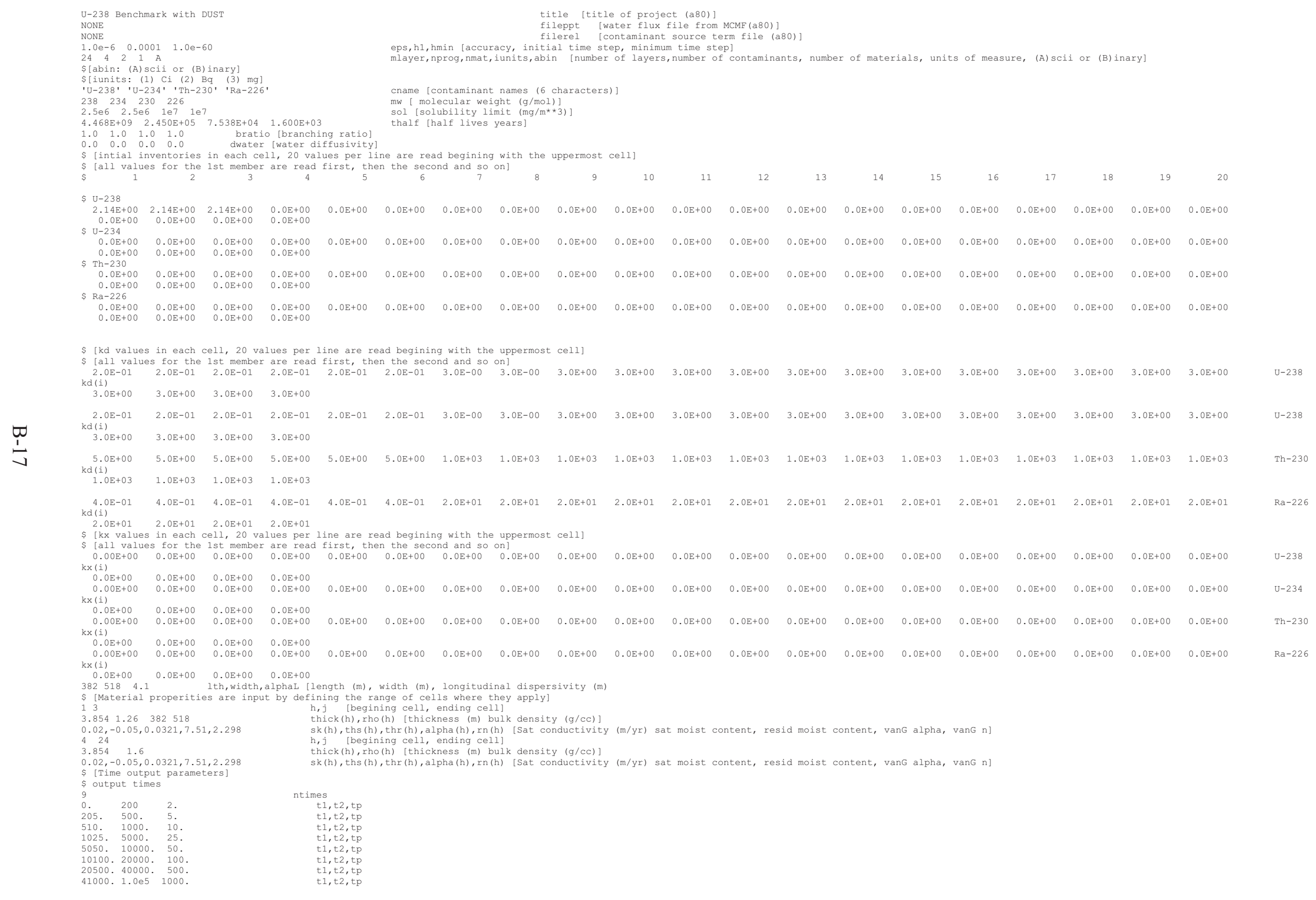




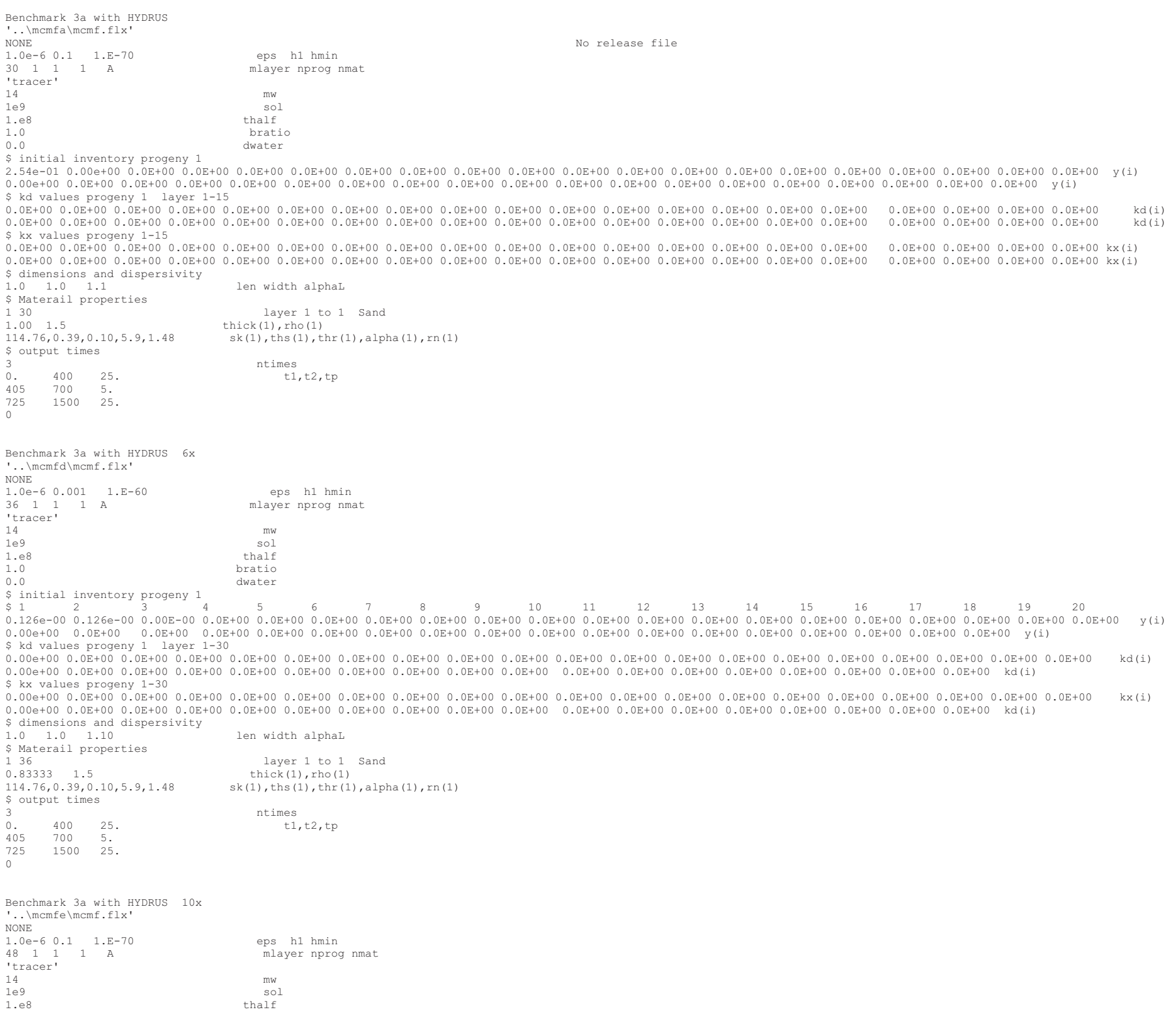




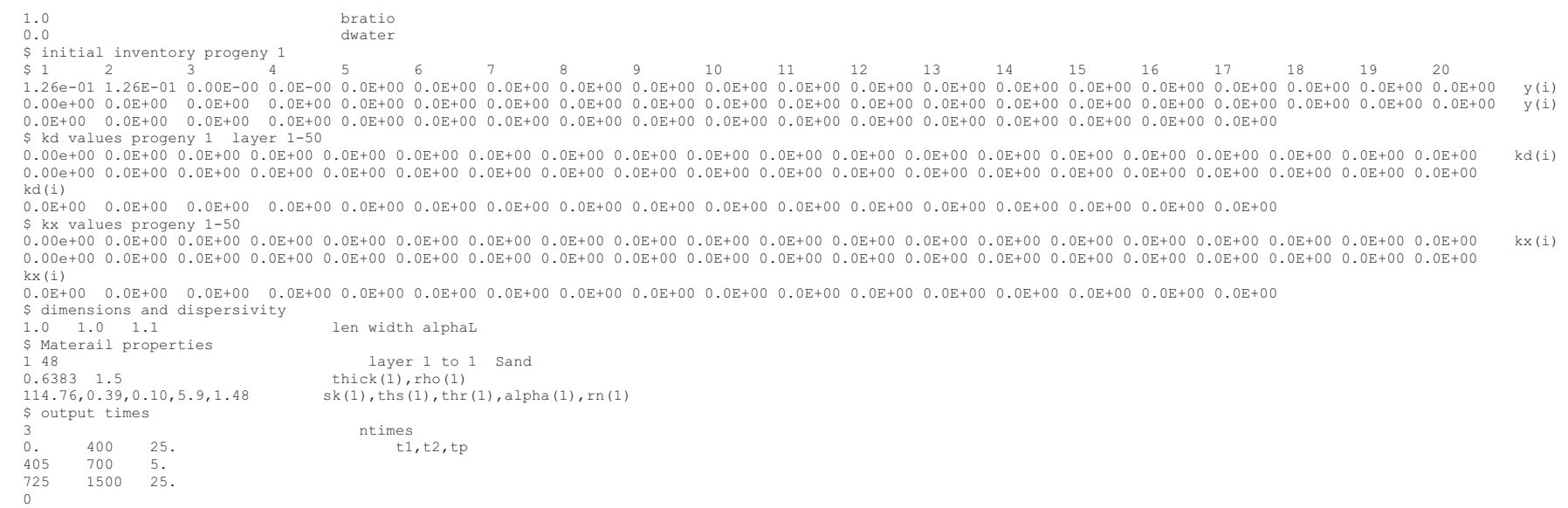

\section{B-5. MCMF INPUT FILES}

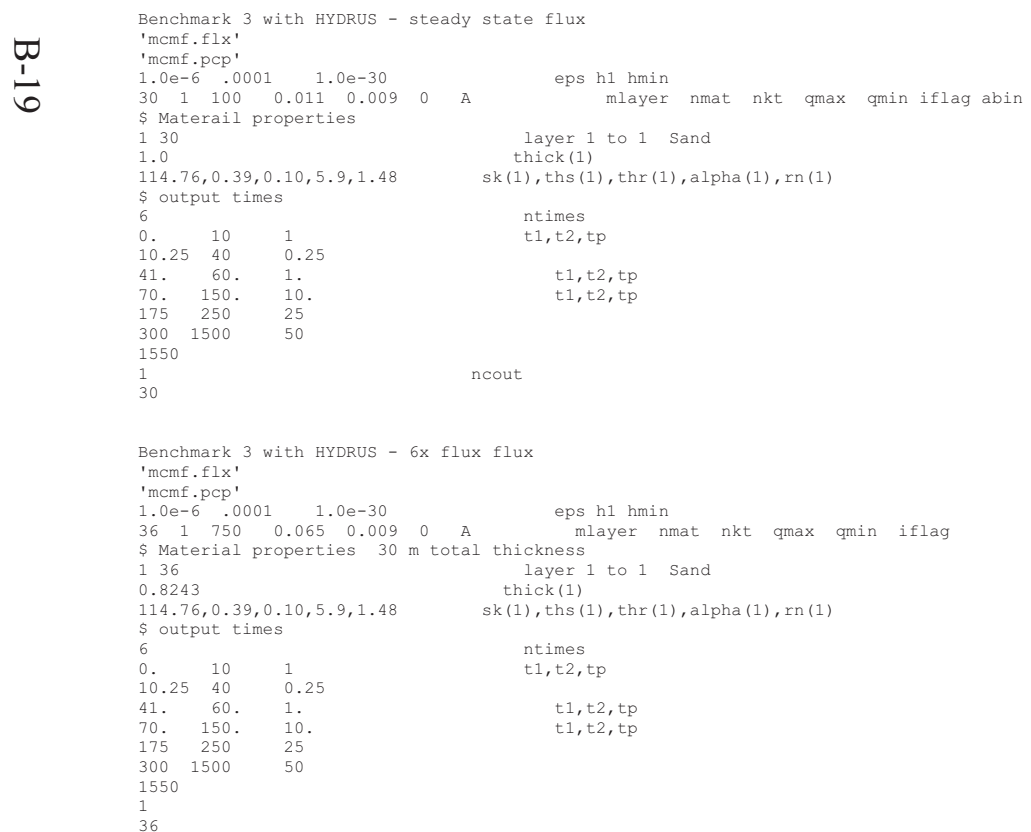


Benchmark with HYDRUS - 10x flux flux

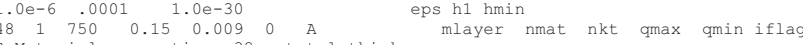

148
0.6265

layer 1 to 1 San

$76,0.39,0.10,5.9,1$.

sk(1), ths (1) thr (1), alpha (1), rn (1)

$\begin{array}{lll}6 & 10 & 1\end{array}$

$\begin{array}{lll}10.25 & 40 & 0.25 \\ 41 . & 60 . & 1 .\end{array}$

$\begin{array}{ccc}70 . & 150 . & 10 . \\ 175 & 250 & 25 \\ 300 & 1500 & 50\end{array}$

ntimes
t1, t2, tp

1550
1
48 


\section{B-6. REFERENCES}

Birchall, A., 1986, “A Microcomputer Algorithm for Solving Compartmental Models, Involving Radionuclide Transformations," Health Physics 50, pp. 389-397.

Rood, A. S., 1999, "A Mixing-Cell Model for Assessment of Contaminant Transport in the Unsaturated Zone Under Steady-State and Transient Flow Conditions," Environmental Engineering Science, 21(6).

Skrable, K. W., C. French, G Chabot, and A. Major, 1974, "A General Equation for the Kinetics of Linear First-Order Phenomena and Suggested Applications," Health Physics 27, 155-157.

Sullivan, T. M., 1996, DUST Disposal Unit Source Term, Data Input Guide, NUREG/CR-6041, BNL-NUREG-52375. Brookhaven National Laboratory, Upton, NY, 1996. 